\title{
Hybrid Quinolinyl Phosphonates as Heterocyclic Carboxylate Isosteres: Synthesis and Biological Evaluation against Topoisomerase 1B (TOP1B)
}

\author{
Asier Selas 1밀 María Fuertes ${ }^{1}$, Estela Melcón-Fernández ${ }^{2}$, Yolanda Pérez-Pertejo ${ }^{2}$, Rosa M. Reguera ${ }^{2}$, \\ Rafael Balaña-Fouce ${ }^{2, *(\mathbb{D})}$, Birgitta R. Knudsen ${ }^{3}$, Francisco Palacios ${ }^{1}$ (D) and Concepcion Alonso ${ }^{1, *(\mathbb{D})}$ \\ 1 Departamento de Química Orgánica I, Facultad de Farmacia and Centro de Investigación Lascaray, \\ Universidad del País Vasco (UPV/EHU), Paseo de la Universidad 7, 01006 Vitoria-Gasteiz, Spain; \\ asier.selas@ehu.eus (A.S.); maria.fuertes@ehu.eus (M.F.); francisco.palacios@ehu.eus (F.P.) \\ 2 Departamento de Ciencias Biomédicas, Facultad de Veterinaria, Universidad de León, 24071 León, Spain; \\ emelf@unileon.es (E.M.-F.); myperp@unileon.es (Y.P.-P.); rmregt@unileon.es (R.M.R.) \\ 3 Department of Molecular Biology, Genetics and Interdisciplinary Nanoscience Center (iNANO), \\ Aarhus University, 8000 Aarhus, Denmark; brk@mbg.au.dk \\ * Correspondence: rbalf@unileon.es (R.B.-F.); concepcion.alonso@ehu.eus (C.A.)
}

check for updates

Citation: Selas, A.; Fuertes, M.; Melcón-Fernández, E.; Pérez-Pertejo, Y.; Reguera, R.M.; Balaña-Fouce, R.; Knudsen, B.R.; Palacios, F.; Alonso, C. Hybrid Quinolinyl Phosphonates as Heterocyclic Carboxylate Isosteres: Synthesis and Biological Evaluation against Topoisomerase 1B (TOP1B). Pharmaceuticals 2021, 14, 784. https: //doi.org/10.3390/ph14080784

Academic Editor: Urszula

K. Komarnicka, Monika Lesiów and Sabina Jaros

Received: 13 July 2021

Accepted: 6 August 2021

Published: 9 August 2021

Publisher's Note: MDPI stays neutral with regard to jurisdictional claims in published maps and institutional affiliations.

Copyright: (C) 2021 by the authors. Licensee MDPI, Basel, Switzerland. This article is an open access article distributed under the terms and conditions of the Creative Commons Attribution (CC BY) license (https:// creativecommons.org/licenses/by/ $4.0 /)$.

\begin{abstract}
This work describes, for the first time, the synthesis of dialkyl (2-arylquinolin-8-yl)phosphonate derivatives. The preparation was carried out through a direct and simple process as a multicomponent Povarov reaction of aminophenylphosphonates, aldehydes, and styrenes and subsequent oxidation with 2,3-dichloro-5,6-dicyano-1,4-benzoquinone (DDQ) or, alternatively, by a cycloaddition reaction between phosphonate aldimines and acetylenes. Based on phosphonate group structural characteristics, considered as phosphorous isosteres of carboxylic heterocycles, they may present interesting biological properties related to cell proliferation. In the current report, a new series of dialkyl (2-arylquinolin-8yl)phosphonates have been synthesized and their antiproliferative effect evaluated on different human cancer and embryonic cells, as well as on Leishmania infantum parasites, a eukaryotic protist responsible for visceral leishmaniasis. Thereby, the antitumor effect was assessed in human lung adenocarcinoma cells (A549), human ovarian carcinoma cells (SKOV3), and human embryonic kidney cells (HEK293) versus the non-cancerous lung fibroblasts cell line (MRC5). On the other hand, the antileishmanial activity was tested against both stages of L. infantum cell cycle, namely free-living promastigotes and intramacrophage amastigotes, using a primary culture of Balb/c splenocytes to calculate the selectivity index. Besides the antiproliferative and antileishmanial capacities, their behavior as topoisomerase $1 \mathrm{~B}$ inhibitors has been evaluated as a possible mechanism of action.
\end{abstract}

Keywords: quinolinyl phosphonates; topoisomerase 1B; enzyme inhibition; antiproliferative effect; leishmaniosis effect

\section{Introduction}

Cancer is one of the most devastating diseases in spite of the substantial advances in the research of antitumor therapies. The incidence of cancer worldwide is over 18 million people and the mortality near 10 million people (in 2018) [1], and research and discovery of new effective and selective drugs/therapies remains a challenge nowadays. On the contrary, leishmaniasis is a neglected tropical disease, caused by parasitic protozoa of the Leishmania genus. Leishmaniasis is endemic in tropical and subtropical areas with annual case incidence ranging from 0.7 to 1 million and over 1 billion people living at risk [2]. The visceral form causes 20,000-30,000 deaths per year mostly in Sub-Saharan African countries. The current treatment of leishmaniasis is complicated and all existing drugs have significant side effects [3].

Chemotherapeutic agents that directly target DNA or modulate enzymes involved in DNA processing are of particular interest in anticancer drug research [4]. Concerning 
this, owing to a detrimental effect on cellular survival of DNA topoisomerase 1B (TOP1B) poisoning, this enzyme has become an interesting and broadly explored druggable target for pathologies related to proliferation phenomena, such as carcinogenesis and infection diseases produced by protist parasites.

TOP1Bs are ATP-independent eukaryotic enzymes that relax supercoiled DNA introducing a transient break in one strand of the duplex DNA. This break allows rotation of the cut strand around the uncut strand, thus decreasing the tension in the DNA created during the replication process. Most TOP1Bs are monomeric enzymes with a catalytic tyrosine residue in the active center involved in the cleavage/binding activities. However, the TOP1B of trypanosomatids-including Leishmania-is a heterodimeric enzyme with the catalytic tyrosine located in the small subunit [5]. This structural difference has been considered an attractive target for therapeutic intervention for diseases caused by these microorganisms [6].

Some compounds have been discovered that target this ubiquitous enzyme which modulates DNA topology in essential cellular events (transcription, replication, and chromatin assembly), as for example camptothecin (CPT, Figure 1) derivatives. However, CPT derivatives present common life-threatening side effects as hematological toxicity and diarrhea and have to deal with cancer cell resistance and structural instability as a result of lactone ring-opening in physiologic conditions. TOP1B inhibitors accepted for clinical practice are topotecan, irinotecan, and belotecan (CPT derivatives). However, these compounds still lead to toxic side effects, chemical instability, and cancer cell resistance, resulting in the limitation of their potential utility as therapeutic drugs [7].
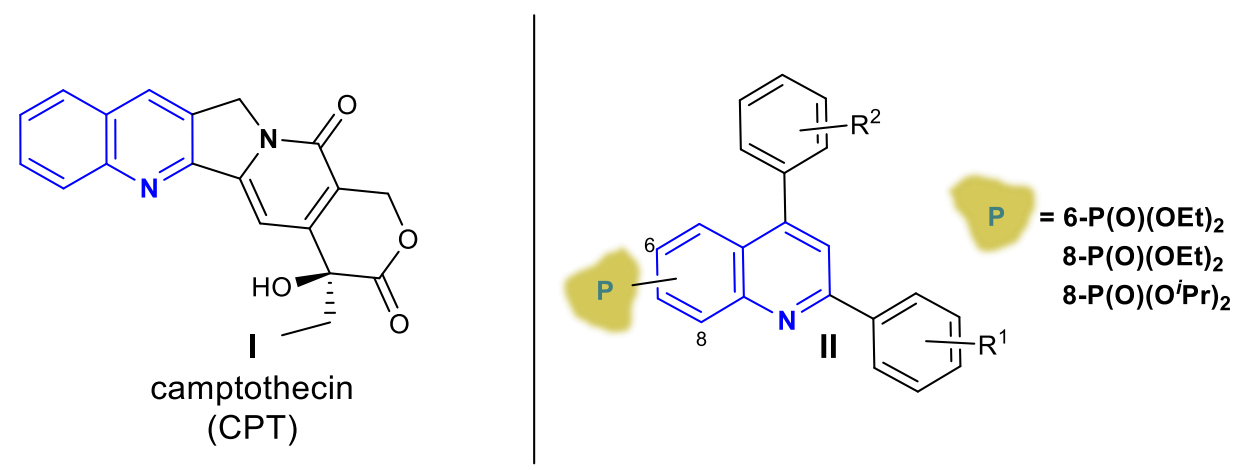

Figure 1. Structures of CPT I and hybrid quinolinyl phosphonates II.

In an attempt to avoid the aforementioned drawbacks, understanding the limitations of CPT derivatives led to the research and development of non-CPT derivatives with planar or quasi-planar nitrogen-containing fused polycyclic structures. Accordingly, several families of compounds with nitrogen-containing heterocyclic scaffolds have been successfully presented as drug candidates for TOP1B inhibitors [8]. In this sense, our group has developed the synthesis of nitrogen-containing heterocycles, such as 1,5-naphthyridine [9] derivatives, and studied their biological activity, showing good results as TOP1B inhibitors with antiproliferative [10,11] and antileishmanial [12,13] activity. In this regard, quinoline is considered a privileged scaffold in cancer drug discovery and quinoline involving central cores are of particular relevance in drugs/candidates with TOP1B inhibition-based mode of action [14-17].

Phosphorus-containing compounds play an important role in Medicinal Chemistry considering the relevance of phosphorated functionalities in their biological activity. For instance, the isosteric replacement of a carboxylic acid functionality by diarylphosphonate analogues in amino acids gives place to the corresponding $\alpha$-aminodiarylphosphonates and their protein extensions (peptidyl- $\alpha$-aminophosphonates), representing a highly convenient framework for improving selectivity against serine protease inhibitors [18]. Likewise, tetrahedral phosphorus is known to be an essential functionality in molecular recognition. LaVoie et al. introduced the concept of bioisosterism, when molecules modulate biological 
activity by virtue of subtle differences in their physicochemical properties, resulting from the substitution of some atoms in their structure [19]. In this sense, phosphorylated moieties have been employed as chemically more stable bioisosteres of phosphates in research dealing with targeting phosphorylated states of proteins, and, accordingly, phosphorylated phosphotyrosine mimetics and phosphonate nucleotides have been described to modulate biological activities of proteins that recognize phosphate groups, like kinases or phosphorylases [20].

Nowadays, it is also observed that the structural conjunction in molecular hybrids can give rise to potent biologically active molecules [21,22]. In previous works, our group focused on the design and preparation of phosphorus (phosphine, phosphine sulphide, and phosphine oxide) substituted quinoline derivatives as TOP1B inhibitors with antiproliferative [23] and antileishmanial [24] activity. We consider the [4 +2] cycloaddition type Povarov reaction a highly convenient approach for the synthesis of quinoline derivatives, giving place to a wide-ranging chemical diversity arising to the large reactant scope able to get involved in the Povarov reaction [25]. In light of these considerations and following with our previous work in the synthesis of new TOP1B inhibitors, herein we report the synthesis of novel hybrid quinoline derivatives with dialkylphosphonate substituents through the Povarov reaction between aminophenylphosphonates, aromatic aldehydes, and styrenes or acetylenes, and their biological evaluation as candidates for TOP1B inhibitors with antiproliferative and antileishmanial activities.

\section{Results and Discussion}

\subsection{Chemistry}

The hybrid phosphonate substituted quinoline derivatives II (Figure 1) were synthesized by the Povarov reaction outlined in Scheme 1. First, we started with the preparation of diethyl (2-aminophenyl)phosphonate 1a (Scheme 1, $\mathrm{R}=\mathrm{Et}$, see Supporting Material) [26] Then, 2-(diethylphosphonate)aldimines $3(\mathrm{R}=\mathrm{Et})$ were prepared in situ by condensation of diethyl (2-aminophenyl)phosphonate 1a and aromatic aldehydes 2 . These aldimines 3 were reacted with styrenes 4 by a two-step Povarov type reaction in the presence of 1 equivalent of $\mathrm{BF}_{3} \cdot \mathrm{Et}_{2} \mathrm{O}$ as a Lewis acid catalyst in refluxing chloroform. For instance, when diethyl (2-(benzylideneamino)phenyl)phosphonate 3 a $\left(R=E t, R^{1}=H\right)$ reacted with phenyl styrene $4 \mathbf{a}\left(\mathrm{R}^{2}=\mathrm{H}\right)$ the formation of the corresponding diethyl (2,4-diphenyl-1,2,3,4tetrahydroquinolin-8-yl)phosphonate $6 a\left(R=E t, R^{1}=H, R^{2}=H\right)$ was observed in the ${ }^{1} \mathrm{H}$ NMR spectrum of the crude mixture. However, attempts for the isolation of these derivatives 6 were unsuccessful and gave rise to the aromatized quinoline derivatives 7 under the purification conditions. Therefore, we explored the reaction of aldimines 3 with styrenes 4 and subsequent in situ dehydrogenation of 1,2,3,4-tetrahydroquinoline derivatives 6 with 2 equivalents of 2,3-dichloro-5,6-dicyano-1,4-benzoquinone (DDQ) in $\mathrm{CHCl}_{3}$ and the corresponding quinolin-8-ylphosphonates 7 were obtained in overall high yields (Scheme 1, Chart 1). The transformation of compounds 6 into compounds 7 was confirmed by ${ }^{1} \mathrm{H}$ NMR spectroscopy, where signals corresponding to the four protons of tetrahydroquinoline ring of compounds 6 disappeared, while fully aromatic quinolines 7 were formed. In this sense, a wide range of compounds was obtained by using a variety of aldehydes and styrenes with both electron-withdrawing and electron-donating substituents. 


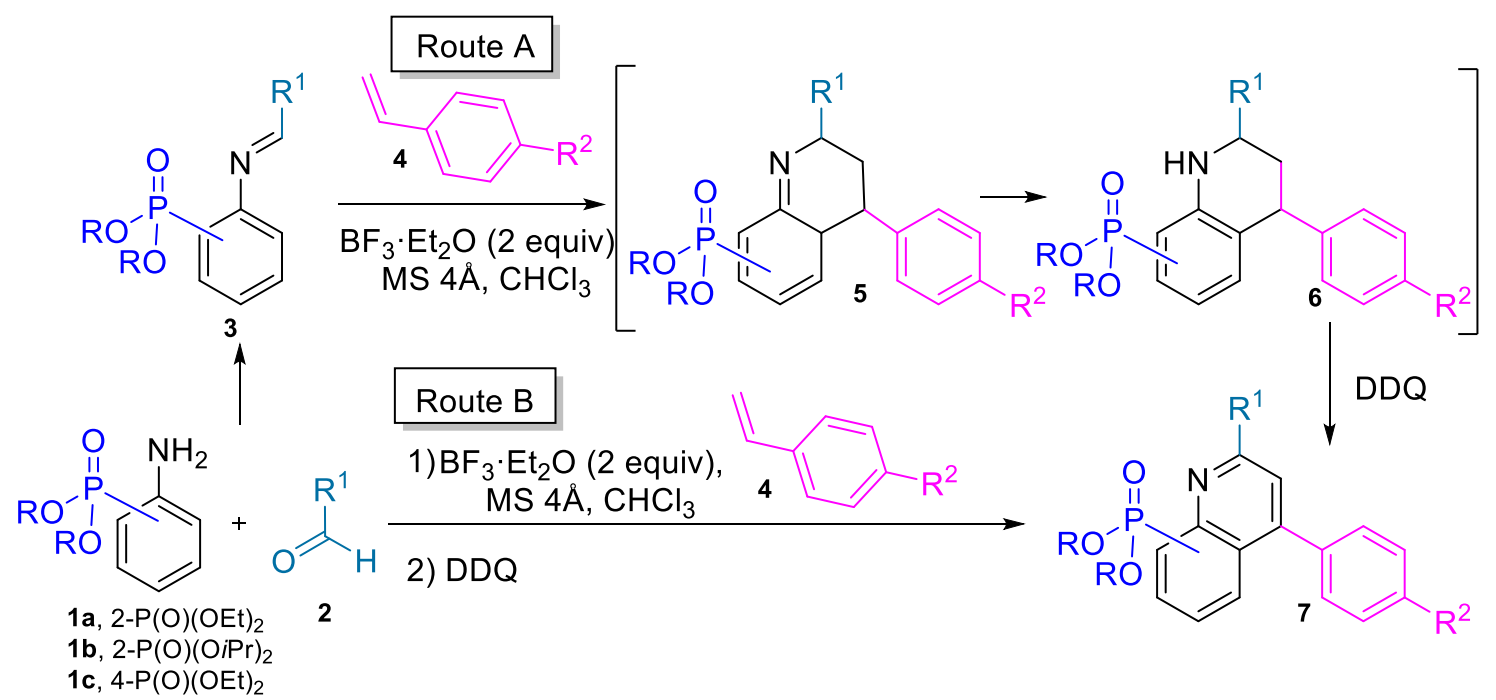

Scheme 1. Syntheses of quinolinylphosphonate derivatives 7 from styrenes 4 .<smiles>CCOP(=O)(OCC)c1cccc2cc(-c3ccccc3)c(-c3ccccc3)nc12</smiles><smiles>CCOP(=O)(OCC)c1cccc2c(-c3ccccc3)cc(-c3ccc(F)cc3)nc12</smiles><smiles>CCOP(=O)(OCC)c1cccc2c(-c3ccccc3)cc(-c3ccc(OC)cc3)nc12</smiles>
7 c $(41 \%)^{c}$<smiles>CCOP(=O)(OCC)c1ccc(C(F)(F)F)c2nc(-c3ccccc3OC)cc(-c3ccccc3)c12</smiles><smiles>CCOP(=O)(OCC)c1cccc2c(-c3ccccc3)cc(-c3ccc4ccccc4c3)nc12</smiles><smiles>CCOP(=O)(OCC)c1cc([18O])cc2c(-c3ccc(F)cc3)cc(-c3ccc(F)c(F)c3)nc12</smiles><smiles>CCOP(=O)(OCC)c1cccc2c(-c3ccccc3)cc(-c3cccc4ccccc34)nc12</smiles>
$7 f(83 \%)^{b}$<smiles>CCOP(=O)(OCC)c1cccc2c(-c3ccc(F)cc3)cc(-c3ccccc3)nc12</smiles><smiles>[18OH][18F]</smiles><smiles>CCOP(=O)(OCC)c1cccc2c(-c3ccc(C)cc3)cc(-c3ccc(F)c(F)c3)nc12</smiles>

Chart 1. Structures of diethyl quinolin-8-ylphosphonates $7 \mathbf{a}-\mathbf{k}$ obtained by Povarov reaction from diethyl (2-aminophenyl)phosphonate $1 \mathbf{a}$ and ${ }^{a}$ by a two-step reaction with styrenes and subsequent oxidation with DDQ or ${ }^{b}$ by MCR and subsequent oxidation with DDQ or ${ }^{c}$ by two-step reaction with acetylenes.

The formation of compound 7 may be explained through a regio- and stereoselective -cycloaddition reaction between aldimine $3 \mathbf{a}\left(\mathrm{R}=\mathrm{Et}, \mathrm{R}^{1}=\mathrm{C}_{6} \mathrm{H}_{5}\right)$ and phenyl styrene $4 \mathbf{a}$ $\left(\mathrm{R}^{2}=\mathrm{H}\right)$ followed by a prototrophic tautomerization of corresponding adduct 5 (Scheme 1 , Route A) to quinoline $\mathbf{6}$ and subsequent aromatization with DDQ towards quinolines 7.

Alternatively, the same compounds 7 can be directly obtained by a multicomponent (MCR) protocol. Thus, the three components, amines $\mathbf{1}$, aldehydes $\mathbf{2}$, and styrenes 4 
were mixed in the presence of the Lewis acid $\left(\mathrm{BF}_{3} \cdot \mathrm{Et}_{2} \mathrm{O}\right)$ in chloroform at reflux and the corresponding crude mixtures were treated with DDQ (Scheme 1, Route B).

As we previously reported, if acetylenes are used as dienophiles instead of olefins when reacting with aldimines, the corresponding aromatized compounds were directly obtained without the addition of an oxidant as DDQ [9]. For this reason, we then studied the preparation of phosphonate quinoline derivatives 7 in a direct way by means of the Povarov reaction by using aldimines 3 and acetylenes 8 in the presence of 1 equivalent of $\mathrm{BF}_{3} \cdot \mathrm{Et}_{2} \mathrm{O}$ as a Lewis acid catalyst in refluxing chloroform (Scheme 2, Chart 1).
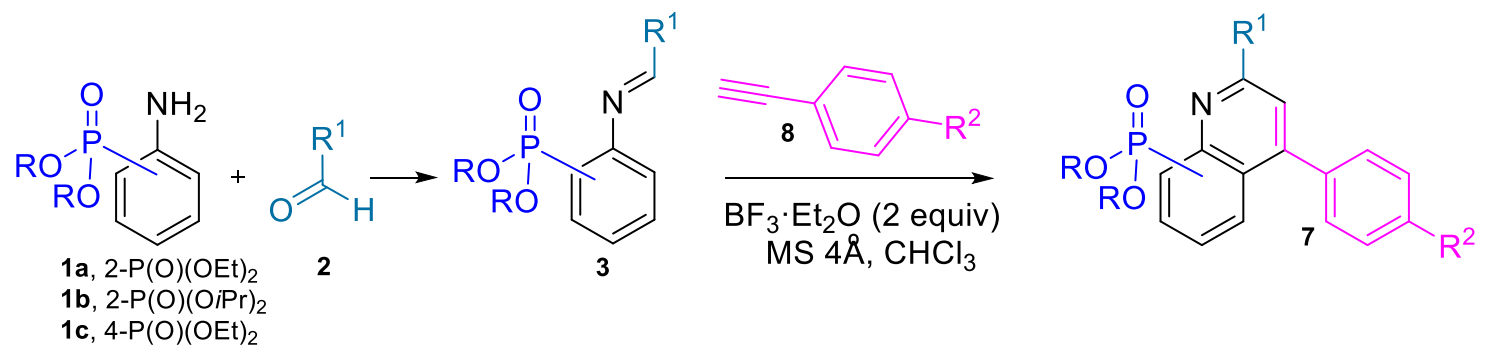

Scheme 2. Syntheses of quinolinylphosphonate derivatives 7 from acetylenic compounds 8 .

In order to increase the diversity, the preparation of isopropyl $\left(\mathrm{R}={ }^{i} \mathrm{Pr}\right)$ phosphonate derivatives was studied. In this case, an MCR protocol was followed by reacting diisopropyl (2-aminophenyl)phosphonate $\mathbf{1 b}\left(\mathrm{R}={ }^{i} \mathrm{Pr}\right.$ ) with aromatic aldehydes $\mathbf{2}$ and styrenes 4 , and after starting reagents consumption followed by the subsequent addition of DDQ and the

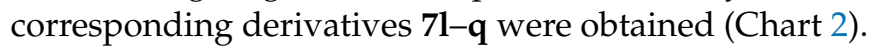<smiles>O=P(O)(O)c1cccc2cc(-c3ccccc3)c(-c3ccccc3)nc12</smiles><smiles></smiles>

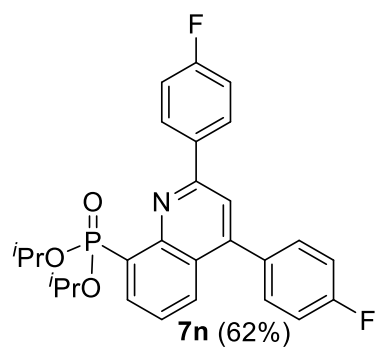<smiles></smiles><smiles>CN(C)c1ccc(-c2cc(-c3ccc(F)cc3)nc3c(P(=O)(O)O)ccc([Pb])c23)cc1</smiles>

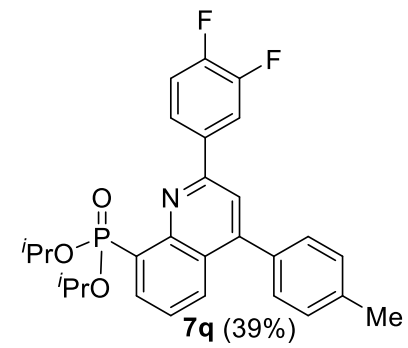

Chart 2. Structures of diisopropyl quinolin-8-ylphosphonates $7 \mathbf{l}-\mathbf{q}$ obtained by a MCR from diisopropyl (2-aminophenyl)phosphonate $\mathbf{1 b}$, aldehydes and styrenes 4 and subsequent oxidation with DDQ.

The scope of the reaction was then expanded to the preparation of quinolinyl derivatives with ethyl phosphonate group at 6-position by employing diethyl (4-aminophenyl)pho sphonate $1 \mathrm{c}(\mathrm{R}=\mathrm{Et})$. First, aldimine 3 formation was carried out by reaction between aniline $\mathbf{1 c}$ and aromatic aldehydes 2 , followed by addition of corresponding styrene 4 and subsequent oxidation with DDQ to give the corresponding derivatives $\mathbf{7 r}-\mathbf{x}(\mathrm{R}=\mathrm{Et}$, Chart 3). 

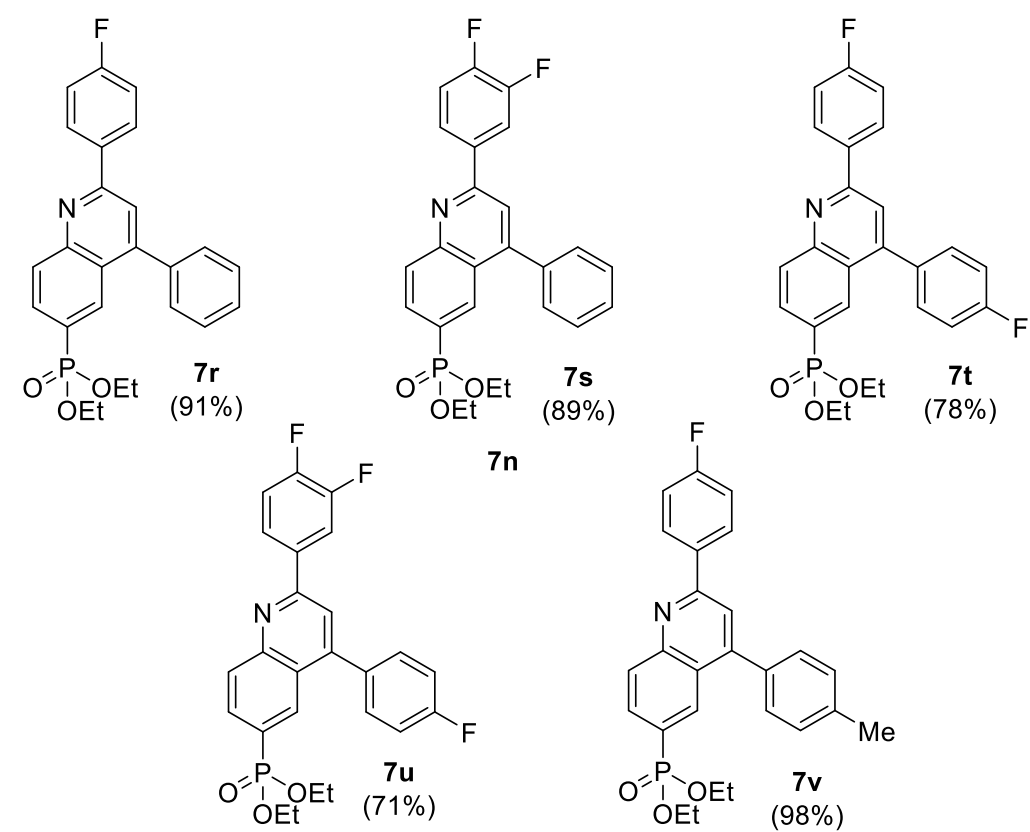

$7 n$<smiles>CCOP(=O)(OCC)c1ccc2nc(-c3ccc(F)cc3)cc(-c3ccc(C)cc3)c2c1</smiles><smiles>CCOP(=O)(OCC)c1ccc2nc(-c3ccc(F)c(F)c3)cc(-c3ccc(C)cc3)c2c1</smiles>

Chart 3. Structures of diethyl quinolin-6-ylphosphonates $7 \mathbf{r}-\mathbf{x}$ obtained by a two-step Povarov reaction from diethyl (4-aminophenyl)phosphonate 1c, aldehydes 2 and styrenes 4.

By the described methodology hybrid diethyl and di-isopropyl quinolines are obtained directly from appropriately functionalized anilines. In the next steps, the biological activity of these novel compounds as antiproliferative agents, TOP1B inhibitors, and antileishmanial agents was studied.

\subsection{In Vitro Cytotoxicity}

The cytotoxicity of the newly synthesized quinolinylphosphonates 7 was evaluated in vitro by testing their antiproliferative activities against several human cancer cell lines: A549 (human lung adenocarcinoma cells), SKOV3 (human ovarian carcinoma), and HEK293 (human embryonic kidney). In order to analyze the selective cytotoxicity facing exclusively cancerous cell lines, cytotoxicity against non-cancerous cell lines (MRC-5, lung fibroblast cells) was also evaluated. Cell counting kit (CCK-8) assay was employed to assess growth inhibition and, cell proliferation inhibitory activities of compounds that are listed in Table 1 as $\mathrm{IC}_{50}$ values. The tested compounds displayed a broad spectrum of antiproliferative activity against the cancer cell lines tested in culture. According to the data presented in Table 1, in general, all these phosphorated derivatives present higher selective cytotoxicity in the A549 cell line than in the other two cell lines, SKOV3 and HEK293, although slight differences are observed compared to human ovarian carcinoma (SKOV3). Moreover, MRC-5 non-malignant lung fibroblasts were tested for studying selective toxicity and none of the synthesized phosphorated compounds exhibited any toxicity toward MRC-5 cells (Table 1). 
Table 1. Antiproliferative activity of compounds 7.

\begin{tabular}{|c|c|c|c|c|c|c|c|c|}
\hline \multirow[b]{2}{*}{ Entry } & \multirow[b]{2}{*}{ Comp. } & \multirow[b]{2}{*}{$\mathrm{PO}(\mathrm{OR})_{2}$} & \multirow[b]{2}{*}{$\mathrm{R}^{1}$} & \multirow[b]{2}{*}{$\mathbf{R}^{2}$} & \multicolumn{4}{|c|}{ Cytotoxicity $\mathrm{IC}_{50}(\mu \mathrm{M})^{a}$} \\
\hline & & & & & $\begin{array}{l}\text { Lung } \\
\text { A549 }\end{array}$ & $\begin{array}{l}\text { Ovarian } \\
\text { SKOV3 }\end{array}$ & $\begin{array}{c}\text { Kidney } \\
\text { HEK293 }\end{array}$ & MRC-5 \\
\hline 1 & \multicolumn{4}{|c|}{$\mathrm{CPT}$} & $\begin{array}{c}(1.0 \pm \\
0.06) \cdot 10^{-3}\end{array}$ & $\begin{array}{c}(5.5 \pm \\
0.01) \cdot 10^{-3}\end{array}$ & - & $\begin{array}{c}(1.7 \pm \\
0.96) \cdot 10^{-5}\end{array}$ \\
\hline 2 & $7 a$ & $8-\left(\mathrm{PO}(\mathrm{OEt})_{2}\right)$ & $\mathrm{C}_{6} \mathrm{H}_{5}$ & $\mathrm{H}$ & $2.26 \pm 0.59$ & $9.30 \pm 0.76$ & $27.29 \pm 2.22$ & $>50$ \\
\hline 3 & $7 \mathrm{~b}$ & $8-\left(\mathrm{PO}(\mathrm{OEt})_{2}\right)$ & $4-\mathrm{F}-\mathrm{C}_{6} \mathrm{H}_{4}$ & $\mathrm{H}$ & $2.16 \pm 0.29$ & $5.29 \pm 1.42$ & $43.04 \pm 4.65$ & $>50$ \\
\hline 4 & $7 \mathrm{c}$ & $8-\left(\mathrm{PO}(\mathrm{OEt})_{2}\right)$ & $\begin{array}{l}\text { 4-OMe- } \\
\mathrm{C}_{6} \mathrm{H}_{4}\end{array}$ & $\mathrm{H}$ & $\begin{array}{c}12.59 \pm \\
1.30\end{array}$ & $25.04 \pm 3.60$ & $38.29 \pm 8.90$ & $>50$ \\
\hline 5 & $7 d$ & $8-\left(\mathrm{PO}(\mathrm{OEt})_{2}\right)$ & $\begin{array}{l}\text { 2-OMe- } \\
\mathrm{C}_{6} \mathrm{H}_{4}\end{array}$ & $\mathrm{H}$ & $\begin{array}{c}12.26 \pm \\
4.10\end{array}$ & $19.38 \pm 1.60$ & $>50$ & $>50$ \\
\hline 6 & $7 e$ & $8-\left(\mathrm{PO}(\mathrm{OEt})_{2}\right)$ & 2-naphthyl & $\mathrm{H}$ & $3.18 \pm 0.27$ & $1.33 \pm 0.76$ & $48.14 \pm 6.39$ & $>50$ \\
\hline 7 & $7 f$ & $8-\left(\mathrm{PO}(\mathrm{OEt})_{2}\right)$ & 1-naphthyl & $\mathrm{H}$ & $2.66 \pm 0.16$ & $4.54 \pm 0.52$ & $35.67 \pm 3.13$ & $>50$ \\
\hline 8 & $7 \mathrm{~g}$ & $8-\left(\mathrm{PO}(\mathrm{OEt})_{2}\right)$ & $\mathrm{C}_{6} \mathrm{H}_{5}$ & $\mathrm{~F}$ & $2.27 \pm 0.32$ & $9.29 \pm 1.79$ & $24.43 \pm 3.46$ & $>50$ \\
\hline 9 & $7 \mathrm{~h}$ & $8-\left(\mathrm{PO}(\mathrm{OEt})_{2}\right)$ & $4-\mathrm{F}-\mathrm{C}_{6} \mathrm{H}_{4}$ & $\mathrm{~F}$ & $3.07 \pm 0.22$ & $9.79 \pm 0.59$ & $15.66 \pm 1.74$ & $>50$ \\
\hline 10 & $7 \mathbf{i}$ & $8-\left(\mathrm{PO}(\mathrm{OEt})_{2}\right)$ & $\begin{array}{l}3,4-\mathrm{F}_{2-}^{-} \\
\mathrm{C}_{6} \mathrm{H}_{3}\end{array}$ & $\mathrm{~F}$ & $4.64 \pm 0.30$ & $37.59 \pm 9.10$ & $>50$ & $>50$ \\
\hline 11 & $7 \mathbf{j}$ & $8-\left(\mathrm{PO}(\mathrm{OEt})_{2}\right)$ & $4-\mathrm{F}-\mathrm{C}_{6} \mathrm{H}_{4}$ & $\mathrm{Me}$ & $0.83 \pm 0.01$ & $10.24 \pm 0.38$ & $>50$ & $>50$ \\
\hline 12 & $7 k$ & $8-\left(\mathrm{PO}(\mathrm{OEt})_{2}\right)$ & $\begin{array}{l}3,4-\mathrm{F}_{2^{-}} \\
\mathrm{C}_{6} \mathrm{H}_{3}\end{array}$ & $\mathrm{Me}$ & $2.72 \pm 0.37$ & $10.59 \pm 1.13$ & $22.26 \pm 1.36$ & $>50$ \\
\hline 13 & 71 & $8-\left(\mathrm{PO}\left(\mathrm{O}^{i} \mathrm{Pr}\right)_{2}\right)$ & $4-\mathrm{F}-\mathrm{C}_{6} \mathrm{H}_{4}$ & $\mathrm{H}$ & $5.01 \pm 2.70$ & $18.73 \pm 1.98$ & $10.12 \pm 1.26$ & $>50$ \\
\hline 14 & $7 \mathrm{~m}$ & $8-\left(\mathrm{PO}\left(\mathrm{O}^{i} \mathrm{Pr}\right)_{2}\right)$ & $\begin{array}{l}3,4-\mathrm{F}_{2^{-}} \\
\mathrm{C}_{6} \mathrm{H}_{3}\end{array}$ & $\mathrm{H}$ & $18.39 \pm 1.4$ & $12.13 \pm 1.7$ & $>50$ & $>50$ \\
\hline 15 & $7 n$ & $8-\left(\mathrm{PO}\left(\mathrm{O}^{i} \mathrm{Pr}\right)_{2}\right)$ & $4-\mathrm{F}-\mathrm{C}_{6} \mathrm{H}_{4}$ & $\mathrm{~F}$ & $\begin{array}{c}10.55 \pm \\
1.73\end{array}$ & $19.82 \pm 3.83$ & $15.01 \pm 0.99$ & $>50$ \\
\hline 16 & 70 & $8-\left(\mathrm{PO}\left(\mathrm{O}^{i} \mathrm{Pr}\right)_{2}\right)$ & $\begin{array}{l}3,4-\mathrm{F}_{2^{-}} \\
\mathrm{C}_{6} \mathrm{H}_{3}\end{array}$ & $\mathrm{~F}$ & $6.79 \pm 3.87$ & $22.12 \pm 4.47$ & $21.04 \pm 4.05$ & $>50$ \\
\hline 17 & $7 p$ & 8- $\left(\mathrm{PO}\left(\mathrm{O}^{i} \mathrm{Pr}\right)_{2}\right)$ & $4-\mathrm{F}-\mathrm{C}_{6} \mathrm{H}_{4}$ & $\mathrm{Me}$ & $6.84 \pm 1.74$ & $12.13 \pm 1.68$ & $14.38 \pm 1.69$ & $>50$ \\
\hline 18 & $7 q$ & $8-\left(\mathrm{PO}\left(\mathrm{O}^{i} \mathrm{Pr}\right)_{2}\right)$ & $\begin{array}{l}3,4-\mathrm{F}_{2^{-}} \\
\mathrm{C}_{6} \mathrm{H}_{3}\end{array}$ & $\mathrm{Me}$ & $8.24 \pm 2.42$ & $4.67 \pm 1.50$ & $12.32 \pm 0.71$ & $>50$ \\
\hline 19 & $7 \mathrm{r}$ & $6-\left(\mathrm{PO}(\mathrm{OEt})_{2}\right)$ & $4-\mathrm{F}-\mathrm{C}_{6} \mathrm{H}_{4}$ & $\mathrm{H}$ & $2.80 \pm 1.24$ & $3.03 \pm 1.24$ & $36.86 \pm 8.06$ & $>50$ \\
\hline 20 & $7 \mathrm{~s}$ & $6-\left(\mathrm{PO}(\mathrm{OEt})_{2}\right)$ & $\begin{array}{l}3,4-\mathrm{F}_{2^{-}} \\
\mathrm{C}_{6} \mathrm{H}_{3}\end{array}$ & $\mathrm{H}$ & $6.19 \pm 0.67$ & $>50$ & $19.18 \pm 1.13$ & $>50$ \\
\hline 21 & $7 t$ & $6-\left(\mathrm{PO}(\mathrm{OEt})_{2}\right)$ & $4-\mathrm{F}-\mathrm{C}_{6} \mathrm{H}_{4}$ & $\mathrm{~F}$ & $2.85 \pm 1.26$ & $>50$ & $>50$ & $>50$ \\
\hline 22 & $7 \mathbf{u}$ & $6-\left(\mathrm{PO}(\mathrm{OEt})_{2}\right)$ & $\begin{array}{l}3,4-\mathrm{F}_{2^{-}} \\
\mathrm{C}_{6} \mathrm{H}_{3}\end{array}$ & $\mathrm{~F}$ & $4.33 \pm 1.11$ & $>50$ & $>50$ & $>50$ \\
\hline 23 & $7 \mathbf{v}$ & $6-\left(\mathrm{PO}(\mathrm{OEt})_{2}\right)$ & $4-\mathrm{F}-\mathrm{C}_{6} \mathrm{H}_{4}$ & $\mathrm{Me}$ & $0.84 \pm 0.23$ & $41.61 \pm 10.01$ & $>50$ & $>50$ \\
\hline 24 & $7 x$ & $6-\left(\mathrm{PO}(\mathrm{OEt})_{2}\right)$ & $\begin{array}{l}3,4-\mathrm{F}_{2-}^{-} \\
\mathrm{C}_{6} \mathrm{H}_{3}\end{array}$ & $\mathrm{Me}$ & $3.05 \pm 0.86$ & $>50$ & $>50$ & $>50$ \\
\hline
\end{tabular}

${ }^{a}$ The cytotoxicity $\mathrm{IC}_{50}$ values listed are the concentrations corresponding to $50 \%$ growth inhibition.

In general ethyl phosphonates $7 \mathbf{a}-\mathbf{k}$ and $\mathbf{7 r}-\mathbf{x}(\mathrm{R}=\mathrm{Et}$, entries $2-12$ and 19-24) present higher cytotoxicity than isopropyl phosphonates $7 \mathbf{l}-\mathbf{q}\left(\mathrm{R}={ }^{i} \mathrm{Pr}\right.$, entries 13-18). In addition, amongst the diethyl phosphonate derivatives, the derivatives with this group in position 6 show the best biological response with cytotoxic values under $7 \mu \mathrm{M}$ (Table 1, entries 19-24). Specifically, the most effective compounds with values in the nanomolar range were the derivative $7 j\left(R=E t\right.$ (phosphonate group at position 8), $R^{1}=4-F, R^{2}=M e$, entry 11) with an $\mathrm{IC}_{50}$ value of $830 \pm 10 \mathrm{nM}$ and the derivative $7 \mathrm{v}(\mathrm{R}=\mathrm{Et}$ (phosphonate group at position 6), $R^{1}=4-F, R^{2}=M e$, entry 23) with an $I_{50}$ value of $840 \pm 230 \mathrm{nM}$.

\subsection{Inhibition of Human TOP1B (hTOP1B)}

The activity as topoisomerase $1 \mathrm{~B}$ inhibitors of newly prepared quinolinylphosphonates 7 was evaluated through the assessment of conventional supercoiled DNA relaxation assay, determining their inhibitory effect on hTOP1B by quantifying the transformation of a supercoiled DNA plasmid into the relaxed form in the presence of the compounds (Table 2). In these experiments, compound samples were mixed with purified enzyme followed by 
the addition of supercoiled plasmid DNA and continued incubation for increasing time periods ( $15 \mathrm{~s}, 1 \mathrm{~min}$, and $3 \mathrm{~min}$ ). The reaction was terminated by the addition of SDS. DNA relaxation products were then resolved by electrophoresis in $1 \%$ agarose gel and visualized by gel red staining. CPT was used as a positive control (Figure 2).

Table 2. Human TOP1B inhibitory activity of compounds 7.

\begin{tabular}{|c|c|c|c|c|c|c|c|}
\hline \multirow{2}{*}{ Entry } & \multirow{2}{*}{ Comp. } & \multirow{2}{*}{$\mathrm{PO}(\mathrm{OR})_{2}$} & \multirow{2}{*}{$\mathbf{R}^{1}$} & \multirow{2}{*}{$\mathbf{R}^{2}$} & \multicolumn{3}{|c|}{$\%$ Inhibition ${ }^{a}$} \\
\hline & & & & & $15 \mathrm{~s}$ & $1 \mathrm{~min}$ & $3 \mathrm{~min}$ \\
\hline 1 & & & PT & & 80 & 76 & 3 \\
\hline 2 & $7 a$ & $8-\left(\mathrm{PO}(\mathrm{OEt})_{2}\right)$ & $\mathrm{C}_{6} \mathrm{H}_{5}$ & $\mathrm{H}$ & 20 & 28 & 1 \\
\hline 3 & $7 \mathrm{~b}$ & $8-\left(\mathrm{PO}(\mathrm{OEt})_{2}\right)$ & $4-\mathrm{F}-\mathrm{C}_{6} \mathrm{H}_{4}$ & $\mathrm{H}$ & 54 & 61 & 21 \\
\hline 4 & $7 c$ & $8-\left(\mathrm{PO}(\mathrm{OEt})_{2}\right)$ & $4-\mathrm{OMe}-\mathrm{C}_{6} \mathrm{H}_{4}$ & $\mathrm{H}$ & 11 & 9 & 4 \\
\hline 5 & $7 d$ & $8-\left(\mathrm{PO}(\mathrm{OEt})_{2}\right)$ & $2-\mathrm{OMe}-\mathrm{C}_{6} \mathrm{H}_{4}$ & $\mathrm{H}$ & 22 & 16 & 3 \\
\hline 6 & $7 e$ & $8-\left(\mathrm{PO}(\mathrm{OEt})_{2}\right)$ & 2-naphthyl & $\mathrm{H}$ & 17 & 36 & 4 \\
\hline 7 & $7 f$ & $8-\left(\mathrm{PO}(\mathrm{OEt})_{2}\right)$ & 1-naphthyl & $\mathrm{H}$ & 27 & 28 & 8 \\
\hline 8 & $7 g$ & $8-\left(\mathrm{PO}(\mathrm{OEt})_{2}\right)$ & $\mathrm{C}_{6} \mathrm{H}_{5}$ & $\mathrm{~F}$ & 28 & 36 & 3 \\
\hline 9 & $7 \mathrm{~h}$ & $8-\left(\mathrm{PO}(\mathrm{OEt})_{2}\right)$ & $4-\mathrm{F}-\mathrm{C}_{6} \mathrm{H}_{4}$ & $\mathrm{~F}$ & 27 & 19 & 4 \\
\hline 10 & $7 \mathbf{i}$ & $8-\left(\mathrm{PO}(\mathrm{OEt})_{2}\right)$ & $3,4-\mathrm{F}_{2}-\mathrm{C}_{6} \mathrm{H}_{3}$ & $\mathrm{~F}$ & 47 & 37 & 2 \\
\hline 11 & $7 \mathbf{j}$ & $8-\left(\mathrm{PO}(\mathrm{OEt})_{2}\right)$ & $4-\mathrm{F}-\mathrm{C}_{6} \mathrm{H}_{4}$ & $\mathrm{Me}$ & 65 & 67 & 3 \\
\hline 12 & $7 \mathbf{k}$ & $8-\left(\mathrm{PO}(\mathrm{OEt})_{2}\right)$ & $3,4-\mathrm{F}_{2}-\mathrm{C}_{6} \mathrm{H}_{3}$ & $\mathrm{Me}$ & 63 & 95 & 5 \\
\hline 13 & 71 & $8-\left(\mathrm{PO}\left(\mathrm{O}^{i} \mathrm{Pr}\right)_{2}\right)$ & $4-\mathrm{F}-\mathrm{C}_{6} \mathrm{H}_{4}$ & $\mathrm{H}$ & 18 & 13 & 2 \\
\hline 14 & $7 \mathrm{~m}$ & $8-\left(\mathrm{PO}\left(\mathrm{O}^{i} \mathrm{Pr}\right)_{2}\right)$ & $3,4-\mathrm{F}_{2}-\mathrm{C}_{6} \mathrm{H}_{3}$ & $\mathrm{H}$ & 26 & 32 & 3 \\
\hline 15 & $7 n$ & $8-\left(\mathrm{PO}\left(\mathrm{O}^{i} \mathrm{Pr}\right)_{2}\right)$ & $4-\mathrm{F}-\mathrm{C}_{6} \mathrm{H}_{4}$ & $\mathrm{~F}$ & 59 & 57 & 7 \\
\hline 16 & 7o & $8-\left(\mathrm{PO}\left(\mathrm{O}^{i} \mathrm{Pr}\right)_{2}\right)$ & $3,4-\mathrm{F}_{2}-\mathrm{C}_{6} \mathrm{H}_{3}$ & $\mathrm{~F}$ & 29 & 27 & 3 \\
\hline 17 & $7 p$ & $8-\left(\mathrm{PO}\left(\mathrm{O}^{i} \mathrm{Pr}\right)_{2}\right)$ & $4-\mathrm{F}-\mathrm{C}_{6} \mathrm{H}_{4}$ & $\mathrm{Me}$ & 32 & 46 & 4 \\
\hline 18 & $7 q$ & $8-\left(\mathrm{PO}\left(\mathrm{O}^{i} \mathrm{Pr}\right)_{2}\right)$ & $3,4-\mathrm{F}_{2}-\mathrm{C}_{6} \mathrm{H}_{3}$ & $\mathrm{Me}$ & 51 & 35 & 6 \\
\hline 19 & $7 r$ & $6-\left(\mathrm{PO}(\mathrm{OEt})_{2}\right)$ & $4-\mathrm{F}-\mathrm{C}_{6} \mathrm{H}_{4}$ & $\mathrm{H}$ & 9 & 15 & 3 \\
\hline 20 & $7 \mathrm{~s}$ & $6-\left(\mathrm{PO}(\mathrm{OEt})_{2}\right)$ & $3,4-\mathrm{F}_{2}-\mathrm{C}_{6} \mathrm{H}_{3}$ & $\mathrm{H}$ & 9 & 13 & 2 \\
\hline 21 & $7 t$ & $6-\left(\mathrm{PO}(\mathrm{OEt})_{2}\right)$ & $4-\mathrm{F}-\mathrm{C}_{6} \mathrm{H}_{4}$ & $\mathrm{~F}$ & 21 & 18 & 5 \\
\hline 22 & $7 \mathbf{u}$ & $6-\left(\mathrm{PO}(\mathrm{OEt})_{2}\right)$ & $3,4-\mathrm{F}_{2}-\mathrm{C}_{6} \mathrm{H}_{3}$ & $\mathrm{~F}$ & 27 & 21 & 14 \\
\hline 23 & $7 \mathbf{v}$ & $6-\left(\mathrm{PO}(\mathrm{OEt})_{2}\right)$ & $4-\mathrm{F}-\mathrm{C}_{6} \mathrm{H}_{4}$ & $\mathrm{Me}$ & 22 & 30 & 12 \\
\hline 24 & $7 x$ & $6-\left(\mathrm{PO}(\mathrm{OEt})_{2}\right)$ & $3,4-\mathrm{F}_{2}-\mathrm{C}_{6} \mathrm{H}_{3}$ & $\mathrm{Me}$ & 18 & 25 & 5 \\
\hline
\end{tabular}

${ }^{a}$ The activity of the compounds inhibiting hTOP1B relaxation was expressed quantitatively by comparison with the inhibitory activity observed for CPT.

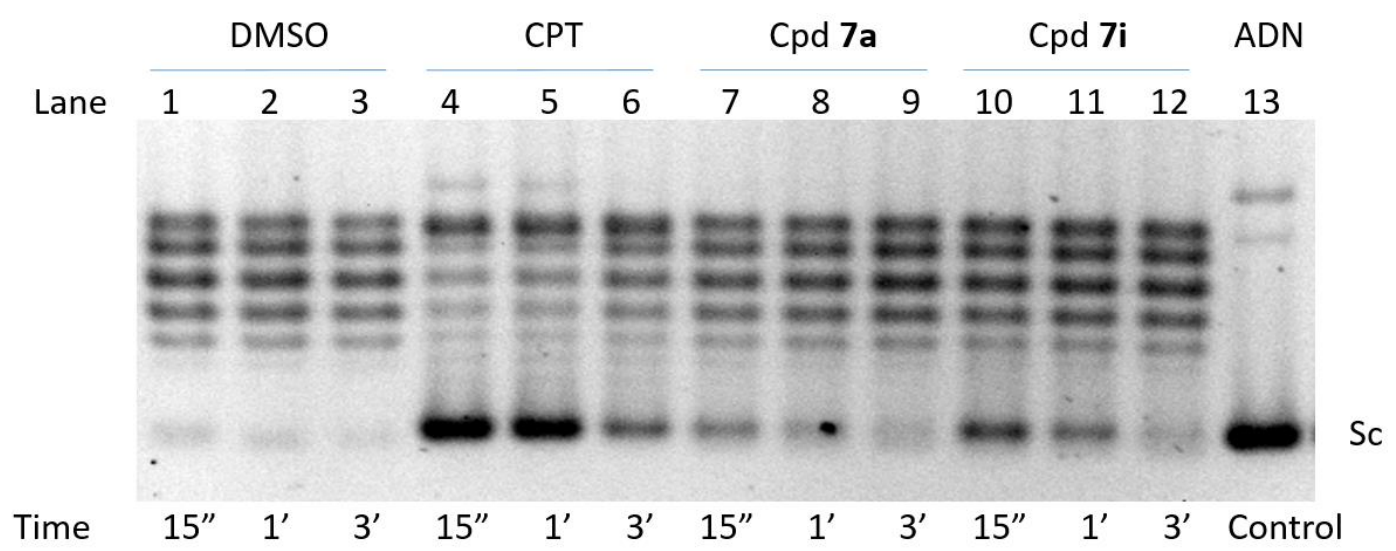

Figure 2. Inhibition of hTOP1B activity along the time $\left(15^{\prime \prime}, 1^{\prime}\right.$ and $\left.3^{\prime}\right)$ by compounds $7 \mathbf{a}, 7 \mathbf{i}$ and CPT at $100 \mu \mathrm{M}$ : lanes $1-3$, DNA + hTOP1B + DMSO; lanes 4-6, DNA + hTOP1B + CPT; lanes 7-9, DNA + hTOP1B + 7a; lanes 10-12, DNA + hTOP1B + 7i; lane 13, control DNA. Reaction samples were mixed with the supercoiled DNA substrate before adding enzyme at $37^{\circ} \mathrm{C}$ and separated by electrophoresis on a 1\% agarose gel, and then stained with gel red, and photographed under UV light as described in the hTOP1B mediated DNA relaxation assay. Sc, supercoiled DNA. 
The effects of CPT and DMSO (used as a solvent for the dissolutions of CPT and the new compounds) were tested as a positive and negative control, respectively, in the experiment. As expected, CPT inhibited the relaxation, as a higher amount of signal corresponding to supercoiled (unrelaxed) plasmid was observed at short reaction times (15 s and $1 \mathrm{~min}$ ) when $100 \mu \mathrm{M} \mathrm{CPT}$ was added than when the enzymatic reaction was performed with the DMSO solvent alone (compare lanes 4 and 5 with lanes 1 and 2 in Figure 2). Only after a longer incubation time, more relaxation was observed in the presence of CPT (lane 6).

By performing these experiments, the inhibitory ability of hTOP1B activity of the new compounds 7 was tested. In Figure 2 it can be seen that for example compound 7a showed slight inhibition of hTOP1B activity at any enzymatic reaction time (lanes 7-9). Also in this Figure 2, the inhibition of hTOP1B activity of compound $7 \mathbf{i}$ is evidenced by the appearance of supercoiled DNA signals (lanes 10 and 11). As a result, the behavior of all the new compounds 7 has been studied and the results have been summarized in Table 2. Some compounds, such as $\mathbf{7 b}, \mathbf{7} \mathbf{j}, \mathbf{7 k}$, and $\mathbf{7 n}$ show inhibition at $15 \mathrm{~s}$ and $1 \mathrm{~min}$ of an enzymatic reaction, similar to that of the natural inhibitor CPT (Table 2, entries 3, 11, 12, and 15).

\subsection{Docking Study}

Among all the compounds synthesized in this work, a molecular docking study of compound $7 \mathbf{b}$ who showed significant inhibition of hTOP1B was carried out to investigate its possible binding pattern and its interaction with the key amino acids and DNA nucleobases in the active site of the hTOP1B. The model was derived by the docking of compound $\mathbf{7 b}$ in the CPT binding site of the CPT-hTOP1B-DNA ternary complex (PDB ID: 1T8I) [27]. The most important evaluation criterion was the observation of whether the ligand was located between C112-TGP11 and A113-T10 nucleobases (Figure 3), where the DNA rupture site is located, avoiding the re-ligation of such bases, according to the concept of interfacial inhibition proposed by Pommier [7,28]. The formation of hydrogen bonds with important residues [29-32] and the existence of hydrophobic interactions with hTOP1B residues and DNA were also taken into account.

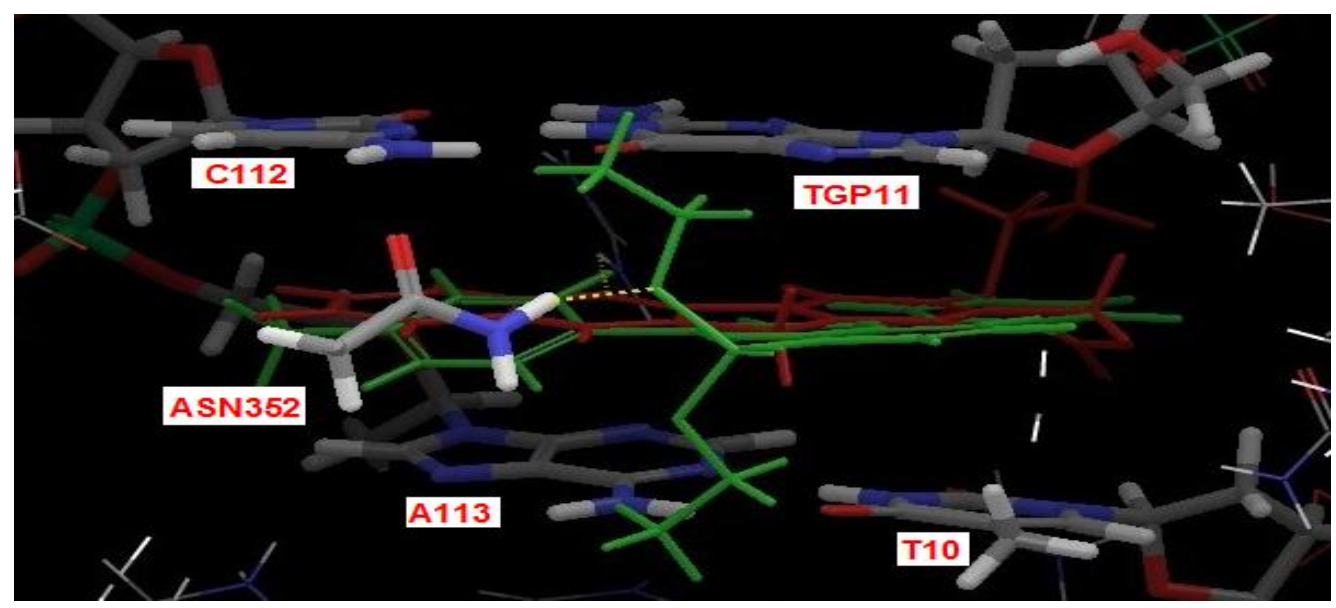

Figure 3. The 3D diagram representation of compound $7 \mathbf{b}$ (in green), superposed with CPT (in red) docked into hTOP1B active site showing its binding interactions with the amino acids binding site.

\subsection{Antileishmanial Activity of New Quinolinylphosphonate Derivatives}

The effect of the new quinolinylphosphonate derivatives 7 synthesized was assessed on both free-living promastigotes and intramacrophage amastigotes of L. infantum as it is described in experimental protocols. Primary cultures of intramacrophage amastigotes were obtained from splenic explants from 6-weeks infected Balb/c mice with L. infantumiRFP promastigotes. The infrared fluorescence emitted by both stage forms of the parasite 
was used as viability criterium, using $0.5 \%$ DMSO as negative control (100\% viability) and $50 \mathrm{mM}$ AMB as a positive control ( $0 \%$ viability).

All the compounds were active against both parasite forms (Table 3). Thus, the $\mathrm{EC}_{50}$ values for promastigotes ranged from $0.91 \pm 0.04 \mu \mathrm{M}$ corresponding to compound $7 \mathbf{a}$ (Table 3, entry 1) to $21.29 \pm 2.34 \mu \mathrm{M}$ related to compound $7 \mathbf{x}$ (Table 3, entry 23). On the other hand, the $\mathrm{EC}_{50}$ values for amastigotes fluctuate between $4.03 \pm 0.30 \mu \mathrm{M}$ for $7 \mathrm{a}$ and $32.95 \pm 6.55$ for $7 \mathbf{x}$ (Table 3, entry 1 and 23). The selectivity of all the compounds was low, which indicates high toxicity, this parameter was calculated as the ratio between the $\mathrm{EC}_{50}$ obtained for amastigotes and the $\mathrm{IC}_{50}$ values for murine splenic cells. The higher selectivity index was obtained for $\mathbf{7} \mathbf{u}$ compound (>3.8) (Table 3, entry 21 ).

Table 3. Bioactivity of phosphonate derivative compounds 7 on both forms of Leishmania parasites.

\begin{tabular}{|c|c|c|c|c|c|c|c|c|c|}
\hline \multirow{2}{*}{ Entry } & \multirow{2}{*}{ Comp. } & \multirow{2}{*}{$\mathrm{PO}(\mathrm{OR})_{2}$} & \multirow{2}{*}{$\mathbf{R}^{1}$} & \multirow{2}{*}{$\mathbf{R}^{2}$} & \multicolumn{2}{|c|}{$\mathrm{EC}_{50} \mathrm{~L}$. Infantum } & \multirow{2}{*}{$\begin{array}{c}\mathrm{IC}_{50} \\
\text { Splenocites }\end{array}$} & \multirow{2}{*}{ SI } & \multirow{2}{*}{$\begin{array}{l}\text { LTOP1B } \\
\text { Inhibition }\end{array}$} \\
\hline & & & & & Promastigotes & Amastigotes & & & \\
\hline 1 & $7 a$ & $8-\left(\mathrm{PO}(\mathrm{OEt})_{2}\right)$ & $\mathrm{C}_{6} \mathrm{H}_{5}$ & $\mathrm{H}$ & $0.91 \pm 0.04$ & $4.03 \pm 0.30$ & $3.61 \pm 0.45$ & 0.9 & 58.87 \\
\hline 2 & $7 \mathbf{b}$ & $8-\left(\mathrm{PO}(\mathrm{OEt})_{2}\right)$ & $4-\mathrm{F}-\mathrm{C}_{6} \mathrm{H}_{4}$ & $\mathrm{H}$ & $7.63 \pm 0.76$ & $14.56 \pm 1.30$ & $12.24 \pm 1.77$ & 0.8 & 24.43 \\
\hline 3 & $7 c$ & $8-\left(\mathrm{PO}(\mathrm{OEt})_{2}\right)$ & $\begin{array}{l}\text { 4-OMe- } \\
\mathrm{C}_{6} \mathrm{H}_{4}\end{array}$ & $\mathrm{H}$ & $9.46 \pm 1.67$ & $8.23 \pm 1.70$ & $15.90 \pm 1.65$ & 1.9 & 45.45 \\
\hline 4 & $7 d$ & $8-\left(\mathrm{PO}(\mathrm{OEt})_{2}\right)$ & $\begin{array}{l}\text { 2-OMe- } \\
\mathrm{C}_{6} \mathrm{H}_{4}\end{array}$ & $\mathrm{H}$ & $11.37 \pm 0.62$ & $19.46 \pm 2.38$ & $30.09 \pm 6.05$ & 1.5 & 46.41 \\
\hline 5 & $7 e$ & $8-\left(\mathrm{PO}(\mathrm{OEt})_{2}\right)$ & 2-naphthyl & $\mathrm{H}$ & $20.38 \pm 1.57$ & $20.44 \pm 5.62$ & $51.62 \pm 1.52$ & 2.5 & 18.36 \\
\hline 6 & $7 f$ & $8-\left(\mathrm{PO}(\mathrm{OEt})_{2}\right)$ & 1-naphthyl & $\mathrm{H}$ & $20.55 \pm 2.19$ & $19.66 \pm 2.39$ & $12.22 \pm 1.49$ & 0.6 & 7.5 \\
\hline 7 & $7 g$ & $8-\left(\mathrm{PO}(\mathrm{OEt})_{2}\right)$ & $\mathrm{C}_{6} \mathrm{H}_{5}$ & $\mathrm{~F}$ & $16.05 \pm 1.94$ & $11.89 \pm 5.17$ & $33.86 \pm 7.98$ & 2.8 & 16.49 \\
\hline 8 & $7 \mathrm{~h}$ & $8-\left(\mathrm{PO}(\mathrm{OEt})_{2}\right)$ & $4-\mathrm{F}-\mathrm{C}_{6} \mathrm{H}_{4}$ & $\mathrm{~F}$ & $8.43 \pm 0.92$ & $24.17 \pm 2.37$ & $20.26 \pm 7.49$ & 0.8 & 22.44 \\
\hline 9 & $7 \mathbf{i}$ & $8-\left(\mathrm{PO}(\mathrm{OEt})_{2}\right)$ & $\begin{array}{l}3,4-\mathrm{F}_{2^{-}} \\
\mathrm{C}_{6} \mathrm{H}_{3}\end{array}$ & $\mathrm{~F}$ & $6.35 \pm 0.16$ & $13.43 \pm 5.53$ & $20.64 \pm 3.11$ & 1.5 & 54.01 \\
\hline 10 & $7 \mathbf{j}$ & $8-\left(\mathrm{PO}(\mathrm{OEt})_{2}\right)$ & $4-\mathrm{F}-\mathrm{C}_{6} \mathrm{H}_{4}$ & $\mathrm{Me}$ & $7.29 \pm 0.94$ & $9.80 \pm 0.48$ & $14.54 \pm 1.56$ & 1.5 & 41.21 \\
\hline 11 & $7 \mathbf{k}$ & $8-\left(\mathrm{PO}(\mathrm{OEt})_{2}\right)$ & $\begin{array}{l}3,4-\mathrm{F}_{2-} \\
\mathrm{C}_{6} \mathrm{H}_{3}\end{array}$ & $\mathrm{Me}$ & $2.59 \pm 0.48$ & $26.23 \pm 3.65$ & $24.07 \pm 7.79$ & 0.9 & 77.02 \\
\hline 12 & 71 & $8-\left(\mathrm{PO}\left(\mathrm{O}^{i} \mathrm{Pr}\right)_{2}\right)$ & $4-\mathrm{F}-\mathrm{C}_{6} \mathrm{H}_{4}$ & $\mathrm{H}$ & $9.57 \pm 0.4$ & $19.47 \pm 2.23$ & $22.1 \pm 4.7$ & 1.1 & 3.55 \\
\hline 13 & $7 \mathrm{~m}$ & $8-\left(\mathrm{PO}\left(\mathrm{O}^{i} \mathrm{Pr}\right)_{2}\right)$ & $\begin{array}{l}3,4-\mathrm{F}_{2^{-}} \\
\mathrm{C}_{6} \mathrm{H}_{3}\end{array}$ & $\mathrm{H}$ & $11.18 \pm 0.74$ & $10.20 \pm 1.34$ & $19.79 \pm 3.76$ & 1.9 & 5.41 \\
\hline 14 & $7 n$ & $8-\left(\mathrm{PO}\left(\mathrm{O}^{i} \mathrm{Pr}\right)_{2}\right)$ & $4-\mathrm{F}-\mathrm{C}_{6} \mathrm{H}_{4}$ & $\mathrm{~F}$ & $4.86 \pm 0.5$ & $5.52 \pm 1.11$ & $15.29 \pm 1.72$ & 2.8 & 43.31 \\
\hline 15 & 70 & $8-\left(\mathrm{PO}\left(\mathrm{O}^{i} \mathrm{Pr}\right)_{2}\right)$ & $\begin{array}{l}3,4-\mathrm{F}_{2^{-}} \\
\mathrm{C}_{6} \mathrm{H}_{3}\end{array}$ & $\mathrm{~F}$ & $19.26 \pm 1.79$ & $19.65 \pm 1.73$ & $18.60 \pm 1.10$ & 0.9 & 73.27 \\
\hline 16 & $7 p$ & $8-\left(\mathrm{PO}\left(\mathrm{O}^{i} \mathrm{Pr}\right)_{2}\right)$ & $4-\mathrm{F}-\mathrm{C}_{6} \mathrm{H}_{4}$ & $\mathrm{Me}$ & $5.01 \pm 0.35$ & $24.32 \pm 2.53$ & $21.23 \pm 3.5$ & 0.9 & 41.62 \\
\hline 17 & $7 q$ & $8-\left(\mathrm{PO}\left(\mathrm{O}^{i} \mathrm{Pr}\right)_{2}\right)$ & $\begin{array}{l}3,4-\mathrm{F}_{2^{-}} \\
\mathrm{C}_{6} \mathrm{H}_{3}\end{array}$ & $\mathrm{Me}$ & $7.46 \pm 0.76$ & $13.91 \pm 3.65$ & $28.33 \pm 9.16$ & 2 & 52.65 \\
\hline 18 & $7 \mathrm{r}$ & 6-(PO(OEt $\left.)_{2}\right)$ & $4-\mathrm{F}-\mathrm{C}_{6} \mathrm{H}_{4}$ & $\mathrm{H}$ & $15.22 \pm 1.14$ & $29.23 \pm 14$ & $28.07 \pm 1.23$ & 1 & 1.94 \\
\hline 19 & $7 \mathrm{~s}$ & $6-\left(\mathrm{PO}(\mathrm{OEt})_{2}\right)$ & $\begin{array}{l}3,4-\mathrm{F}_{2-}^{-} \\
\mathrm{C}_{6} \mathrm{H}_{3}\end{array}$ & $\mathrm{H}$ & $14.72 \pm 1.78$ & $14.20 \pm 2.83$ & $26.23 \pm 0.51$ & 1.8 & 14.56 \\
\hline 20 & $7 t$ & $6-\left(\mathrm{PO}(\mathrm{OEt})_{2}\right)$ & $4-\mathrm{F}-\mathrm{C}_{6} \mathrm{H}_{4}$ & $\mathrm{~F}$ & $16.73 \pm 0.72$ & $31.46 \pm 2.71$ & $\begin{array}{c}44.97 \pm \\
10.24\end{array}$ & 1.4 & 37.86 \\
\hline 21 & $7 \mathbf{u}$ & 6- $\left(\mathrm{PO}(\mathrm{OEt})_{2}\right)$ & $\begin{array}{l}3,4-\mathrm{F}_{2-}^{-} \\
\mathrm{C}_{6} \mathrm{H}_{3}\end{array}$ & $\mathrm{~F}$ & $7.07 \pm 0.61$ & $26.36 \pm 2.2$ & $>100$ & $>3.8$ & 50.24 \\
\hline 22 & $7 v$ & $6-\left(\mathrm{PO}(\mathrm{OEt})_{2}\right)$ & $4-\mathrm{F}-\mathrm{C}_{6} \mathrm{H}_{4}$ & $\mathrm{Me}$ & $7.02 \pm 0.94$ & $17.56 \pm 7.81$ & $11.18 \pm 4.42$ & 0.6 & 43.25 \\
\hline 23 & $7 x$ & $6-\left(\mathrm{PO}(\mathrm{OEt})_{2}\right)$ & $\begin{array}{l}3,4-\mathrm{F}_{2-}^{-} \\
\mathrm{C}_{6} \mathrm{H}_{3}\end{array}$ & $\mathrm{Me}$ & $21.29 \pm 2.34$ & $32.95 \pm 6.55$ & $32.33 \pm 3.36$ & 1 & 43.84 \\
\hline
\end{tabular}

Antileishmanial effects $\left(\mathrm{EC}_{50} \pm \mathrm{SD}\right)$ on promastigotes and amastigotes of $L$. infantum. Cytotoxicity effects $\left(\mathrm{IC}_{50} \pm \mathrm{SD}\right)$ on murine splenocytes. SI: Selective Index. Inhibition of leishmanial TOP1B enzyme (LTOP1B inhibition \pm SD) at $100 \mu \mathrm{M}$ of every compound.

\subsection{Inhibition of Leishmanial TOP1 (LTOP1B)}

The inhibition of relaxation activity of LTOP1B by the compounds was tested at $100 \mu \mathrm{M}$. The reactions were performed for $1 \mathrm{~min}$ in the way described in the experimental protocols section. The percentage of inhibition was calculated by measuring the intensity of the band corresponding to the supercoiled DNA when the different DNA topoisomers were separated in an agarose gel. At the concentration tested, none of the compounds 
inhibited completely the LTOP1B enzyme, being $\mathbf{7 k}$ and $\mathbf{7 o}$ derivatives the best inhibitors, with percentages of inhibition of 77.02 and 73.27, respectively (Table 3, entries 11 and 15).

\section{Materials and Methods}

\subsection{Chemistry}

\subsubsection{General Methods}

All reagents from commercial suppliers were used without further purification. All solvents were freshly distilled before use from appropriate drying agents. All other reagents were recrystallized or distilled when necessary. Reactions were performed under a dry nitrogen atmosphere. Analytical TLCs were performed with silica gel $60 \mathrm{~F}_{254}$ plates. Visualization was accomplished by UV light. Column chromatography was carried out using silica gel 60 (230-400 mesh ASTM). Melting points were determined with an Electrothermal IA9100 Digital Melting Point Apparatus without correction. NMR spectra were obtained on a Bruker Avance $400 \mathrm{MHz}$ and a Varian VXR $300 \mathrm{MHz}$ spectrometer and recorded at $25^{\circ} \mathrm{C}$. Chemical shifts for ${ }^{1} \mathrm{H}$ NMR spectra are reported in ppm downfield from TMS, chemical shifts for ${ }^{13} \mathrm{C}$ NMR spectra are recorded in ppm relative to internal deuterated chloroform $\left(\delta=77.2 \mathrm{ppm}\right.$ for $\left.{ }^{13} \mathrm{C}\right)$, chemical shifts for ${ }^{19} \mathrm{~F}$ NMR are reported in ppm downfield from fluorotrichloromethane $\left(\mathrm{CFCl}_{3}\right)$. Coupling constants $(J)$ are reported in Hertz. The terms $\mathrm{m}$, $\mathrm{s}, \mathrm{d}, \mathrm{t}, \mathrm{q}$ refer to multiplet, singlet, doublet, triplet, quartet. ${ }^{13} \mathrm{C}$ NMR and ${ }^{19} \mathrm{~F}$ NMR were broadband decoupled from hydrogen nuclei. High-resolution mass spectra (HRMS) were measured by the EI method with an Agilent LC-Q-TOF-MS 6520 spectrometer.

\subsubsection{Compounds Purity Analysis}

All synthesized compounds were analyzed by HPLC to determine their purity. The analyses were performed on Agilent 1260 Infinity HPLC system (C-18 column, Hypersil, BDS, $5 \mu \mathrm{m}, 0.4 \mathrm{~mm} \times 25 \mathrm{~mm}$ ). All the tested compounds were dissolved in dichloromethane, and $1 \mu \mathrm{L}$ of the sample was loaded onto the column. Ethanol and heptane were used as mobile phase, and the flow rate was set at $1.0 \mathrm{~mL} / \mathrm{min}$. The maximal absorbance at the range of 190-625 nm was used as the detection wavelength. The purity of all the tested compounds is $>95 \%$, which meets the purity requirement by the Journal.

\subsubsection{Synthesis of Aminophenyl Phosphonates 1}

General procedure. To a suspension of 1 equiv. ( $75 \mathrm{mmol}, 12.608 \mathrm{~g}$ ) of 1,2-dinitrobenzene in $40 \mathrm{~mL}$ of dry $\mathrm{MeCN}$, was added to the appropriate phosphite derivative (1.2 equiv) and stirred at MeCN reflux for $12 \mathrm{~h}$. The crude obtained was purified by silica column chromatography ( $10 \%$ of ethyl acetate in hexane) and subsequently recrystallized in ethyl acetate at $4{ }^{\circ} \mathrm{C}$, to afford the corresponding nitro derivative as a yellow solid. Subsequently, this derivative was hydrogenated with a spoon of RANEY ${ }^{\circledR}$ Nickel (approx. $5 \mathrm{~g}$ ) in $60 \mathrm{~mL}$ of $\mathrm{MeOH}$ at $80 \mathrm{psi}$ at room temperature for $12 \mathrm{~h}$. The reaction mixture was then filtered off through a pad of cellite and evaporated to dryness to obtain the corresponding aminophenyl phosphonate derivative 1 .

Diethyl (2-aminophenyl)phosphonate (1a). General procedure was used with triethyl phosphite $(90 \mathrm{mmol}, 14.96 \mathrm{~g}, 15.44 \mathrm{~mL}$ ). The crude obtained was purified by column chromatography to afford $15.28 \mathrm{~g}(59 \mathrm{mmol})$ of diethyl (2-nitrophenyl)phosphonate as a yellow solid (79\%) mp 58-60 ${ }^{\circ} \mathrm{C}$ (ethyl acetate/hexane). ${ }^{1} \mathrm{H}$ NMR $\left(300 \mathrm{MHz}, \mathrm{CDCl}_{3}\right) \delta$ : 1.28-1.32 (m, $\left.6 \mathrm{H}, 2 \mathrm{CH}_{3}\right), 4.11-4.23\left(\mathrm{~m}, 4 \mathrm{H}, 2 \mathrm{CH}_{2}\right), 7.63-7.66(\mathrm{~m}, 2 \mathrm{H}), 7.79-7.83(\mathrm{~m}, 1 \mathrm{H})$, 8.00-8.06 (m, $1 \mathrm{H}) \mathrm{ppm} ;{ }^{13} \mathrm{C}\left\{{ }^{1} \mathrm{H}\right\} \mathrm{NMR}\left(75 \mathrm{MHz}, \mathrm{CDCl}_{3}\right) \delta: 16.2\left(\mathrm{~d},{ }^{3} J_{\mathrm{CP}}=6.5 \mathrm{~Hz}, 2 \mathrm{CH}_{3}\right)$, $63.3\left(\mathrm{~d},{ }^{2} J_{\mathrm{CP}}=6.1 \mathrm{~Hz}, 2 \mathrm{CH}_{2}\right), 123.3\left(\mathrm{~d},{ }^{1} J_{\mathrm{CP}}=190.3 \mathrm{~Hz}, \mathrm{C}\right), 124.1\left(\mathrm{~d},{ }^{3} J_{\mathrm{CP}}=8.6 \mathrm{~Hz}, \mathrm{HC}\right)$, $132.2\left(\mathrm{~d},{ }^{3} J_{\mathrm{CP}}=13.0 \mathrm{~Hz}, \mathrm{HC}\right), 133.2\left(\mathrm{~d},{ }^{4} J_{\mathrm{CP}}=2.5 \mathrm{~Hz}, \mathrm{HC}\right), 135.0\left(\mathrm{~d},{ }^{2} J_{\mathrm{CP}}=5.9 \mathrm{~Hz}, \mathrm{HC}\right)$, $152.0\left(\mathrm{~d},{ }^{4} J_{\mathrm{CP}}=2.5 \mathrm{~Hz}, \mathrm{C}\right) \mathrm{ppm} ;{ }^{31} \mathrm{P}\left\{{ }^{1} \mathrm{H}\right\} \mathrm{NMR}\left(120 \mathrm{MHz}, \mathrm{CDCl}_{3}\right) \delta: 12.7 \mathrm{ppm}$.

The hydrogenation of this derivative produced $13.39 \mathrm{~g}(58 \mathrm{mmol})$ of diethyl (2aminophenyl)phosphonate 1a (99\%) as a brown oil, $\mathrm{Rf}=0.42$ (50:50 EtOAc/hexane). ${ }^{1} \mathrm{H}$ NMR (300 MHz, $\left.\mathrm{CDCl}_{3}\right) \delta: 1.23-1.38\left(\mathrm{~m}, 6 \mathrm{H}, 2 \mathrm{CH}_{3}\right), 4.00-4.17\left(\mathrm{~m}, 4 \mathrm{H}, 2 \mathrm{CH}_{2}\right), 5.14$ (sa, $\left.\mathrm{NH}_{2}\right), 6.62-6.72(\mathrm{~m}, 2 \mathrm{H}), 7.23-7.29(\mathrm{~m}, 1 \mathrm{H}), 7.40-7.48(\mathrm{~m}, 1 \mathrm{H}) \mathrm{ppm} ;{ }^{13} \mathrm{C}\left\{{ }^{1} \mathrm{H}\right\} \mathrm{NMR}$ 
$\left(75 \mathrm{MHz} \mathrm{CDCl}_{3}\right) \delta: 16.5\left(\mathrm{~d},{ }^{3} J_{\mathrm{CP}}=6.6 \mathrm{~Hz}, 2 \mathrm{CH}_{3}\right), 62.2\left(\mathrm{~d},{ }^{2} J_{\mathrm{CP}}=4.9 \mathrm{~Hz}, 2 \mathrm{CH}_{2}\right), 108.3(\mathrm{~d}$, $\left.{ }^{1} J_{\mathrm{CP}}=183.5 \mathrm{~Hz}, \mathrm{C}\right), 116.4\left(\mathrm{~d},{ }^{3} J_{\mathrm{CP}}=12.7 \mathrm{~Hz}, \mathrm{HC}\right), 117.1\left(\mathrm{~d},{ }^{3} J_{\mathrm{CP}}=13.9 \mathrm{~Hz}, \mathrm{HC}\right), 133.4(\mathrm{~d}$, $\left.{ }^{2} J_{\mathrm{CP}}=7.3 \mathrm{~Hz}, \mathrm{HC}\right), 134.0\left(\mathrm{~d},{ }^{4} J_{\mathrm{CP}}=2.1 \mathrm{~Hz}, \mathrm{HC}\right), 151.4\left(\mathrm{~d},{ }^{2} J_{\mathrm{CP}}=8.4 \mathrm{~Hz}, \mathrm{C}\right) \mathrm{ppm} ;{ }^{31} \mathrm{P}\left\{{ }^{1} \mathrm{H}\right\}$ NMR $\left(120 \mathrm{MHz}, \mathrm{CDCl}_{3}\right) \delta: 22.3 \mathrm{ppm}$.

Diisopropyl (2-aminophenyl)phosphonate $(\mathbf{1 b})$. General procedure was used with triisopropyl phosphite $(90 \mathrm{mmol}, 18.74 \mathrm{~g}, 22.21 \mathrm{~mL}$ ). The crude obtained was purified by column chromatography to afford $17.88 \mathrm{~g}(62.25 \mathrm{mmol})$ of diisopropyl (2-nitrophenyl)phosphonate as a brown oil (83\%), $\mathrm{Rf}=0.39$ (50:50 EtOAc/hexane). $\left.{ }^{1} \mathrm{H} \mathrm{NMR} \mathrm{(300} \mathrm{MHz}, \mathrm{CDCl}_{3}\right) \delta: 1.28$ $\left(\mathrm{d},{ }^{3} \mathrm{~J}_{\mathrm{HH}}=6.2 \mathrm{~Hz}, 2 \mathrm{CH}_{3}\right), 1.39\left(\mathrm{~d},{ }^{3} \mathrm{~J}_{\mathrm{HH}}=6.2 \mathrm{~Hz}, 2 \mathrm{CH}_{3}\right), 4.77-4.85(\mathrm{~m}, 2 \mathrm{H}, 2 \mathrm{CH}), 7.65-7.67$ $(\mathrm{m}, 2 \mathrm{H}), 7.79-7.83(\mathrm{~m}, 1 \mathrm{H}), 8.10-8.16(\mathrm{~m}, 1 \mathrm{H}) \mathrm{ppm} ;{ }^{13} \mathrm{C}\left\{{ }^{1} \mathrm{H}\right\}$ NMR $\left(75 \mathrm{MHz}, \mathrm{CDCl}_{3}\right) \delta$ : $23.8\left(\mathrm{~d},{ }^{3} J_{\mathrm{CP}}=4.9 \mathrm{~Hz}, 2 \mathrm{CH}_{3}\right), 24.1\left(\mathrm{~d},{ }^{3} J_{\mathrm{CP}}=4.4 \mathrm{~Hz}, 2 \mathrm{CH}_{3}\right), 72.4\left(\mathrm{~d},{ }^{2} J_{\mathrm{CP}}=6.2 \mathrm{~Hz}, 2 \mathrm{CH}\right)$, $124.2\left(\mathrm{~d},{ }^{3} J_{\mathrm{CP}}=8.6 \mathrm{~Hz}, \mathrm{HC}\right), 124.6\left(\mathrm{~d},{ }^{1} J_{\mathrm{CP}}=189.9 \mathrm{~Hz}, \mathrm{C}\right), 132.1\left(\mathrm{~d},{ }^{3} J_{\mathrm{CP}}=13.1 \mathrm{~Hz}, \mathrm{HC}\right)$, $133.1\left(\mathrm{~d},{ }^{4} J_{\mathrm{CP}}=2.1 \mathrm{~Hz}, \mathrm{HC}\right), 135.3\left(\mathrm{~d},{ }^{2} J_{\mathrm{CP}}=6.2 \mathrm{~Hz}, \mathrm{HC}\right), 152.3(\mathrm{C}) \mathrm{ppm} ;{ }^{31} \mathrm{P}\left\{{ }^{1} \mathrm{H}\right\} \mathrm{NMR}$ $\left(120 \mathrm{MHz} \mathrm{CDCl}_{3}\right) \delta: 10.2 \mathrm{ppm}$.

The hydrogenation of this derivative produced $15.84 \mathrm{~g}$ (61.62 $\mathrm{mmol})$ of diisopropyl (2aminophenyl)phosphonate $1 \mathrm{c}$ as a white solid (98\%) $\mathrm{mp} 122-124{ }^{\circ} \mathrm{C}$ (ethyl acetate/hexane). ${ }^{1} \mathrm{H} \mathrm{NMR}\left(300 \mathrm{MHz} \mathrm{CDCl}_{3}\right) \delta: 1.20\left(\mathrm{~d},{ }^{3} J_{\mathrm{HH}}=6.2 \mathrm{~Hz}, 2 \mathrm{CH}_{3}\right), 1.34\left(\mathrm{~d},{ }^{3} J_{\mathrm{HH}}=6.2 \mathrm{~Hz}, 2\right.$ $\left.\mathrm{CH}_{3}\right), 4.56-4.68(\mathrm{~m}, 2 \mathrm{H}, 2 \mathrm{CH}), 5.16\left(\mathrm{sa}, 2 \mathrm{H}, \mathrm{NH}_{2}\right), 6.58-6.68(\mathrm{~m}, 2 \mathrm{H}), 7.18-7.26(\mathrm{~m}, 1 \mathrm{H})$, 7.39-7.47 (m, $1 \mathrm{H}) \mathrm{ppm} ;{ }^{13} \mathrm{C}\left\{{ }^{1} \mathrm{H}\right\} \mathrm{NMR}\left(75 \mathrm{MHz}^{\mathrm{CDCl}}\right)_{3} \delta: 23.9\left(\mathrm{~d},{ }^{3} \mathrm{~J}_{\mathrm{CP}}=5.0 \mathrm{~Hz}, 2 \mathrm{CH}_{3}\right)$, $24.3\left(\mathrm{~d},{ }^{3} J_{\mathrm{CP}}=3.8 \mathrm{~Hz}, 2 \mathrm{CH}_{3}\right), 70.8\left(\mathrm{~d},{ }^{2} J_{\mathrm{CP}}=5.1 \mathrm{~Hz}, 2 \mathrm{CH}\right), 109.8\left(\mathrm{~d},{ }^{1} J_{\mathrm{CP}}=184.3 \mathrm{~Hz}, \mathrm{C}\right)$, $116.3\left(\mathrm{~d},{ }^{3} J_{\mathrm{CP}}=10.6 \mathrm{~Hz}, \mathrm{HC}\right), 116.9\left(\mathrm{~d},{ }^{3} J_{\mathrm{CP}}=14.0 \mathrm{~Hz}, \mathrm{HC}\right), 133.6\left(\mathrm{~d},{ }^{2} J_{\mathrm{CP}}=7.2 \mathrm{~Hz}, \mathrm{HC}\right)$, $133.7\left(\mathrm{~d},{ }^{2} J_{\mathrm{CP}}=2.2 \mathrm{~Hz}, \mathrm{HC}\right), 151.1\left(\mathrm{~d},{ }^{4} J_{\mathrm{CP}}=8.6 \mathrm{~Hz}, \mathrm{C}\right) \mathrm{ppm} ;{ }^{31} \mathrm{P}\left\{{ }^{1} \mathrm{H}\right\} \mathrm{NMR}(120 \mathrm{MHz}$, $\left.\mathrm{CDCl}_{3}\right) \delta: 20.1 \mathrm{ppm}$.

Diethyl (4-aminophenyl)phosphonate (1c). To a suspension of 1 equiv. ( $25 \mathrm{mmol}, 5.050 \mathrm{~g}$ ) of 1-bromo-4-nitrobenzene with $6 \%$ mol of triphenylphosphine, $2 \%$ mol of palladium(II) acetate and 1.5 equiv. of freshly distilled triethylamine $(37.50 \mathrm{mmol}, 3.80 \mathrm{~g}, 5.23 \mathrm{~mL})$ in $50 \mathrm{~mL}$ of deoxygenated dry EtOH, 1.2 equiv. ( $30 \mathrm{mmol}, 4.143 \mathrm{~g}, 4.711 \mathrm{~mL}$ ) of diethyl phosphite were added and stirred at EtOH reflux for $12 \mathrm{~h}$. The crude obtained was purified by silica column chromatography (30\% of ethyl acetate in hexane) and subsequently recrystalized in ethyl acetate at $4{ }^{\circ} \mathrm{C}$, to afford $5.249 \mathrm{~g}(20.25 \mathrm{mmol})$ of diethyl (4-nitrophenyl)phosphonate as a brown oil (81\%), Rf $=0.39$ (50:50 EtOAc/hexane). ${ }^{1} \mathrm{H}$ NMR $\left(300 \mathrm{MHz}, \mathrm{CDCl}_{3}\right) \delta: 1.16-1.20(\mathrm{~m}$, $\left.6 \mathrm{H}, 2 \mathrm{CH}_{3}\right), 3.92-4.09\left(\mathrm{~m}, 4 \mathrm{H}, 2 \mathrm{CH}_{2}\right), 7.82-7.87(\mathrm{~m}, 2 \mathrm{H}), 8.12-8.15(\mathrm{~m}, 2 \mathrm{H}) \mathrm{ppm} ;{ }^{13} \mathrm{C}\left\{{ }^{1} \mathrm{H}\right\}$ $\operatorname{NMR}\left(75 \mathrm{MHz}_{\mathrm{CDCl}}\right) \delta: 16.2\left(\mathrm{~d},{ }^{3} J_{\mathrm{CP}}=6.3 \mathrm{~Hz}, 2 \mathrm{CH}_{3}\right), 62.7\left(\mathrm{~d},{ }^{2} J_{\mathrm{CP}}=5.7 \mathrm{~Hz}, 2 \mathrm{CH}_{2}\right), 123.2$ $\left(\mathrm{d},{ }^{3} J_{\mathrm{CP}}=15.3 \mathrm{~Hz}, 2 \mathrm{HC}\right), 132.9\left(\mathrm{~d},{ }^{2} J_{\mathrm{CP}}=10.5 \mathrm{~Hz}, 2 \mathrm{HC}\right), 135.7\left(\mathrm{~d},{ }^{1} J_{\mathrm{CP}}=187.2 \mathrm{~Hz}, \mathrm{C}\right), 150.1$ $\left(\mathrm{d},{ }^{4} J_{\mathrm{CP}}=3.8 \mathrm{~Hz}, \mathrm{C}\right) \mathrm{ppm} ;{ }^{31} \mathrm{P}\left\{{ }^{1} \mathrm{H}\right\} \mathrm{NMR}\left(120 \mathrm{MHz}, \mathrm{CDCl}_{3}\right) \delta: 16.0 \mathrm{ppm}$.

Subsequently, this derivative was hydrogenated with RANEY ${ }^{\circledR}$ Nickel (approx. $5 \mathrm{~g}$ ) in $60 \mathrm{~mL}$ of $\mathrm{MeOH}$ at $80 \mathrm{psi}$ at room temperature during $12 \mathrm{~h}$. The reaction mixture was then filtered off through a pad of cellite and evaporate to dryness to obtain $4.55 \mathrm{~g}$ (19.85 mmol) of diethyl (4-aminophenyl)phosphonate $\mathbf{1 b}$ as a white solid (98\%) $\mathrm{mp} 125-127^{\circ} \mathrm{C}$ (ethyl acetate/hexane). ${ }^{1} \mathrm{H} \mathrm{NMR}\left(300 \mathrm{MHz} \mathrm{CDCl}_{3}\right) \delta$ : 1.22-1.26 (m, $\left.2 \mathrm{CH}_{3}\right), 3.93-4.06$ (m, 2 $\left.\mathrm{CH}_{2}\right), 4.27$ (sa, $\left.2 \mathrm{H}, \mathrm{NH}_{2}\right), 6.61-6.64(\mathrm{~m}, 2 \mathrm{H}), 7.47-7.52(\mathrm{~m}, 2 \mathrm{H}) \mathrm{ppm} ;{ }^{13} \mathrm{C}\left\{{ }^{1} \mathrm{H}\right\} \mathrm{NMR}(75 \mathrm{MHz}$, $\left.\mathrm{CDCl}_{3}\right) \delta: 16.3\left(\mathrm{~d},{ }^{3} J_{\mathrm{CP}}=6.6 \mathrm{~Hz}, 2 \mathrm{CH}_{3}\right), 61.7\left(\mathrm{~d},{ }^{2} J_{\mathrm{CP}}=5.2 \mathrm{~Hz}, 2 \mathrm{CH}\right), 114.0\left(\mathrm{~d},{ }^{3} J_{\mathrm{CP}}=17.2 \mathrm{~Hz}\right.$, $2 \mathrm{HC}), 115.0\left(\mathrm{~d},{ }^{1} J_{\mathrm{CP}}=188.4 \mathrm{~Hz}, \mathrm{C}\right), 133.5\left(\mathrm{~d},{ }^{3} J_{\mathrm{CP}}=11.3 \mathrm{~Hz}, 2 \mathrm{HC}\right), 150.8(\mathrm{C}) \mathrm{ppm} ;{ }^{31} \mathrm{P}\left\{{ }^{1} \mathrm{H}\right\}$ NMR (120 MHz, $\left.\mathrm{CDCl}_{3}\right) \delta: 22.3 \mathrm{ppm}$.

\subsubsection{Synthesis of Quinolinyl Phosphonates}

General procedure. To a solution of the freshly distilled aldehyde $(1 \mathrm{mmol})$ and aminophenyl phosphonate $(1 \mathrm{mmol})$ in $\mathrm{CHCl}_{3}(20 \mathrm{~mL})$, the styrene derivative $(1.5 \mathrm{mmol})$ was added in presence of molecular sieves $(4 \AA)$ and one drop of $\mathrm{BF}_{3} \cdot \mathrm{Et}_{2} \mathrm{O}(1.5 \mathrm{mmol}, 0.19 \mathrm{~mL})$. The reaction was refluxed for $16 \mathrm{~h}$. The reaction mixture was washed with a $2 \mathrm{M}$ aqueous solution of $\mathrm{NaOH}(50 \mathrm{~mL})$ and water $(50 \mathrm{~mL})$, extracted with dichloromethane $(2 \times 25 \mathrm{~mL})$, and dried over anhydrous $\mathrm{MgSO}_{4}$. The solvent was removed under vacuum affording an oil that was purified by silica gel flash column chromatography using an elution of $20-80 \%$ ethyl acetate-hexane to afford products 7. 
Diethyl (2,4-diphenylquinolin-8-yl)phosphonate (7a). The general procedure was followed using aminophenylphosphonate $1 \mathrm{a}(1 \mathrm{mmol}, 0.23 \mathrm{~g})$, benzaldehyde (1 mmol, $0.10 \mathrm{~mL})$, styrene $(1.5 \mathrm{mmol}, 0.17 \mathrm{~mL})$ and $\mathrm{BF}_{3} . \mathrm{Et}_{2} \mathrm{O}$ affording $0.31 \mathrm{~g}(74 \%)$ of a white solid identified as $7 \mathbf{a}, \mathrm{mp} 118-120{ }^{\circ} \mathrm{C}$ (ethyl acetate/hexane). ${ }^{1} \mathrm{H}$ NMR $\left(300 \mathrm{MHz}, \mathrm{CDCl}_{3}\right) \delta: 1.32-1.36$ $\left(\mathrm{m}, 6 \mathrm{H}, 2 \mathrm{CH}_{3}\right), 4.26-4.44\left(\mathrm{~m}, 4 \mathrm{H}, 2 \mathrm{CH}_{2}\right), 7.45-7.57(\mathrm{~m}, 9 \mathrm{H}), 7.92(\mathrm{~s}, 1 \mathrm{H}), 8.06-8.08(\mathrm{~d}$, $\left.{ }^{3} J_{\mathrm{HH}}=8.4 \mathrm{~Hz}, 1 \mathrm{H}\right) 8.37-8.43(\mathrm{~m}, 3 \mathrm{H}) \mathrm{ppm} ;{ }^{13} \mathrm{C}\left\{{ }^{1} \mathrm{H}\right\} \mathrm{NMR}\left(75 \mathrm{MHz}, \mathrm{CDCl}_{3}\right) \delta: 16.7(\mathrm{~d}$, $\left.{ }^{3} J_{\mathrm{CP}}=6.6 \mathrm{~Hz}, 2 \mathrm{CH}_{3}\right), 62.5\left(\mathrm{~d},{ }^{2} J_{\mathrm{CP}}=5.7 \mathrm{~Hz}, 2 \mathrm{CH}_{2}\right), 119.3(\mathrm{HC}), 125.5\left(\mathrm{~d},{ }^{3} J_{\mathrm{CP}}=16.2 \mathrm{~Hz}\right.$, $\mathrm{HC}), 126.0\left(\mathrm{~d},{ }^{3} J_{\mathrm{CP}}=10.7 \mathrm{~Hz}, \mathrm{C}\right), 128.0(2 \mathrm{HC}), 128.6\left(\mathrm{~d},{ }^{1} J_{\mathrm{CP}}=193.7 \mathrm{~Hz}, \mathrm{C}\right), 128.7(\mathrm{HC})$, 128.8 (2 HC), 128.9 (2 HC), 129.7 (2 HC), 129.9 (HC), 130.7 (HC), 136.9 (d, ${ }^{2} J_{\mathrm{CP}}=7.4 \mathrm{~Hz}$, $\mathrm{HC}), 138.2(\mathrm{C}), 139.0(\mathrm{C}), 148.8\left(\mathrm{~d},{ }^{2} J_{\mathrm{CP}}=6.7 \mathrm{~Hz}, \mathrm{C}\right), 149.6(\mathrm{C}), 156.6(\mathrm{C}) \mathrm{ppm} ;{ }^{31} \mathrm{P}\left\{{ }^{1} \mathrm{H}\right\} \mathrm{NMR}$ $\left(120 \mathrm{MHz}, \mathrm{CDCl}_{3}\right.$ ) $\delta$ : 18.5 ppm; HRMS (EI): calculated for $\mathrm{C}_{25} \mathrm{H}_{24} \mathrm{NO}_{3} \mathrm{P}[\mathrm{M}]^{+} 417.1494$; found 417.1494. Purity 99.30\% (EtOH/Heptane $=10 / 90, \mathrm{Rt}=5.627 \mathrm{~min})$.

Diethyl (4-Phenyl-2-(fluorophenyl)quinolin-8-il) phosphonate (7b). The general procedure was followed using aminophenylphosphonate $1 \mathrm{a}(1 \mathrm{mmol}, 0.23 \mathrm{~g})$, 4-fluorobenzaldehyde $(1 \mathrm{mmol}, 0.11 \mathrm{~mL})$, styrene $(1.5 \mathrm{mmol}, 0.17 \mathrm{~mL})$ and $\mathrm{BF}_{3} \cdot \mathrm{Et}_{2} \mathrm{O}$ affording $0.313(72 \%)$ of a yellow solid identified as $7 \mathbf{b}, \mathrm{mp} 116-118{ }^{\circ} \mathrm{C}$ (ethyl acetate/hexane). ${ }^{1} \mathrm{H}-\mathrm{RMN}(300 \mathrm{MHz}$, $\left.\mathrm{CDCl}_{3}\right): \delta=1.24-1.29\left(\mathrm{~m}, 6 \mathrm{H}, 2 \mathrm{CH}_{3}\right), 4.17-4.37\left(\mathrm{~m}, 2 \mathrm{H}, \mathrm{CH}_{2}\right), 7.10-7.16(\mathrm{~m}, 2 \mathrm{H}), 7.39-7.50$ $(\mathrm{m}, 6 \mathrm{H}), 7.79(\mathrm{~s}, 1 \mathrm{H}), 7.97-8.00(\mathrm{~m}, 1 \mathrm{H}), 8.26-8.33(\mathrm{~m}, 3 \mathrm{H}) \mathrm{ppm} .{ }^{13} \mathrm{C}\left\{{ }^{1} \mathrm{H}\right\} \mathrm{NMR}(75 \mathrm{MHz}$, $\left.\mathrm{CDCl}_{3}\right): \delta=16.4\left(2 \mathrm{CH}_{3}\right), 62.2\left(2 \mathrm{OCH}_{2}\right), 115.5\left(\mathrm{~d},{ }^{2} J_{\mathrm{CF}}=21.6 \mathrm{~Hz}, 2 \mathrm{HC}\right), 118.7(\mathrm{HC}), 125.3$ $\left(\mathrm{d},{ }^{3} J_{\mathrm{CP}}=16.2 \mathrm{~Hz}, \mathrm{HC}\right), 125.7\left(\mathrm{~d},{ }^{3} J_{\mathrm{CP}}=10.8 \mathrm{~Hz}, \mathrm{C}\right), 128,2\left(\mathrm{~d},{ }^{1} J_{\mathrm{CP}}=188.5 \mathrm{~Hz}, \mathrm{C}\right), 128.6$ (HC), $128.7(2 \mathrm{HC}), 129.4(2 \mathrm{HC}), 129.7\left(\mathrm{~d},{ }^{3} J_{\mathrm{CF}}=8.5 \mathrm{~Hz}, 2 \mathrm{HC}\right), 130.6(\mathrm{HC}), 135.0(\mathrm{C}), 136.7$ $\left(\mathrm{d},{ }^{2} J_{\mathrm{CP}}=7.4 \mathrm{~Hz}, \mathrm{HC}\right), 138.0(\mathrm{C}), 148.6\left(\mathrm{~d},{ }^{2} J_{\mathrm{CP}}=6.8 \mathrm{~Hz}, \mathrm{C}\right), 149.6(\mathrm{C}), 155.3(\mathrm{C}), 163.9(\mathrm{~d}$, $\left.{ }^{1} J_{\mathrm{CF}}=249.8 \mathrm{~Hz}, \mathrm{C}-\mathrm{F}\right) \mathrm{ppm} .{ }^{31} \mathrm{P}\left\{{ }^{1} \mathrm{H}\right\} \mathrm{NMR}\left(120 \mathrm{MHz}, \mathrm{CDCl}_{3}\right): \delta=18.5 \mathrm{ppm} .{ }^{19} \mathrm{~F}-\mathrm{RMN}$ $\left(282 \mathrm{MHz}, \mathrm{CDCl}_{3}\right): \delta=-112.0$ ppm. IR: $v=2982,1588,1225,1023,963,771 \mathrm{~cm}^{-1}$. HRMS (CI): calculated for $\mathrm{C}_{25} \mathrm{H}_{23} \mathrm{NO}_{3} \mathrm{PF}[\mathrm{M}]^{+}$435.1400; found 435.1401. Purity $98.60 \%$ $(\mathrm{EtOH} /$ Heptane $=10 / 90, \mathrm{Rt}=6.210 \mathrm{~min})$.

Diethyl (2-(4-methoxyphenyl)-4-phenylquinolin-8-yl)phosphonate (7c). The general procedure was followed using aminophenylphosphonate $1 \mathrm{a}(1 \mathrm{mmol}, 0.23 \mathrm{~g}), p$-anisaldehyde (1 mmol, $0.12 \mathrm{~mL})$, styrene $(1.5 \mathrm{mmol}, 0.17 \mathrm{~mL})$ and $\mathrm{BF}_{3} . \mathrm{Et}_{2} \mathrm{O}$ affording $0.18 \mathrm{~g}(41 \%)$ of a white solid identified as 7c, mp $120-122{ }^{\circ} \mathrm{C}$ (ethyl acetate/hexane). ${ }^{1} \mathrm{H}$ NMR (400 MHz, $\left.\mathrm{CDCl}_{3}\right) \delta$ : 1.23-1.27 (m, $\left.6 \mathrm{H}, 2 \mathrm{CH}_{3}\right), 3.86\left(\mathrm{~s}, 3 \mathrm{H}, \mathrm{OCH}_{3}\right), 4.16-4.35\left(\mathrm{~m}, 4 \mathrm{H}, 2 \mathrm{OCH}_{2}\right)$, 6.93-6.95 (m, 1 H), 7.31-7.48 (m, 7 H), 7.79-7.82 (m, $2 \mathrm{H}), 7.98-8.00(\mathrm{~m}, 2 \mathrm{H}), 8.28-8.34$ (m, $\mathrm{H}) \mathrm{ppm} ;{ }^{13} \mathrm{C}\left\{{ }^{1} \mathrm{H}\right\} \mathrm{NMR}\left(100 \mathrm{MHz}, \mathrm{CDCl}_{3}\right) \delta=16.5\left(\mathrm{~d},{ }^{3} \mathrm{~J}_{\mathrm{CP}}=6.7 \mathrm{~Hz}, 2 \mathrm{CH}_{3}\right), 55.4\left(\mathrm{OCH}_{3}\right)$, $62.3\left(\mathrm{~d},{ }^{2} J_{\mathrm{CP}}=5.7 \mathrm{~Hz}, 2 \mathrm{OCH}_{2}\right), 112.6(\mathrm{HC}), 116.3(\mathrm{HC}), 119.2(\mathrm{HC}), 120.0(\mathrm{HC}), 125.4(\mathrm{~d}$, $\left.{ }^{3} J_{\mathrm{CP}}=16.3 \mathrm{~Hz}, \mathrm{HC}\right), 125.9\left(\mathrm{~d},{ }^{2} J_{\mathrm{CP}}=10.7 \mathrm{~Hz}, \mathrm{C}\right), 128.5\left(\mathrm{~d},{ }^{1} J_{\mathrm{CP}}=188.5 \mathrm{~Hz}, \mathrm{C}\right), 128.6(\mathrm{HC})$, 128.7 (2 HC), 129.5 (2 HC), 129.6 (HC), $130.6(\mathrm{HC}), 136.9$ (d, $\left.{ }^{2} J_{\mathrm{CP}}=7.5 \mathrm{~Hz}, \mathrm{HC}\right), 138.0(\mathrm{C})$, $140.3(\mathrm{C}), 148.5\left(\mathrm{~d},{ }^{2} J_{\mathrm{CP}}=6.8 \mathrm{~Hz}, \mathrm{C}\right), 149.4(\mathrm{C}), 156.1(\mathrm{C}), 160.1(\mathrm{C}) \mathrm{ppm} ;{ }^{31} \mathrm{P}\left\{{ }^{1} \mathrm{H}\right\} \mathrm{NMR}$ $\left(120 \mathrm{MHz}, \mathrm{CDCl}_{3}\right) \delta=18,7 \mathrm{ppm}$. HRMS (EI): calculated for $\mathrm{C}_{26} \mathrm{H}_{26} \mathrm{NO}_{4} \mathrm{P}[\mathrm{M}]^{+} 447.1599$; found 447.1597. Purity 99.02\% $(\mathrm{EtOH} /$ Heptane $=10 / 90, \mathrm{Rt}=6.765 \mathrm{~min})$.

Diethyl (2-(2-methoxyphenyl)-4-phenylquinolin-8-yl)phosphonate (7d). The general procedure was followed using aminophenylphosphonate $1 a(1 \mathrm{mmol}, 0.23 \mathrm{~g})$, o-anisaldehyde $(1 \mathrm{mmol}, 0.12 \mathrm{~mL})$, styrene $(1.5 \mathrm{mmol}, 0.17 \mathrm{~mL})$ and $\mathrm{BF}_{3} . \mathrm{Et}_{2} \mathrm{O}$ affording $0.21 \mathrm{~g}(48 \%)$ of a white solid identified as $7 \mathbf{d}, \mathrm{mp} 121-123{ }^{\circ} \mathrm{C}$ (ethyl acetate/hexane). ${ }^{1} \mathrm{H}$ NMR (400 MHz, $\left.\mathrm{CDCl}_{3}\right) \delta: 1.25-1.28\left(\mathrm{~m}, 6 \mathrm{H}, 2 \mathrm{CH}_{3}\right), 3.81\left(\mathrm{~s}, 3 \mathrm{H}, \mathrm{OCH}_{3}\right), 4.17-4.35\left(\mathrm{~m}, 4 \mathrm{H}, 2 \mathrm{OCH}_{2}\right)$, 6.95-6.97 (m, $2 \mathrm{H}), 7.36-7.49(\mathrm{~m}, 6 \mathrm{H}), 7.77(\mathrm{~s}, 1 \mathrm{H}), 7.95-7.97\left(\mathrm{~d},{ }^{3} J_{\mathrm{HH}}=8.4 \mathrm{~Hz}, 1 \mathrm{H}\right)$, 8.26-8.31 (m, $3 \mathrm{H}) \mathrm{ppm} ;{ }^{13} \mathrm{C}\left\{{ }^{1} \mathrm{H}\right\} \mathrm{NMR}\left(100 \mathrm{MHz}, \mathrm{CDCl}_{3}\right) \delta=16.5\left(\mathrm{~d},{ }^{3} J_{\mathrm{CP}}=6.6 \mathrm{~Hz}, 2 \mathrm{CH}_{3}\right)$, $55.4\left(\mathrm{OCH}_{3}\right), 62.3\left(\mathrm{~d},{ }^{2} \mathrm{~J}_{\mathrm{CP}}=5.5 \mathrm{~Hz}, 2 \mathrm{OCH}_{2}\right), 114.1(3 \mathrm{HC}), 118.6(\mathrm{HC}), 124.9\left(\mathrm{~d},{ }^{3} \mathrm{~J}_{\mathrm{CP}}=16.2\right.$ $\mathrm{Hz}, \mathrm{HC}), 125.6\left(\mathrm{~d},{ }^{3} J_{\mathrm{CP}}=10.7 \mathrm{~Hz}, \mathrm{C}\right), 128.1\left(\mathrm{~d},{ }^{1} J_{\mathrm{CP}}=187.9 \mathrm{~Hz}, \mathrm{C}\right), 128.5(\mathrm{HC}), 128.6(3 \mathrm{HC})$, $129.3(\mathrm{HC}), 129.5(\mathrm{HC}), 130.6(\mathrm{HC}), 131.5(\mathrm{C}), 136.7$ (d, $\left.{ }^{2} J_{\mathrm{CP}}=7.5 \mathrm{~Hz}, \mathrm{HC}\right), 138.2(\mathrm{C}), 148.7$ $\left(\mathrm{d},{ }^{2} J_{\mathrm{CP}}=6.7 \mathrm{~Hz}, \mathrm{C}\right), 149.2(\mathrm{C}), 156.1(\mathrm{C}), 161.1(\mathrm{C}) \mathrm{ppm} ;{ }^{31} \mathrm{P}\left\{{ }^{1} \mathrm{H}\right\} \mathrm{NMR}\left(120 \mathrm{MHz}, \mathrm{CDCl}_{3}\right)$ $\delta=18,8 \mathrm{ppm}$. HRMS (EI): calculated for $\mathrm{C}_{26} \mathrm{H}_{26} \mathrm{NO}_{4} \mathrm{P}[\mathrm{M}]^{+} 447.1599$; found 447.1597. Purity 97.30\% (EtOH/Heptane $=10 / 90, \mathrm{Rt}=5.704 \mathrm{~min})$.

Diethyl (2-(naphthalen-2-yl)-4-phenylquinolin-8-yl)phosphonate (7e). The general procedure was followed using aminophenylphosphonate $1 \mathrm{a}(1 \mathrm{mmol}, 0.23 \mathrm{~g})$, 2-naphthaldehyde 
$(1 \mathrm{mmol}, 0.13 \mathrm{~mL})$, styrene $(1.5 \mathrm{mmol}, 0.17 \mathrm{~mL})$ and $\mathrm{BF}_{3}$. $\mathrm{Et}_{2} \mathrm{O}$ affording $0.30 \mathrm{~g}(64 \%)$ of a yellow solid identified as 7e, mp $135-137^{\circ} \mathrm{C}$ (ethyl acetate/hexane). ${ }^{1} \mathrm{H}$ NMR $(300 \mathrm{MHz}$, $\left.\mathrm{CDCl}_{3}\right) \delta:$ 1.34-1.39 (m, $\left.6 \mathrm{H}, 2 \mathrm{CH}_{3}\right), 4.30-4.48\left(\mathrm{~m}, 4 \mathrm{H}, 2 \mathrm{CH}_{2}\right), 7.53-7.58(\mathrm{~m}, 8 \mathrm{H}), 7.90-8.11$ $(\mathrm{m}, 5 \mathrm{H}), 8.38-8.46(\mathrm{~m}, 1 \mathrm{H}), 8.65-8.75(\mathrm{~m}, 2 \mathrm{H}) \mathrm{ppm} ;{ }^{13} \mathrm{C}\left\{{ }^{1} \mathrm{H}\right\} \mathrm{NMR}\left(75 \mathrm{MHz}, \mathrm{CDCl}_{3}\right) \delta$ : $16.7\left(\mathrm{~d},{ }^{3} J_{\mathrm{CP}}=6.5 \mathrm{~Hz}, 2 \mathrm{CH}_{3}\right), 62.6\left(\mathrm{~d},{ }^{2} J_{\mathrm{CP}}=5.3 \mathrm{~Hz}, 2 \mathrm{CH}_{2}\right), 119.5(\mathrm{HC}), 125.5(\mathrm{HC}), 125.6$ (HC), $125.7(\mathrm{HC}), 126.1\left(\mathrm{~d},{ }^{3} J_{\mathrm{CP}}=10.6 \mathrm{~Hz}, \mathrm{C}\right), 126.5(\mathrm{HC}), 127.1(\mathrm{HC}), 127.4(\mathrm{HC}), 127.6$ (HC), $128.6(\mathrm{HC}), 128.7\left(\mathrm{~d},{ }^{1} J_{\mathrm{CP}}=187.5 \mathrm{~Hz}, \mathrm{C}\right), 128.8(\mathrm{HC}), 128.9(2 \mathrm{HC}), 129.0(\mathrm{HC}), 129.7$ (2 HC), 130.7 (HC), 133.5 (C), 134.3 (C), 136.5 (C), $137.0\left(\mathrm{~d},{ }^{2} J_{\mathrm{CP}}=7.3 \mathrm{~Hz}, \mathrm{HC}\right), 138.2(\mathrm{C})$, $148.9\left(\mathrm{~d},{ }^{2} J_{\mathrm{CP}}=6.3 \mathrm{~Hz} \mathrm{C}\right), 149.7(\mathrm{C}), 156.5(\mathrm{C}) \mathrm{ppm} ;{ }^{31} \mathrm{P}\left\{{ }^{1} \mathrm{H}\right\} \mathrm{NMR}\left(120 \mathrm{MHz}, \mathrm{CDCl}_{3}\right) \delta: 18.6$ ppm; HRMS (EI): calculated for $\mathrm{C}_{29} \mathrm{H}_{26} \mathrm{NO}_{3} \mathrm{P}[\mathrm{M}]^{+} 467.1650$; found 467.1649. Purity $99.91 \%$ $(\mathrm{EtOH} / \mathrm{Heptane}=10 / 90, \mathrm{Rt}=6.136 \mathrm{~min})$.

Diethyl (2-(naphthalen-1-yl)-4-phenylquinolin-8-yl)phosphonate (7f). The general procedure was followed using aminophenylphosphonate $1 \mathrm{a}(1 \mathrm{mmol}, 0.23 \mathrm{~g})$, 1-naphthaldehyde $(1 \mathrm{mmol}, 0.13 \mathrm{~mL})$, styrene $(1.5 \mathrm{mmol}, 0.17 \mathrm{~mL})$ and $\mathrm{BF}_{3} . \mathrm{Et}_{2} \mathrm{O}$ affording $0.39 \mathrm{~g}(83 \%)$ of a yellow solid identified as 7f, mp 140-142 ${ }^{\circ} \mathrm{C}$ (ethyl acetate/hexane). ${ }^{1} \mathrm{H}$ NMR $(300 \mathrm{MHz}$, $\left.\mathrm{CDCl}_{3}\right) \delta: 1.16-1.20\left(\mathrm{~m}, 6 \mathrm{H}, 2 \mathrm{CH}_{3}\right), 4.19-4.30\left(\mathrm{~m}, 4 \mathrm{H}, 2 \mathrm{CH}_{2}\right), 7.51-7.62(\mathrm{~m}, 9 \mathrm{H}), 7.77(\mathrm{~s}$, $1 \mathrm{H}), 7.86-7.97(\mathrm{~m}, 3 \mathrm{H}), 8.15-8.17\left(\mathrm{~d},{ }^{3} \mathrm{~J}_{\mathrm{HH}}=8.4 \mathrm{~Hz}, 1 \mathrm{H}\right), 8.39-8.44(\mathrm{~m}, 1 \mathrm{H}), 8.58-8.60(\mathrm{~d}$, $\left.{ }^{3} J_{\mathrm{HH}}=8.3 \mathrm{~Hz}, 1 \mathrm{H}\right) \mathrm{ppm} ;{ }^{13} \mathrm{C}\left\{{ }^{1} \mathrm{H}\right\} \mathrm{NMR}\left(75 \mathrm{MHz}, \mathrm{CDCl}_{3}\right) \delta: 16.5\left(\mathrm{~d},{ }^{3} J_{\mathrm{CP}}=6.1 \mathrm{~Hz}, 2 \mathrm{CH}_{3}\right)$, $62.9\left(\mathrm{~d},{ }^{2} J_{\mathrm{CP}}=5.3 \mathrm{~Hz}, 2 \mathrm{CH}_{2}\right), 124.0(\mathrm{HC}), 125.4(\mathrm{HC}), 125.7(\mathrm{C}), 125.8(\mathrm{HC}), 125.9(\mathrm{HC}), 126.2$ (HC), $126.5(\mathrm{HC}), 126.9$ (HC), $128.4(\mathrm{HC}), 128.8(\mathrm{HC}), 128.9(2 \mathrm{HC}), 129.5\left(\mathrm{~d},{ }^{1} J_{\mathrm{CP}}=191.1 \mathrm{~Hz}\right.$, C), $129.6(\mathrm{HC}), 129.8(2 \mathrm{HC}), 130.6(\mathrm{HC}), 131.1(\mathrm{C}), 134.0(\mathrm{C}), 136.5 \mathrm{ppm}\left(\mathrm{d},{ }^{2} J_{\mathrm{CP}}=6.6 \mathrm{~Hz}, \mathrm{HC}\right)$, $137.9(\mathrm{C}), 138.1(\mathrm{C}), 148.7 \mathrm{ppm}\left(\mathrm{d},{ }^{2} J_{\mathrm{CP}}=5.8 \mathrm{~Hz}, \mathrm{C}\right), 149.2(\mathrm{C}), 159.0$ (C) ppm; ${ }^{31} \mathrm{P}\left\{{ }^{1} \mathrm{H}\right\} \mathrm{NMR}$ $\left(120 \mathrm{MHz}, \mathrm{CDCl}_{3}\right) \delta$ : $17.2 \mathrm{ppm}$; HRMS (EI): calculated for $\mathrm{C}_{29} \mathrm{H}_{26} \mathrm{NO}_{3} \mathrm{P}[\mathrm{M}]^{+} 467.1650$; found 467.1651. Purity 99.77\% (EtOH/Heptane $=10 / 90, \mathrm{Rt}=7.120 \mathrm{~min})$.

Diethyl (4-(4-fluorophenyl)-2-phenylquinolin-8-yl))phosphonate (7g). The general procedure was followed using aminophenylphosphonate $1 \mathrm{a}(1 \mathrm{mmol}, 0.23 \mathrm{~g})$, benzaldehyde $(1 \mathrm{mmol}, 0.10 \mathrm{~mL})$, 4-fluorostyrene $(1.5 \mathrm{mmol}, 0.18 \mathrm{~mL})$ and $\mathrm{BF}_{3} \cdot \mathrm{Et}_{2} \mathrm{O}$ affording $0.26 \mathrm{~g}$ $(60 \%)$ of a white solid identified as $7 \mathrm{~g}, \mathrm{mp} 172-174{ }^{\circ} \mathrm{C}$ (ethyl acetate/hexane). ${ }^{1} \mathrm{H}$ NMR $\left(300 \mathrm{MHz}, \mathrm{CDCl}_{3}\right) \delta: 1.32-1.37\left(\mathrm{~m}, 6 \mathrm{H}, 2 \mathrm{CH}_{3}\right), 4.27-4.44\left(\mathrm{~m}, 4 \mathrm{H}, 2 \mathrm{CH}_{2}\right), 7.26-7.29(\mathrm{~m}$, $2 \mathrm{H}), 7.48-7.56(\mathrm{~m}, 6 \mathrm{H}), 7.89(\mathrm{~s}, 1 \mathrm{H}), 8.01\left(\mathrm{~d},{ }^{3} J_{\mathrm{HP}}=8.4 \mathrm{~Hz}, 1 \mathrm{H}\right), 8.37-8.44(\mathrm{~m}, 3 \mathrm{H}) \mathrm{ppm}$; ${ }^{13} \mathrm{C}\left\{{ }^{1} \mathrm{H}\right\} \mathrm{NMR}\left(75 \mathrm{MHz}, \mathrm{CDCl}_{3}\right) \delta: 16.6\left(\mathrm{~d},{ }^{3} J_{\mathrm{CP}}=6.6 \mathrm{~Hz}, 2 \mathrm{CH}_{3}\right), 62.5\left(\mathrm{~d},{ }^{2} J_{\mathrm{CP}}=5.8 \mathrm{~Hz}, 2\right.$ $\left.\mathrm{CH}_{2}\right), 115.9\left(\mathrm{~d},{ }^{2} J_{\mathrm{CF}}=21.6 \mathrm{~Hz}, 2 \mathrm{HC}\right), 119.3(\mathrm{HC}), 125.6\left(\mathrm{~d},{ }^{3} J_{\mathrm{CP}}=16.2 \mathrm{~Hz}, \mathrm{HC}\right), 126.0(\mathrm{~d}$, $\left.{ }^{3} J_{\mathrm{CP}}=10.7 \mathrm{~Hz}, \mathrm{C}\right), 128.0(2 \mathrm{HC}), 128.5\left(\mathrm{~d},{ }^{1} J_{\mathrm{CP}}=188.5 \mathrm{~Hz}, \mathrm{C}\right), 128.9(2 \mathrm{HC}), 130.0(\mathrm{HC})$, $130.4(\mathrm{HC}), 131.3(\mathrm{HC}), 131.4(\mathrm{HC}), 134.1(\mathrm{C}), 136.9\left(\mathrm{~d},{ }^{2} J_{\mathrm{CP}}=7.4 \mathrm{~Hz}, \mathrm{HC}\right), 138.8(\mathrm{C}), 148.5$ $(\mathrm{C}), 148.7\left(\mathrm{~d},{ }^{2} J_{\mathrm{CP}}=6.8 \mathrm{~Hz}, \mathrm{C}\right), 156.6(\mathrm{C}), 163.1\left(\mathrm{~d},{ }^{1} J_{\mathrm{CF}}=248.6 \mathrm{~Hz}, \mathrm{C}-\mathrm{F}\right) \mathrm{ppm} ;{ }^{31} \mathrm{P}\left\{{ }^{1} \mathrm{H}\right\} \mathrm{NMR}$ $\left(120 \mathrm{MHz}, \mathrm{CDCl}_{3}\right) \delta: 18.4 \mathrm{ppm} ;{ }^{19} \mathrm{~F}$ NMR $\left(282 \mathrm{MHz}, \mathrm{CDCl}_{3}\right) \delta:-113.3 \mathrm{ppm}$. HRMS (EI): calculated for $\mathrm{C}_{25} \mathrm{H}_{23} \mathrm{FNO}_{3} \mathrm{P}[\mathrm{M}]^{+}$435.1400; found 435.1402. Purity $95.92 \%$ (EtOH/Heptane $=10 / 90, \mathrm{Rt}=6.038 \mathrm{~min})$.

Diethyl (2,4-bis(4-fluorophenyl)quinolin-8-yl)phosphonate (7h). The general procedure was followed using aminophenylphosphonate $1 \mathrm{a}(1 \mathrm{mmol}, 0.23 \mathrm{~g})$, 4-fluorobenzaldehyde $(1 \mathrm{mmol}, 0.11 \mathrm{~mL})$, 4-fluorostyrene $(1.5 \mathrm{mmol}, 0.18 \mathrm{~mL})$ and $\mathrm{BF}_{3} . \mathrm{Et}_{2} \mathrm{O}$ affording 0.29 (68\%) of a white solid identified as $7 \mathrm{~h}, \mathrm{mp} 121-123{ }^{\circ} \mathrm{C}$ (ethyl acetate/hexane). ${ }^{1} \mathrm{H}$ NMR $\left(300 \mathrm{MHz}, \mathrm{CDCl}_{3}\right) \delta: 1.32-1.36\left(\mathrm{~m}, 6 \mathrm{H}, 2 \mathrm{CH}_{3}\right), 4.25-4.42\left(\mathrm{~m}, 4 \mathrm{H}, 2 \mathrm{CH}_{2}\right), 7.18-7.28(\mathrm{~m}, 4$ $\mathrm{H}), 7.47-7.55(\mathrm{~m}, 3 \mathrm{H}), 7.83(\mathrm{~s}, 1 \mathrm{H}), 8.02\left(\mathrm{~d},{ }^{3} J_{\mathrm{HP}}=8.4 \mathrm{~Hz}, 1 \mathrm{H}\right), 8.33-8.41(\mathrm{~m}, 3 \mathrm{H}) \mathrm{ppm}$; ${ }^{13} \mathrm{C}\left\{{ }^{1} \mathrm{H}\right\}$ NMR $\left(75 \mathrm{MHz}, \mathrm{CDCl}_{3}\right) \delta: 16.6\left(\mathrm{~d},{ }^{3} J_{\mathrm{CP}}=6.4 \mathrm{~Hz}, 2 \mathrm{CH}_{3}\right), 62.5\left(\mathrm{~d},{ }^{2} \mathrm{~J}_{\mathrm{CP}}=5.5 \mathrm{~Hz}, 2\right.$ $\left.\mathrm{CH}_{2}\right), 115.8\left(\mathrm{~d},{ }^{2} J_{\mathrm{CF}}=21.6 \mathrm{~Hz}, 2 \mathrm{HC}\right), 116.1\left(\mathrm{~d},{ }^{2} J_{\mathrm{CF}}=21.6 \mathrm{~Hz}, \mathrm{HC}\right), 118.9(\mathrm{HC}), 125.7(\mathrm{~d}$, $\left.{ }^{3} J_{\mathrm{CP}}=15.8 \mathrm{~Hz}, \mathrm{HC}\right), 125.9(\mathrm{C}), 128.7\left(\mathrm{~d},{ }^{1} J_{\mathrm{CP}}=188.8 \mathrm{~Hz}, \mathrm{C}\right), 129.9\left(\mathrm{~d},{ }^{3} J_{\mathrm{CF}}=8.3 \mathrm{~Hz}, 2 \mathrm{HC}\right)$, $130.4(\mathrm{HC}), 131.4\left(\mathrm{~d},{ }^{3} J_{\mathrm{CF}}=8.2 \mathrm{~Hz}, 2 \mathrm{HC}\right), 134.0(\mathrm{C}), 135.0(\mathrm{C}), 137.0\left(\mathrm{~d},{ }^{2} J_{\mathrm{CP}}=7.4 \mathrm{~Hz}, \mathrm{HC}\right)$, 148.7 (C), $155.5(\mathrm{C}), 163.2\left(\mathrm{~d},{ }^{1} J_{\mathrm{CF}}=248.6 \mathrm{~Hz}, \mathrm{C}-\mathrm{F}\right), 164.2\left(\mathrm{~d},{ }^{1} J_{\mathrm{CF}}=249.8 \mathrm{~Hz}, \mathrm{C}-\mathrm{F}\right) \mathrm{ppm}$; ${ }^{31} \mathrm{P}\left\{{ }^{1} \mathrm{H}\right\} \mathrm{NMR}\left(120 \mathrm{MHz}, \mathrm{CDCl}_{3}\right) \delta: 18.3 \mathrm{ppm} ;{ }^{19} \mathrm{~F} \mathrm{NMR}\left(282 \mathrm{MHz}, \mathrm{CDCl}_{3}\right) \delta:-111.9$ and -113.1 (m) ppm.HRMS (EI): calculated for $\mathrm{C}_{25} \mathrm{H}_{22} \mathrm{~F}_{2} \mathrm{NO}_{3} \mathrm{P}[\mathrm{M}]^{+} 453.1305$; found 453.1307 . Purity $99.60 \%(\mathrm{EtOH} /$ Heptane $=10 / 90, \mathrm{Rt}=5.720 \mathrm{~min})$.

Diethyl (2-(3,4-difluorophenyl)-4-(4-fluorophenyl)quinolin-8-yl)phosphonate (7i). The general procedure was followed using aminophenylphosphonate $1 \mathrm{a}(1 \mathrm{mmol}, 0.23 \mathrm{~g}), 3,4-$ 
difluorobenzaldehyde (1 mmol, $0.11 \mathrm{~mL})$, 4-fluorostyrene $(1.5 \mathrm{mmol}, 0.18 \mathrm{~mL})$ and $\mathrm{BF}_{3} . \mathrm{Et}_{2} \mathrm{O}$ affording $0.20 \mathrm{~g}(43 \%)$ of a white solid identified as $7 \mathbf{i}, \mathrm{mp} 159-161^{\circ} \mathrm{C}$ (ethyl acetate/hexane). ${ }^{1} \mathrm{H}$ NMR (300 MHz, $\left.\mathrm{CDCl}_{3}\right) \delta: 1.33-1.38\left(\mathrm{~m}, 6 \mathrm{H}, 2 \mathrm{CH}_{3}\right), 4.21-4.44\left(\mathrm{~m}, 4 \mathrm{H}, 2 \mathrm{CH}_{2}\right), 7.23-$ $7.58(\mathrm{~m}, 6 \mathrm{H}), 7.81(\mathrm{~s}, 1 \mathrm{H}), 8.01-8.11(\mathrm{~m}, 2 \mathrm{H}), 8.25-8.44(\mathrm{~m}, 2 \mathrm{H}) \mathrm{ppm} ;{ }^{13} \mathrm{C}\left\{{ }^{1} \mathrm{H}\right\} \mathrm{NMR}$ $\left(75 \mathrm{MHz} \mathrm{CDCl}_{3}\right) \delta: 16.7\left(\mathrm{~d},{ }^{3} J_{\mathrm{CP}}=6.5 \mathrm{~Hz}, 2 \mathrm{CH}_{3}\right), 62.5\left(\mathrm{~d},{ }^{2} J_{\mathrm{CP}}=5.8 \mathrm{~Hz}, 2 \mathrm{CH}_{2}\right), 116.1(\mathrm{~d}$, $\left.{ }^{2} J_{\mathrm{CF}}=21.7 \mathrm{~Hz}, 2 \mathrm{HC}\right), 117.0\left(\mathrm{~d},{ }^{2} J_{\mathrm{CF}}=18.7 \mathrm{~Hz}, \mathrm{HC}\right), 117.7\left(\mathrm{~d},{ }^{2} J_{\mathrm{CF}}=17.4 \mathrm{~Hz}, \mathrm{HC}\right), 118.7$ (HC), $120.5(\mathrm{C}), 124.0(\mathrm{HC}), 126.0\left(\mathrm{~d},{ }^{3} J_{\mathrm{CP}}=16.0 \mathrm{~Hz}, \mathrm{HC}\right), 128.7\left(\mathrm{~d},{ }^{1} J_{\mathrm{CP}}=188.8 \mathrm{~Hz}, \mathrm{C}\right)$, 130.5 (HC), 131.3 (HC), $131.4(\mathrm{HC}), 133.9(\mathrm{C}), 136.0(\mathrm{C}), 137.4(\mathrm{HC}), 148.6$ (d, ${ }^{2} J_{\mathrm{CP}}=6.4$ $\mathrm{Hz}, \mathrm{C}), 149.1(\mathrm{C}), 151.0\left(\mathrm{dd},{ }^{2} J_{\mathrm{CF}}=12.5 \mathrm{~Hz},{ }^{1} J_{\mathrm{CF}}=239.2 \mathrm{~Hz}, \mathrm{C}\right), 151.8\left(\mathrm{dd},{ }^{2} J_{\mathrm{CF}}=12.5 \mathrm{~Hz}\right.$, $\left.{ }^{1} J_{\mathrm{CF}}=247.6 \mathrm{~Hz}, \mathrm{C}\right), 154.2(\mathrm{C}), 163.2\left(\mathrm{~d},{ }^{1} J_{\mathrm{CF}}=249.0 \mathrm{~Hz}, \mathrm{C}-\mathrm{F}\right) \mathrm{ppm} ;{ }^{31} \mathrm{P}\left\{{ }^{1} \mathrm{H}\right\} \mathrm{NMR}(120 \mathrm{MHz}$, $\left.\mathrm{CDCl}_{3}\right) \delta: 18.3 \mathrm{ppm} ;{ }^{19} \mathrm{~F} \mathrm{NMR}\left(282 \mathrm{MHz}, \mathrm{CDCl}_{3}\right) \delta$ : $-112.9,-136.4$ and -137.3 (m) ppm. HRMS (EI): calculated for $\mathrm{C}_{25} \mathrm{H}_{21} \mathrm{~F}_{3} \mathrm{NO}_{3} \mathrm{P}[\mathrm{M}]^{+}$471.1211; found 471.1215. Purity $99.47 \%$ $(\mathrm{EtOH} /$ Heptane $=10 / 90, \mathrm{Rt}=5.892 \mathrm{~min})$.

Diethyl (2-(4-fluorophenyl)-4-(p-tolyl)quinolin-8-yl)phosphonate (7j). The general procedure was followed using aminophenylphosphonate 1a (1 mmol, $0.23 \mathrm{~g})$, 4-fluorobenzaldehyde $(1 \mathrm{mmol}, 0.11 \mathrm{~mL})$, 4-methylstyrene $(1.5 \mathrm{mmol}, 0.20 \mathrm{~mL})$ and $\mathrm{BF}_{3} . \mathrm{Et}_{2} \mathrm{O}$ affording $0.23 \mathrm{~g}$ (52\%) of a white solid identified as $7 \mathbf{j}, \mathrm{mp} 139-141^{\circ} \mathrm{C}$ (ethyl acetate/hexane). ${ }^{1} \mathrm{H}$ NMR $\left(300 \mathrm{MHz}_{\mathrm{CDCl}}\right)$ ) $\mathrm{CD}_{1}$ 1.32-1.36 (m, $\left.6 \mathrm{H}, 2 \mathrm{CH}_{3}\right), 2.48\left(\mathrm{~s}, 3 \mathrm{H}, \mathrm{CH}_{3}\right), 4.22-4.44(\mathrm{~m}, 4 \mathrm{H}, 2$ $\left.\mathrm{CH}_{2}\right), 7.17-7.23(\mathrm{~m}, 2 \mathrm{H}), 7.35-7.43(\mathrm{~m}, 4 \mathrm{H}), 7.47-7.53(\mathrm{~m}, 1 \mathrm{H}), 7.86(\mathrm{~s}, 1 \mathrm{H}), 8.08-8.11(\mathrm{~m}$, $1 \mathrm{H}), 8.32-8.40(\mathrm{~m}, 3 \mathrm{H}) \mathrm{ppm} ;{ }^{13} \mathrm{C}\left\{{ }^{1} \mathrm{H}\right\} \mathrm{NMR}\left(75 \mathrm{MHz}, \mathrm{CDCl}_{3}\right) \delta: 16.6\left(\mathrm{~d},{ }^{3} J_{\mathrm{CP}}=6.5 \mathrm{~Hz}\right.$, $\left.2 \mathrm{CH}_{3}\right), 21.5\left(\mathrm{CH}_{3}\right), 62.5\left(\mathrm{~m}, 2 \mathrm{CH}_{2}\right), 115.9\left(\mathrm{~d},{ }^{2} J_{\mathrm{CF}}=21.7 \mathrm{~Hz}, 2 \mathrm{HC}\right), 118.9(\mathrm{HC}), 125.5(\mathrm{~d}$, $\left.{ }^{3} J_{\mathrm{CP}}=18.0 \mathrm{~Hz}, \mathrm{HC}\right), 126.0\left(\mathrm{~d},{ }^{3} J_{\mathrm{CP}}=10.7 \mathrm{~Hz}, \mathrm{C}\right), 128.2\left(\mathrm{~d},{ }^{1} J_{\mathrm{CP}}=166.3 \mathrm{~Hz}, \mathrm{C}\right), 129.6(3 \mathrm{HC})$, 129.8 (HC), 129.9 (HC), 130.9 (2 HC), 135.1 (2 C), 136.9 (HC), 138.9 (C), 148.7 (C), 150.1 (d, $\left.{ }^{2} J_{\mathrm{CP}}=17.2 \mathrm{~Hz}, \mathrm{C}\right), 155.4(\mathrm{C}), 164.2\left(\mathrm{~d},{ }^{1} J_{\mathrm{CF}}=249.8 \mathrm{~Hz}, \mathrm{C}-\mathrm{F}\right) \mathrm{ppm} ;{ }^{31} \mathrm{P}\left\{{ }^{1} \mathrm{H}\right\} \mathrm{NMR}(120 \mathrm{MHz}$, $\left.\mathrm{CDCl}_{3}\right) \delta: 18.6 \mathrm{ppm} ;{ }^{19} \mathrm{~F} \mathrm{NMR}\left(282 \mathrm{MHz}, \mathrm{CDCl}_{3}\right) \delta:-112.0 \mathrm{ppm}$. HRMS (EI): calculated for $\mathrm{C}_{26} \mathrm{H}_{25} \mathrm{FNO}_{3} \mathrm{P}[\mathrm{M}]^{+}$449.1556; found 449.1562. Purity 97.07\% (EtOH/Heptane = 10/90, $\mathrm{Rt}=5.166 \mathrm{~min})$.

Diethyl (2-(3,4-difluorophenyl)-4-(p-tolyl)quinolin-8-yl)phosphonate (7k). The general procedure was followed using aminophenylphosphonate $1 \mathrm{a}(1 \mathrm{mmol}, 0.23 \mathrm{~g}), 3$,4-difluorobenzaldehyde (1 mmol, $0.11 \mathrm{~mL})$, 4-methylstyrene $(1.5 \mathrm{mmol}, 0.20 \mathrm{~mL})$ and $\mathrm{BF}_{3} . \mathrm{Et}_{2} \mathrm{O}$ affording $0.32 \mathrm{~g}$ (47\%) of a white solid identified as $7 \mathbf{k}, \mathrm{mp} 133-135{ }^{\circ} \mathrm{C}$ (ethyl acetate/hexane). ${ }^{1} \mathrm{H}$ NMR $\left(300 \mathrm{MHz}, \mathrm{CDCl}_{3}\right) \delta: 1.34-1.39\left(\mathrm{~m}, 6 \mathrm{H}, 2 \mathrm{CH}_{3}\right), 2.49\left(\mathrm{~s}, 1 \mathrm{H}, \mathrm{CH}_{3}\right), 4.21-4.43\left(\mathrm{~m}, 4 \mathrm{H}, 2 \mathrm{CH}_{2}\right)$, 7.28-7.31 (m, 1 H), 7.36-7.43 (m, 4 H), 7.49-7.56 (m, 1 H), $7.82(\mathrm{~s}, 1 \mathrm{H}), 8.07-8.12(\mathrm{~m}, 2 \mathrm{H})$, 8.26-8.43 (m, $2 \mathrm{H}) \mathrm{ppm} ;{ }^{13} \mathrm{C}\left\{{ }^{1} \mathrm{H}\right\} \operatorname{NMR}\left(75 \mathrm{MHz}, \mathrm{CDCl}_{3}\right) \delta: 16.7\left(\mathrm{~d},{ }^{3} J_{\mathrm{CP}}=6.5 \mathrm{~Hz}, 2 \mathrm{CH}_{3}\right)$, $21.5\left(\mathrm{CH}_{3}\right), 62.4\left(\mathrm{~d},{ }^{2} J_{\mathrm{CP}}=5.8 \mathrm{~Hz}, 2 \mathrm{CH}_{2}\right), 117.0\left(\mathrm{~d},{ }^{2} J_{\mathrm{CF}}=18.9 \mathrm{~Hz}, \mathrm{HC}\right), 117.6\left(\mathrm{~d},{ }^{2} J_{\mathrm{CF}}=17.4\right.$ $\mathrm{Hz}, \mathrm{HC}), 118.6(\mathrm{HC}), 123.9\left(\mathrm{dd},{ }^{3} J_{\mathrm{CF}}=6.5 \mathrm{~Hz},{ }^{4} J_{\mathrm{C}-\mathrm{F}}=3.3 \mathrm{~Hz}, \mathrm{HC}\right), 125.8\left(\mathrm{~d},{ }^{3} J_{\mathrm{CP}}=16.2 \mathrm{~Hz}\right.$, $\mathrm{HC}), 126.2\left(\mathrm{~d},{ }^{3} J_{\mathrm{CP}}=10.6 \mathrm{~Hz}, \mathrm{C}\right), 128.5\left(\mathrm{~d},{ }^{1} J_{\mathrm{CP}}=188.5 \mathrm{~Hz}, \mathrm{C}\right), 129.5(2 \mathrm{HC}), 129.6(2 \mathrm{HC})$, $130.9(\mathrm{C}), 135.0(\mathrm{C}), 136.3(\mathrm{C}), 137.2\left(\mathrm{~d},{ }^{2} J_{\mathrm{CP}}=7.6 \mathrm{~Hz}, \mathrm{HC}\right), 139.0(\mathrm{C}), 148.7\left(\mathrm{~d},{ }^{2} J_{\mathrm{CP}}=6.6\right.$ $\mathrm{Hz}, \mathrm{C}), 150.2(\mathrm{C}), 150.8\left(\mathrm{dd},{ }^{1} J_{\mathrm{CF}}=247.4 \mathrm{~Hz},{ }^{2} J_{\mathrm{CF}}=12.1 \mathrm{~Hz}, \mathrm{C}\right), 151.7\left(\mathrm{dd},{ }^{1} J_{\mathrm{CF}}=250.7 \mathrm{~Hz}\right.$, $\left.{ }^{2} J_{\mathrm{CF}}=12.3 \mathrm{~Hz}, \mathrm{C}\right), 153.5(\mathrm{C}) \mathrm{ppm} .{ }^{31} \mathrm{P}\left\{{ }^{1} \mathrm{H}\right\} \mathrm{NMR}\left(120 \mathrm{MHz}, \mathrm{CDCl}_{3}\right) \delta: 18.5 \mathrm{ppm} ;{ }^{19} \mathrm{~F} \mathrm{NMR}$ $\left(282 \mathrm{MHz}, \mathrm{CDCl}_{3}\right) \delta:-136.65$ and -137.50 (m) ppm. HRMS (EI): calculated for $\mathrm{C}_{26} \mathrm{H}_{24} \mathrm{~F}_{2} \mathrm{NO}_{3} \mathrm{P}$ $[\mathrm{M}]^{+}$467.1462; found 467.1465. Purity 98.21\% (EtOH/Heptane = 10/90, Rt = $\left.5.307 \mathrm{~min}\right)$.

Diisopropyl (2-(4-fluorophenyl)-4-phenylquinolin-8-yl)phosphonate (71). The general procedure was followed using aminophenylphosphonate $\mathbf{1 b}$ (1 mmol, $0.23 \mathrm{~g})$, 4-fluorobenzaldehyde $(1 \mathrm{mmol}, 0.11 \mathrm{~mL})$, styrene $(1.5 \mathrm{mmol}, 0.17 \mathrm{~mL})$ and $\mathrm{BF}_{3} . \mathrm{Et}_{2} \mathrm{O}$ affording $0.16 \mathrm{~g}(34 \%)$ of a white solid identified as 71, mp $107-109{ }^{\circ} \mathrm{C}$ (ethyl acetate/hexane). ${ }^{1} \mathrm{H}$ NMR (300 MHz, $\left.\mathrm{CDCl}_{3}\right) \delta: 1.15\left(\mathrm{~d},{ }^{3} \mathrm{~J}_{\mathrm{HH}}=6.2 \mathrm{~Hz}, 2 \mathrm{CH}_{3}\right), 1.33\left(\mathrm{~d},{ }^{3} \mathrm{~J}_{\mathrm{HH}}=6.2 \mathrm{~Hz}, 2 \mathrm{CH}_{3}\right), 4.90-4.98(\mathrm{~m}, 2$ H, 2 CH), 7.10-7.14 (m, 2 H), 7.39-7.50 (m, 6 H), 7.77 (s, $1 \mathrm{H}), 7.96-7.98$ (m, 1 H), 8.27-8.33 $(\mathrm{m}, 3 \mathrm{H}) \mathrm{ppm} ;{ }^{13} \mathrm{C}\left\{{ }^{1} \mathrm{H}\right\} \mathrm{NMR}\left(75 \mathrm{MHz}, \mathrm{CDCl}_{3}\right) \delta: 23.9\left(\mathrm{~d},{ }^{3} J_{\mathrm{CP}}=5.1 \mathrm{~Hz}, 2 \mathrm{CH}_{3}\right), 24.3(\mathrm{~d}$, $\left.{ }^{3} J_{\mathrm{CP}}=3.8 \mathrm{~Hz}, 2 \mathrm{CH}_{3}\right), 70.7\left(\mathrm{~d},{ }^{2} J_{\mathrm{CP}}=6.0 \mathrm{~Hz}, 2 \mathrm{CH}\right), 115.6\left(\mathrm{~d},{ }^{2} J_{\mathrm{CF}}=21.6 \mathrm{~Hz}, 2 \mathrm{HC}\right), 118.6$ (HC), $125.3\left(\mathrm{~d},{ }^{3} J_{\mathrm{CP}}=16.2 \mathrm{~Hz}, \mathrm{HC}\right), 125.7\left(\mathrm{~d},{ }^{3} J_{\mathrm{CP}}=10.8 \mathrm{~Hz}, \mathrm{C}\right), 128.6(\mathrm{HC}), 128.7(2 \mathrm{HC})$, $129.4\left(\mathrm{~d},{ }^{1} J_{\mathrm{CP}}=189.7 \mathrm{~Hz}, \mathrm{C}\right), 129.5(2 \mathrm{HC}), 129.7\left(\mathrm{~d},{ }^{3} J_{\mathrm{CF}}=8.4 \mathrm{~Hz}, 2 \mathrm{HC}\right), 130.4(\mathrm{HC}), 135.1$ (C), $136.8\left(\mathrm{~d},{ }^{2} J_{\mathrm{CP}}=7.5 \mathrm{~Hz}, \mathrm{HC}\right), 138.0(\mathrm{C}), 148.5\left(\mathrm{~d},{ }^{2} J_{\mathrm{CP}}=6.7 \mathrm{~Hz}, \mathrm{C}\right), 149.5(\mathrm{C}), 155.1(\mathrm{C})$, $164.0\left(\mathrm{~d},{ }^{1} J_{\mathrm{CF}}=249.6 \mathrm{~Hz}, \mathrm{C}-\mathrm{F}\right) \mathrm{ppm} ;{ }^{31} \mathrm{P}\left\{{ }^{1} \mathrm{H}\right\}$ NMR $\left(120 \mathrm{MHz}, \mathrm{CDCl}_{3}\right) \delta: 16.3 \mathrm{ppm} ;{ }^{19} \mathrm{~F}$ 
NMR (282 MHz, $\mathrm{CDCl}_{3}$ ) $\delta:-112.2 \mathrm{ppm}$. HRMS (EI): calculated for $\mathrm{C}_{27} \mathrm{H}_{27} \mathrm{FNO}_{3} \mathrm{P}[\mathrm{M}]^{+}$ 463.1713; found 463.1720. Purity 99.78\% $(\mathrm{EtOH} /$ Heptane $=10 / 90, \mathrm{Rt}=4.631 \mathrm{~min})$.

Diisopropyl (2-(3,4-difluorophenyl)-4-phenylquinolin-8-yl)phosphonate $(7 \mathbf{m})$. The general procedure was followed using aminophenylphosphonate $\mathbf{1 b}(1 \mathrm{mmol}, 0.23 \mathrm{~g}), 3,4-$ difluorobenzaldehyde $(1 \mathrm{mmol}, 0.11 \mathrm{~mL})$, styrene $(1.5 \mathrm{mmol}, 0.17 \mathrm{~mL})$ and $\mathrm{BF}_{3}$. $\mathrm{Et}_{2} \mathrm{O}$ affording $0.18 \mathrm{~g}(38 \%)$ of a white solid identified as $7 \mathrm{~m}, \mathrm{mp} 127-129^{\circ} \mathrm{C}$ (ethyl acetate/hexane). ${ }^{1} \mathrm{H} \mathrm{NMR}\left(300 \mathrm{MHz}, \mathrm{CDCl}_{3}\right) \delta: 1.15\left(\mathrm{~d},{ }^{3} J_{\mathrm{HH}}=6.2 \mathrm{~Hz}, 2 \mathrm{CH}_{3}\right), 1.35\left(\mathrm{~d},{ }^{3} \mathrm{~J}_{\mathrm{HH}}=6.2 \mathrm{~Hz}, 2 \mathrm{CH}_{3}\right)$, 4.88-4.96 (m, $2 \mathrm{H}, 2 \mathrm{CH}), 7.17-7.23(\mathrm{~m}, 1 \mathrm{H}), 7.40-7.49(\mathrm{~m}, 6 \mathrm{H}), 7.74(\mathrm{~s}, 1 \mathrm{H}), 7.95-7.98(\mathrm{~m}$, $1 \mathrm{H}), 8.00-8.03(\mathrm{~m}, \mathrm{H}), 8.23-8.28(\mathrm{~m}, \mathrm{H}), 8.30-8.37(\mathrm{~m}, \mathrm{H}) \mathrm{ppm} ;{ }^{13} \mathrm{C}\left\{{ }^{1} \mathrm{H}\right\} \mathrm{NMR}(75 \mathrm{MHz}$, $\left.\mathrm{CDCl}_{3}\right) \delta: 23.9\left(\mathrm{~d},{ }^{3} J_{\mathrm{CP}}=5.0 \mathrm{~Hz}, 2 \mathrm{CH}_{3}\right), 24.3\left(\mathrm{~d},{ }^{3} J_{\mathrm{CP}}=4.0 \mathrm{~Hz}, 2 \mathrm{CH}_{3}\right), 70.7\left(\mathrm{~d},{ }^{2} J_{\mathrm{CP}}=6.0\right.$ $\mathrm{Hz}, 2 \mathrm{CH}), 116.8\left(\mathrm{~d},{ }^{2} J_{\mathrm{CF}}=18.7 \mathrm{~Hz}, \mathrm{HC}\right), 117.3\left(\mathrm{~d},{ }^{2} J_{\mathrm{CF}}=17.5 \mathrm{~Hz}, \mathrm{HC}\right), 118.2(\mathrm{HC}), 123.6$ $\left(\mathrm{dd},{ }^{3} J_{\mathrm{CF}}=6.6 \mathrm{~Hz},{ }^{4} J_{\mathrm{CF}}=3.5 \mathrm{~Hz}, \mathrm{HC}\right), 125.6\left(\mathrm{~d},{ }^{3} J_{\mathrm{CP}}=16.3 \mathrm{~Hz}, \mathrm{HC}\right), 125.9\left(\mathrm{~d},{ }^{3} J_{\mathrm{CP}}=10.6 \mathrm{~Hz}\right.$, C), $128.7(2 \mathrm{HC}), 129.5(2 \mathrm{HC}), 129.5\left(\mathrm{~d},{ }^{1} J_{\mathrm{CP}}=189.3 \mathrm{~Hz}, \mathrm{C}\right), 130.4(\mathrm{HC}), 130.6(\mathrm{HC}), 136.1$ $\left(\mathrm{dd},{ }^{3} J_{\mathrm{CF}}=6.7 \mathrm{~Hz},{ }^{4} J_{\mathrm{CF}}=3.6 \mathrm{~Hz}, \mathrm{C}\right), 137.1\left(\mathrm{~d},{ }^{3} J_{\mathrm{CF}}=7.7 \mathrm{~Hz}, \mathrm{HC}\right), 137.8(\mathrm{C}), 148.4\left(\mathrm{~d},{ }^{2} J_{\mathrm{CP}}=\right.$ $6.4 \mathrm{~Hz}, \mathrm{C}), 149.8(\mathrm{C}), 150.8\left(\mathrm{dd},{ }^{2} J_{\mathrm{CF}}=12.7 \mathrm{~Hz},{ }^{1} J_{\mathrm{CF}}=247.7 \mathrm{~Hz}, \mathrm{C}\right), 151.6\left(\mathrm{dd},{ }^{2} J_{\mathrm{CF}}=12.7 \mathrm{~Hz}\right.$, $\left.{ }^{1} J_{\mathrm{CF}}=251.7 \mathrm{~Hz}, \mathrm{C}\right), 153.7(\mathrm{C}) \mathrm{ppm} ;{ }^{31} \mathrm{P}\left\{{ }^{1} \mathrm{H}\right\} \mathrm{NMR}\left(120 \mathrm{MHz}, \mathrm{CDCl}_{3}\right) \delta: 16.2 \mathrm{ppm} ;{ }^{19} \mathrm{~F} \mathrm{NMR}$ $\left(282 \mathrm{MHz}, \mathrm{CDCl}_{3}\right) \delta:-136.7$ and $-137.7 \mathrm{ppm}$. HRMS (EI): calculated for $\mathrm{C}_{27} \mathrm{H}_{26} \mathrm{~F}_{2} \mathrm{NO}_{3} \mathrm{P}$ $[\mathrm{M}]^{+}$481.1618; found 481.1625. Purity 99.99\% $(\mathrm{EtOH} /$ Heptane $=10 / 90, \mathrm{Rt}=4.799 \mathrm{~min})$.

Diisopropyl (2,4-bis(4-fluorophenyl)quinolin-8-yl)phosphonate (7n). The general procedure was followed using aminophenylphosphonate $\mathbf{1 b}(1 \mathrm{mmol}, 0.23 \mathrm{~g})$, 4-fluorobenzaldehyde $(1 \mathrm{mmol}, 0.11 \mathrm{~mL})$, 4-fluorostyrene $(1.5 \mathrm{mmol}, 0.18 \mathrm{~mL})$ and $\mathrm{BF}_{3} . \mathrm{Et}_{2} \mathrm{O}$ affording $0.30 \mathrm{~g}$ (62\%) of a white solid identified as $7 \mathbf{n}, \mathrm{mp} 113-115^{\circ} \mathrm{C}$ (ethyl acetate/hexane). ${ }^{1} \mathrm{H}$ NMR $\left(300 \mathrm{MHz}, \mathrm{CDCl}_{3}\right) \delta: 1.15\left(\mathrm{~d},{ }^{3} \mathrm{~J}_{\mathrm{HH}}=6.2 \mathrm{~Hz}, 2 \mathrm{CH}_{3}\right), 1.35\left(\mathrm{~d},{ }^{3} \mathrm{~J}_{\mathrm{HH}}=6.1 \mathrm{~Hz}, 2 \mathrm{CH}_{3}\right), 4.90-4.99$ $(\mathrm{m}, 2 \mathrm{H}, 2 \mathrm{CH}), 7.11-7.20(\mathrm{~m}, 4 \mathrm{H}), 7.40-7.46(\mathrm{~m}, 3 \mathrm{H}), 7.75(\mathrm{~s}, 1 \mathrm{H}), 7.91-7.93(\mathrm{~m}, 1 \mathrm{H})$, 8.29-8.35 (m, $3 \mathrm{H}) \mathrm{ppm} ;{ }^{13} \mathrm{C}\left\{{ }^{1} \mathrm{H}\right\}$ NMR $\left(75 \mathrm{MHz}, \mathrm{CDCl}_{3}\right) \delta: 23.9\left(\mathrm{~d},{ }^{3} J_{\mathrm{CP}}=5.1 \mathrm{~Hz}, 2 \mathrm{CH}_{3}\right)$, $24.3\left(\mathrm{~d},{ }^{3} J_{\mathrm{CP}}=3.8 \mathrm{~Hz}, 2 \mathrm{CH}_{3}\right), 70.7\left(\mathrm{~d},{ }^{2} \mathrm{~J}_{\mathrm{CP}}=6.0 \mathrm{~Hz}, 2 \mathrm{CH}\right), 115.6\left(\mathrm{~d},{ }^{2} J_{\mathrm{CF}}=21.5 \mathrm{~Hz}, 2 \mathrm{HC}\right)$, $115.8\left(\mathrm{~d},{ }^{2} J_{\mathrm{CF}}=21.6 \mathrm{~Hz}, 2 \mathrm{HC}\right), 118.6(\mathrm{HC}), 125.5\left(\mathrm{~d},{ }^{3} J_{\mathrm{CP}}=16.1 \mathrm{~Hz}, \mathrm{HC}\right), 125.7\left(\mathrm{~d},{ }^{3} J_{\mathrm{CP}}=\right.$ $10.6 \mathrm{~Hz}, \mathrm{C}), 129.6\left(\mathrm{~d},{ }^{1} J_{\mathrm{CP}}=189.7 \mathrm{~Hz}, \mathrm{C}\right), 131.2\left(\mathrm{~d},{ }^{3} J_{\mathrm{CF}}=8.1 \mathrm{~Hz}, 2 \mathrm{HC}\right), 134.0(\mathrm{C}), 134.9$ (C), $136.8\left(\mathrm{~d},{ }^{2} J_{\mathrm{CP}}=7.4 \mathrm{~Hz}, \mathrm{HC}\right), 148.4(\mathrm{C}), 148.5\left(\mathrm{~d},{ }^{2} J_{\mathrm{CP}}=6.8 \mathrm{~Hz}, \mathrm{C}\right), 150.1(\mathrm{C}), 163.0(\mathrm{~d}$, $\left.{ }^{1} J_{\mathrm{CF}}=248.3 \mathrm{~Hz}, \mathrm{C}-\mathrm{F}\right), 164.0\left(\mathrm{~d},{ }^{1} J_{\mathrm{CF}}=249.7 \mathrm{~Hz}, \mathrm{C}-\mathrm{F}\right) \mathrm{ppm} ;{ }^{31} \mathrm{P}\left\{{ }^{1} \mathrm{H}\right\} \mathrm{NMR}\left(120 \mathrm{MHz}, \mathrm{CDCl}_{3}\right)$ $\delta: 16.1 \mathrm{ppm} ;{ }^{19} \mathrm{~F}$ NMR $\left(282 \mathrm{MHz}, \mathrm{CDCl}_{3}\right) \delta:-112.1$ and $-113.3 \mathrm{ppm}$. HRMS (EI): calculated for $\mathrm{C}_{27} \mathrm{H}_{26} \mathrm{~F}_{2} \mathrm{NO}_{3} \mathrm{P}[\mathrm{M}]^{+}$481.1618; found 481.1632. Purity $99.99 \%$ (EtOH/Heptane $=10 / 90$, $\mathrm{Rt}=4.696 \mathrm{~min})$.

Diisopropyl (2-(3,4-difluorophenyl)-4-(4-fluorophenyl)quinolin-8-yl)phosphonate (7o). The general procedure was followed using aminophenylphosphonate $\mathbf{1 b}(1 \mathrm{mmol}, 0.23 \mathrm{~g})$, 3,4-difluorobenzaldehyde ( $1 \mathrm{mmol}, 0.11 \mathrm{~mL})$, 4-fluorostyrene $(1.5 \mathrm{mmol}, 0.18 \mathrm{~mL})$ and $\mathrm{BF}_{3}$. $\mathrm{Et}_{2} \mathrm{O}$ affording $0.44 \mathrm{~g}(88 \%)$ of a white solid identified as 7o, mp $144-146{ }^{\circ} \mathrm{C}$ (ethyl acetate/hexane). ${ }^{1} \mathrm{H}$ NMR $\left(300 \mathrm{MHz}, \mathrm{CDCl}_{3}\right) \delta: 1.06\left(\mathrm{~d},{ }^{3} \mathrm{~J}_{\mathrm{HH}}=6.2 \mathrm{~Hz}, 2 \mathrm{CH}_{3}\right), 1.25(\mathrm{~d}$, $\left.{ }^{3} J_{\mathrm{HH}}=6.2 \mathrm{~Hz}, 2 \mathrm{CH}_{3}\right), 4.79-4.87(\mathrm{~m}, 2 \mathrm{H}, 2 \mathrm{CH}), 7.17-7.23(\mathrm{~m}, 1 \mathrm{H}), 7.40-7.49(\mathrm{~m}, 6 \mathrm{H}), 7.74$ $(\mathrm{s}, 1 \mathrm{H}), 7.95-7.98(\mathrm{~m}, 1 \mathrm{H}), 8.00-8.03(\mathrm{~m}, \mathrm{H}), 8.23-8.28(\mathrm{~m}, \mathrm{H}), 8.30-8.37(\mathrm{~m}, \mathrm{H}) \mathrm{ppm} ;{ }^{13} \mathrm{C}$ $\left\{{ }^{1} \mathrm{H}\right\} \mathrm{NMR}\left(75 \mathrm{MHz}, \mathrm{CDCl}_{3}\right) \delta: 23.8\left(\mathrm{~d},{ }^{3} J_{\mathrm{CP}}=5.0 \mathrm{~Hz}, 2 \mathrm{CH}_{3}\right), 24.1\left(\mathrm{~d},{ }^{3} J_{\mathrm{CP}}=3.9 \mathrm{~Hz}, 2 \mathrm{CH}_{3}\right)$, $70.7\left(\mathrm{~d},{ }^{2} J_{\mathrm{CP}}=6.0 \mathrm{~Hz}, 2 \mathrm{CH}\right), 115.7\left(\mathrm{~d},{ }^{3} J_{\mathrm{CF}}=20.6 \mathrm{~Hz}, 2 \mathrm{HC}\right), 116.8\left(\mathrm{~d},{ }^{2} J_{\mathrm{CF}}=18.7 \mathrm{~Hz}, \mathrm{HC}\right)$, $117.2\left(\mathrm{~d},{ }^{2} \mathrm{~J}_{\mathrm{CF}}=17.5 \mathrm{~Hz}, \mathrm{HC}\right), 118.2(\mathrm{HC}), 123.6\left(\mathrm{dd},{ }^{3} J_{\mathrm{CF}}=6.5 \mathrm{~Hz},{ }^{4} J_{\mathrm{CF}}=3.3 \mathrm{~Hz}, \mathrm{HC}\right), 125.7$ $\left(\mathrm{d},{ }^{3} J_{\mathrm{CP}}=17.6 \mathrm{~Hz}, \mathrm{HC}\right), 125.7(\mathrm{C}), 129.4\left(\mathrm{~d},{ }^{1} J_{\mathrm{CP}}=189.5 \mathrm{~Hz}, \mathrm{C}\right), 129.9(\mathrm{HC}), 131.1(\mathrm{HC}), 131.2$ $(2 \mathrm{HC}), 133.6(\mathrm{C}), 135.8\left(\mathrm{dd},{ }^{3} J_{\mathrm{CF}}=5.7 \mathrm{~Hz},{ }^{4} J_{\mathrm{CF}}=3.5 \mathrm{~Hz}, \mathrm{C}\right), 136.9\left(\mathrm{~d},{ }^{3} J_{\mathrm{CF}}=7.6 \mathrm{~Hz}, \mathrm{HC}\right)$, $148.3\left(\mathrm{~d},{ }^{2} J_{\mathrm{CP}}=6.5 \mathrm{~Hz}, \mathrm{C}\right), 148.6(\mathrm{C}), 150.6\left(\mathrm{dd},{ }^{2} J_{\mathrm{CF}}=12.6 \mathrm{~Hz},{ }^{1} J_{\mathrm{CF}}=247.8 \mathrm{~Hz}, \mathrm{C}\right), 151.5(\mathrm{dd}$, $\left.{ }^{2} J_{\mathrm{CF}}=12.7 \mathrm{~Hz},{ }^{1} J_{\mathrm{CF}}=251.6 \mathrm{~Hz}, \mathrm{C}\right), 153.6(\mathrm{C}), 162.9\left(\mathrm{~d},{ }^{1} J_{\mathrm{CF}}=248.9 \mathrm{~Hz}, \mathrm{C}-\mathrm{F}\right), \mathrm{ppm} ;{ }^{31} \mathrm{P}\left\{{ }^{1} \mathrm{H}\right\}$ NMR $\left(120 \mathrm{MHz}, \mathrm{CDCl}_{3}\right) \delta: 15.9 \mathrm{ppm} ;{ }^{19} \mathrm{~F} \mathrm{NMR}\left(282 \mathrm{MHz}, \mathrm{CDCl}_{3}\right) \delta:-112.9,-136.6$ and -137.7 (m) ppm. HRMS (EI): calculated for $\mathrm{C}_{27} \mathrm{H}_{25} \mathrm{~F}_{3} \mathrm{NO}_{3} \mathrm{P}[\mathrm{M}]^{+} 499.1524$; found 499.1534. Purity $99.72 \%(\mathrm{EtOH} /$ Heptane $=10 / 90, \mathrm{Rt}=4.826 \mathrm{~min})$.

Diisopropyl (2-(4-fluorophenyl)-4-(p-tolyl)quinolin-8-yl)phosphonate (7p). The general procedure was followed using aminophenylphosphonate $\mathbf{1 b}(1 \mathrm{mmol}, 0.23 \mathrm{~g})$, 4-fluorobenzaldehyde $(1 \mathrm{mmol}, 0.11 \mathrm{~mL})$, 4-methylstyrene $(1.5 \mathrm{mmol}, 0.20 \mathrm{~mL})$ and $\mathrm{BF}_{3} . \mathrm{Et}_{2} \mathrm{O}$ affording $0.28 \mathrm{~g}$ (58\%) of a white solid identified as $7 \mathbf{p}, \mathrm{mp} 121-123^{\circ} \mathrm{C}$ (ethyl acetate/hexane). ${ }^{1} \mathrm{H}$ NMR (300 
$\left.\mathrm{MHz}, \mathrm{CDCl}_{3}\right) \delta: 1.14\left(\mathrm{~d},{ }^{3} J_{\mathrm{HH}}=6.1 \mathrm{~Hz}, 2 \mathrm{CH}_{3}\right), 1.33\left(\mathrm{~d},{ }^{3} J_{\mathrm{HH}}=6.2 \mathrm{~Hz}, 2 \mathrm{CH}_{3}\right), 2.40\left(\mathrm{CH}_{3}\right)$, 4.89-4.97 (m, 2 H, 2 CH), 7.09-7.13 (m, 2 H), 7.27-7.34 (m, 4 H), 7.37-7.42 (m, $1 \mathrm{H}), 7.75$ (s, $1 \mathrm{H}), 7.98-8.00(\mathrm{~m}, 1 \mathrm{H}), 8.26-8.32(\mathrm{~m}, 3 \mathrm{H}) \mathrm{ppm} ;{ }^{13} \mathrm{C}\left\{{ }^{1} \mathrm{H}\right\} \mathrm{NMR}\left(75 \mathrm{MHz}, \mathrm{CDCl}_{3}\right) \delta: 21.3$ $\left(\mathrm{CH}_{3}\right), 23.9\left(\mathrm{~d},{ }^{3} J_{\mathrm{CP}}=5.1 \mathrm{~Hz}, 2 \mathrm{CH}_{3}\right), 24.3\left(\mathrm{~d},{ }^{3} J_{\mathrm{CP}}=3.8 \mathrm{~Hz}, 2 \mathrm{CH}_{3}\right), 70.6\left(\mathrm{~d},{ }^{2} J_{\mathrm{CP}}=6.0 \mathrm{~Hz}\right.$, $2 \mathrm{CH}), 115.5\left(\mathrm{~d},{ }^{2} J_{\mathrm{CF}}=21.6 \mathrm{~Hz}, 2 \mathrm{HC}\right), 118.5(\mathrm{HC}), 125.2\left(\mathrm{~d},{ }^{3} J_{\mathrm{CP}}=16.2 \mathrm{~Hz}, \mathrm{HC}\right), 125.8(\mathrm{~d}$, $\left.{ }^{3} J_{\mathrm{CP}}=10.7 \mathrm{~Hz}, \mathrm{C}\right), 129.4(2 \mathrm{HC}), 129.4(2 \mathrm{HC}), 129.7\left(\mathrm{~d},{ }^{3} J_{\mathrm{CF}}=7.4 \mathrm{~Hz}, 2 \mathrm{HC}\right), 130.0\left(\mathrm{~d},{ }^{1} J_{\mathrm{CP}}\right.$ $=189.3 \mathrm{~Hz}, \mathrm{C}), 130.5\left(\mathrm{~d},{ }^{4} J_{\mathrm{CP}}=5.0 \mathrm{~Hz}, \mathrm{HC}\right), 135.1\left(\mathrm{~d},{ }^{4} J_{\mathrm{CP}}=4.7 \mathrm{~Hz}, \mathrm{C}\right), 135.1(\mathrm{C}), 136.7(\mathrm{~d}$, $\left.{ }^{2} J_{\mathrm{CP}}=7.5 \mathrm{~Hz}, \mathrm{HC}\right), 138.6(\mathrm{C}), 148.6\left(\mathrm{~d},{ }^{2} J_{\mathrm{CP}}=6.6 \mathrm{~Hz}, \mathrm{C}\right), 149.6(\mathrm{C}), 155.1(\mathrm{C}), 164.0\left(\mathrm{~d},{ }^{1} J_{\mathrm{CF}}\right.$ $=249.5 \mathrm{~Hz}, \mathrm{C}) \mathrm{ppm} ;{ }^{31} \mathrm{P}\left\{{ }^{1} \mathrm{H}\right\} \mathrm{NMR}\left(120 \mathrm{MHz}, \mathrm{CDCl}_{3}\right) \delta: 16.4 \mathrm{ppm} ;{ }^{19} \mathrm{~F} \mathrm{NMR}(282 \mathrm{MHz}$, $\left.\mathrm{CDCl}_{3}\right) \delta$ : $-112.2 \mathrm{ppm}$. HRMS (EI): calculated for $\mathrm{C}_{28} \mathrm{H}_{29} \mathrm{FNO}_{3} \mathrm{P}[\mathrm{M}]^{+} 477.1869$; found 477.1876. Purity $99.48 \%(\mathrm{EtOH} / \mathrm{Heptane}=10 / 90, \mathrm{Rt}=4.343 \mathrm{~min})$.

Diisopropyl (2-(3,4-difluorophenyl)-4-(p-tolyl)quinolin-8-yl)phosphonate (7q). The general procedure was followed using aminophenylphosphonate $\mathbf{1 b}(1 \mathrm{mmol}, 0.23 \mathrm{~g}), 3,4$-difluorobenzald ehyde $(1 \mathrm{mmol}, 0.11 \mathrm{~mL})$, 4-methylstyrene $(1.5 \mathrm{mmol}, 0.20 \mathrm{~mL})$ and $\mathrm{BF}_{3} . \mathrm{Et}_{2} \mathrm{O}$ affording $0.19 \mathrm{~g}(39 \%)$ of a white solid identified as $7 \mathbf{q}, \mathrm{mp} 140-142{ }^{\circ} \mathrm{C}$ (ethyl acetate/hexane). ${ }^{1} \mathrm{H}$ NMR $\left(300 \mathrm{MHz}, \mathrm{CDCl}_{3}\right) \delta: 1.15\left(\mathrm{~d},{ }^{3} J_{\mathrm{HH}}=6.2 \mathrm{~Hz}, 2 \mathrm{CH}_{3}\right), 1.34\left(\mathrm{~d},{ }^{3} \mathrm{~J}_{\mathrm{HH}}=6.2 \mathrm{~Hz}, 2 \mathrm{CH}_{3}\right), 2.39\left(\mathrm{CH}_{3}\right)$, 4.88-4.96 (m, $2 \mathrm{H}, 2 \mathrm{CH}), 7.16-7.23(\mathrm{~m}, 1 \mathrm{H}), 7.26-7.33(\mathrm{~m}, 4 \mathrm{H}), 7.40-7.44(\mathrm{~m}, 1 \mathrm{H}), 7.72(\mathrm{~s}, 1$ $\mathrm{H}), 7.99-8.02(\mathrm{~m}, 2 \mathrm{H}), 8.23-8.36(\mathrm{~m}, 2 \mathrm{H}) \mathrm{ppm} ;{ }^{13} \mathrm{C}\left\{{ }^{1} \mathrm{H}\right\} \mathrm{NMR}\left(75 \mathrm{MHz}, \mathrm{CDCl}_{3}\right) \delta: 21.2\left(\mathrm{CH}_{3}\right)$, $23.9\left(\mathrm{~d},{ }^{3} J_{\mathrm{CP}}=5.0 \mathrm{~Hz}, 2 \mathrm{CH}_{3}\right), 24.3\left(\mathrm{~d},{ }^{3} J_{\mathrm{CP}}=4.8 \mathrm{~Hz}, 2 \mathrm{CH}_{3}\right), 70.7\left(\mathrm{~d},{ }^{2} J_{\mathrm{CP}}=5.9 \mathrm{~Hz}, 2 \mathrm{CH}\right)$, $116.8\left(\mathrm{~d},{ }^{2} J_{\mathrm{CF}}=18.7 \mathrm{~Hz}, \mathrm{HC}\right), 117.3\left(\mathrm{~d},{ }^{2} J_{\mathrm{CF}}=17.5 \mathrm{~Hz}, \mathrm{HC}\right), 118.2(\mathrm{HC}), 123.6\left(\mathrm{dd},{ }^{3} J_{\mathrm{CF}}=6.6\right.$ $\left.\mathrm{Hz},{ }^{4} J_{\mathrm{CF}}=3.4 \mathrm{~Hz}, \mathrm{HC}\right), 125.5\left(\mathrm{~d},{ }^{3} J_{\mathrm{CP}}=16.2 \mathrm{~Hz}, \mathrm{HC}\right), 126.0\left(\mathrm{~d},{ }^{3} J_{\mathrm{CP}}=10.4 \mathrm{~Hz}, \mathrm{C}\right), 129.4(2 \mathrm{HC})$, $129.4(2 \mathrm{HC}), 129.5\left(\mathrm{~d},{ }^{1} J_{\mathrm{CP}}=188.1 \mathrm{~Hz}, \mathrm{C}\right), 130.5(\mathrm{HC}), 134.9(\mathrm{HC}), 136.2\left(\mathrm{dd},{ }^{3} J_{\mathrm{CF}}=5.8 \mathrm{~Hz}\right.$, $\left.{ }^{4} J_{\mathrm{CF}}=3.6 \mathrm{~Hz}, \mathrm{C}\right), 137.1\left(\mathrm{~d},{ }^{3} J_{\mathrm{CF}}=7.7 \mathrm{~Hz}, \mathrm{HC}\right), 138.7(\mathrm{C}), 148.4\left(\mathrm{~d},{ }^{2} J_{\mathrm{CP}}=6.4 \mathrm{~Hz}, \mathrm{C}\right), 149.9(\mathrm{C})$, $150.8\left(\mathrm{dd},{ }^{2} J_{\mathrm{CF}}=12.6 \mathrm{~Hz},{ }^{1} J_{\mathrm{CF}}=247.6 \mathrm{~Hz}, \mathrm{C}\right), 151.6\left(\mathrm{dd},{ }^{2} J_{\mathrm{CF}}=12.7 \mathrm{~Hz},{ }^{1} J_{\mathrm{CF}}=251.3 \mathrm{~Hz}, \mathrm{C}\right)$, 153.7 (C) ppm; ${ }^{31} \mathrm{P}\left\{{ }^{1} \mathrm{H}\right\}$ NMR (120 MHz, $\left.\mathrm{CDCl}_{3}\right) \delta: 16.3 \mathrm{ppm} ;{ }^{19} \mathrm{~F}$ NMR $\left(282 \mathrm{MHz}, \mathrm{CDCl}_{3}\right)$ $\delta$ : -136.8 and $-137.7 \mathrm{ppm}$. HRMS (EI): calculated for $\mathrm{C}_{28} \mathrm{H}_{28} \mathrm{~F}_{2} \mathrm{NO}_{3} \mathrm{P}[\mathrm{M}]^{+} 495.1775$; found 495.1784. Purity $99.99 \%(\mathrm{EtOH} / \mathrm{Heptane}=10 / 90, \mathrm{Rt}=4.450 \mathrm{~min})$.

Diethyl (2-(4-fluorophenyl)-4-phenylquinolin-6-yl)phosphonate (7r). The general procedure was followed using aminophenylphosphonate $1 \mathrm{c}(1 \mathrm{mmol}, 0.23 \mathrm{~g})$, 4-fluorobenzaldehyde $(1 \mathrm{mmol}, 0.11 \mathrm{~mL})$, styrene $(1.5 \mathrm{mmol}, 0.17 \mathrm{~mL})$ and $\mathrm{BF}_{3}$. $\mathrm{Et}_{2} \mathrm{O}$ affording $0.40 \mathrm{~g}(91 \%)$ of a white solid identified as $7 \mathbf{r}, \mathrm{mp} 137-139{ }^{\circ} \mathrm{C}$ (ethyl acetate/hexane). ${ }^{1} \mathrm{H}$ NMR (300 MHz, $\left.\mathrm{CDCl}_{3}\right) \delta: 1.29-1.33\left(\mathrm{~m}, 6 \mathrm{H}, 2 \mathrm{CH}_{3}\right), 4.06-4.19\left(\mathrm{~m}, 4 \mathrm{H}, 2 \mathrm{CH}_{2}\right), 7.19-7.26(\mathrm{~m}, 2 \mathrm{H}), 7.53-7.60$ $(\mathrm{m}, 5 \mathrm{H}), 7.84(\mathrm{~s}, 1 \mathrm{H}), 8.00-8.05(\mathrm{~m}, 1 \mathrm{H}), 8.20-8.24(\mathrm{~m}, 2 \mathrm{H}), 8.26-8.29(\mathrm{~m}, 1 \mathrm{H}), 8.45-8.49$ $(\mathrm{m}, 1 \mathrm{H}) \mathrm{ppm} ;{ }^{13} \mathrm{C}\left\{{ }^{1} \mathrm{H}\right\} \mathrm{NMR}\left(75 \mathrm{MHz}, \mathrm{CDCl}_{3}\right) \delta: 16.3\left(\mathrm{~d},{ }^{3} J_{\mathrm{CP}}=6.5 \mathrm{~Hz}, 2 \mathrm{CH}_{3}\right), 62.3(\mathrm{~d}$, $\left.{ }^{2} J_{\mathrm{CP}}=5.5 \mathrm{~Hz}, 2 \mathrm{CH}_{2}\right), 115.9\left(\mathrm{~d},{ }^{2} J_{\mathrm{CF}}=21.7 \mathrm{~Hz}, 2 \mathrm{HC}\right), 119.8(\mathrm{HC}), 124.9\left(\mathrm{~d},{ }^{3} J_{\mathrm{CP}}=17.3 \mathrm{~Hz}\right.$, C), $126.2\left(\mathrm{~d},{ }^{1} J_{\mathrm{CP}}=189.7 \mathrm{~Hz}, \mathrm{C}\right), 128.9(2 \mathrm{HC}), 128.9(\mathrm{HC}), 129.5(2 \mathrm{HC}), 129.6\left(\mathrm{~d},{ }^{3} J_{\mathrm{CF}}=8.5\right.$ $\mathrm{Hz}, 2 \mathrm{HC}), 130.4\left(\mathrm{~d},{ }^{2} J_{\mathrm{CP}}=3.8 \mathrm{~Hz}, \mathrm{HC}\right), 130.6(\mathrm{HC}), 131.6\left(\mathrm{~d},{ }^{2} J_{\mathrm{CP}}=11.9 \mathrm{~Hz}, \mathrm{HC}\right), 135.2(\mathrm{C})$, $137.4(\mathrm{C}), 150.2\left(\mathrm{~d},{ }^{4} J_{\mathrm{CP}}=3.0 \mathrm{~Hz}, \mathrm{C}\right), 150.3(\mathrm{C}), 157.6(\mathrm{C}), 164.1\left(\mathrm{~d},{ }^{1} J_{\mathrm{CF}}=250.2 \mathrm{~Hz}, \mathrm{C}-\mathrm{F}\right) \mathrm{ppm}$; ${ }^{31} \mathrm{P}\left\{{ }^{1} \mathrm{H}\right\}$ NMR (120 MHz, $\left.\mathrm{CDCl}_{3}\right) \delta: 19.3 \mathrm{ppm} ;{ }^{19} \mathrm{~F} \mathrm{NMR}\left(282 \mathrm{MHz}, \mathrm{CDCl}_{3}\right) \delta:-111.8 \mathrm{ppm}$. HRMS (EI): calculated for $\mathrm{C}_{25} \mathrm{H}_{23} \mathrm{FNO}_{3} \mathrm{P}$ [M] ${ }^{+}$435.1400; found 435.1415. Purity $95.42 \%$ $(\mathrm{EtOH} /$ Heptane $=10 / 90, \mathrm{Rt}=5.523 \mathrm{~min})$.

Diethyl (2-(3,4-difluorophenyl)-4-phenylquinolin-6-yl)phosphonate (7s). The general procedure was followed using aminophenylphosphonate $1 \mathrm{c}(1 \mathrm{mmol}, 0.23 \mathrm{~g})$, 3,4-difluorobenzaldehyde $(1 \mathrm{mmol}, 0.11 \mathrm{~mL})$, styrene $(1.5 \mathrm{mmol}, 0.17 \mathrm{~mL})$ and $\mathrm{BF}_{3} . \mathrm{Et}_{2} \mathrm{O}$ affording $0.40 \mathrm{~g}(89 \%)$ of a white solid identified as 7s, mp 134-136 ${ }^{\circ} \mathrm{C}$ (ethyl acetate/hexane). ${ }^{1} \mathrm{H}$ NMR (300 MHz, $\left.\mathrm{CDCl}_{3}\right) \delta: 1.28-1.33\left(\mathrm{~m}, 6 \mathrm{H}, 2 \mathrm{CH}_{3}\right), 4.03-4.21\left(\mathrm{~m}, 4 \mathrm{H}, 2 \mathrm{CH}_{2}\right), 7.29-7.32(\mathrm{~m}, 1 \mathrm{H}), 7.50-7.59$ $(\mathrm{m}, 5 \mathrm{H}), 7.80(\mathrm{~s}, 1 \mathrm{H}), 7.90-7.93(\mathrm{~m}, 1 \mathrm{H}), 7.99-8.14(\mathrm{~m}, 2 \mathrm{H}), 8.24-8.28(\mathrm{~m}, 1 \mathrm{H}), 8.44-8.50$ $(\mathrm{m}, 1 \mathrm{H}) \mathrm{ppm} ;{ }^{13} \mathrm{C}\left\{{ }^{1} \mathrm{H}\right\} \mathrm{NMR}\left(75 \mathrm{MHz}, \mathrm{CDCl}_{3}\right) \delta: 16.2\left(\mathrm{~d},{ }^{3} J_{\mathrm{CP}}=6.5 \mathrm{~Hz}, 2 \mathrm{CH}_{3}\right), 62.3(\mathrm{~d}$, $\left.{ }^{2} J_{\mathrm{CP}}=5.5 \mathrm{~Hz}, 2 \mathrm{CH}_{2}\right), 116.7\left(\mathrm{~d},{ }^{2} J_{\mathrm{CF}}=18.5 \mathrm{~Hz}, \mathrm{HC}\right), 117.6\left(\mathrm{~d},{ }^{2} J_{\mathrm{CF}}=17.6 \mathrm{~Hz}, \mathrm{HC}\right), 119.4$ $(\mathrm{HC}), 123.7\left(\mathrm{dd},{ }^{3} J_{\mathrm{CF}}=6.7 \mathrm{~Hz},{ }^{4} J_{\mathrm{CF}}=3.5 \mathrm{~Hz}, \mathrm{HC}\right), 125.1\left(\mathrm{~d},{ }^{3} J_{\mathrm{CP}}=17.3 \mathrm{~Hz}, \mathrm{C}\right), 126.7\left(\mathrm{~d},{ }^{1} J_{\mathrm{CP}}\right.$ $=189.5 \mathrm{~Hz}, \mathrm{C}), 128.9(2 \mathrm{HC}), 129.0(\mathrm{HC}), 129.4(2 \mathrm{HC}), 130.6\left(\mathrm{~d},{ }^{2} J_{\mathrm{CP}}=24.5 \mathrm{~Hz}, \mathrm{C}\right), 130.6$ $(\mathrm{HC}), 131.6\left(\mathrm{~d},{ }^{2} J_{\mathrm{CP}}=11.7 \mathrm{~Hz}, \mathrm{HC}\right), 136.0\left(\mathrm{dd},{ }^{3} J_{\mathrm{CF}}=5.7 \mathrm{~Hz},{ }^{4} J_{\mathrm{CF}}=3.7 \mathrm{~Hz}, \mathrm{C}\right), 137.2(\mathrm{C})$, $150.1\left(\mathrm{~d},{ }^{4} J_{\mathrm{CP}}=3.0 \mathrm{~Hz}, \mathrm{C}\right), 150.6(\mathrm{C}), 150.7\left(\mathrm{dd},{ }^{2} J_{\mathrm{CF}}=12.7 \mathrm{~Hz},{ }^{1} J_{\mathrm{CF}}=248.4 \mathrm{~Hz}, \mathrm{C}\right), 151.6$ $\left(\mathrm{dd},{ }^{2} J_{\mathrm{CF}}=12.7 \mathrm{~Hz},{ }^{1} J_{\mathrm{CF}}=251.9 \mathrm{~Hz}, \mathrm{C}\right), 156.2(\mathrm{C}) \mathrm{ppm} ;{ }^{31} \mathrm{P}\left\{{ }^{1} \mathrm{H}\right\} \mathrm{NMR}\left(120 \mathrm{MHz}, \mathrm{CDCl}_{3}\right) \delta$ : 
$19.1 \mathrm{ppm} ;{ }^{19} \mathrm{~F}$ NMR (282 MHz, $\left.\mathrm{CDCl}_{3}\right) \delta:-136.2$ and $-137.2 \mathrm{ppm}$. HRMS (EI): calculated for $\mathrm{C}_{25} \mathrm{H}_{22} \mathrm{~F}_{2} \mathrm{NO}_{3} \mathrm{P}[\mathrm{M}]^{+}$453.1305; found 453.1317. Purity 98.94\% (EtOH/Heptane $=10 / 90$, $\mathrm{Rt}=5.605 \mathrm{~min})$.

Diethyl (2,4-bis(4-fluorophenyl)quinolin-6-yl)phosphonate (7t). The general procedure was followed using aminophenylphosphonate $1 \mathrm{c}(1 \mathrm{mmol}, 0.23 \mathrm{~g})$, 4-fluorobenzaldehyde $(1 \mathrm{mmol}, 0.11 \mathrm{~mL})$, 4-fluorostyrene $(1.5 \mathrm{mmol}, 0.18 \mathrm{~mL})$ and $\mathrm{BF}_{3} . \mathrm{Et}_{2} \mathrm{O}$ affording $0.35 \mathrm{~g}(78 \%)$ of a white solid identified as $7 \mathrm{t}, \mathrm{mp} 161-164{ }^{\circ} \mathrm{C}$ (ethyl acetate/hexane). ${ }^{1} \mathrm{H}$ NMR $(300 \mathrm{MHz}$, $\left.\mathrm{CDCl}_{3}\right) \delta: 1.21-1.25\left(\mathrm{~m}, 6 \mathrm{H}, 2 \mathrm{CH}_{3}\right), 3.97-4.13\left(\mathrm{~m}, 4 \mathrm{H}, 2 \mathrm{CH}_{2}\right), 7.12-7.21(\mathrm{~m}, 4 \mathrm{H}), 7.43-7.47$ $(\mathrm{m}, 2 \mathrm{H}), 7.73(\mathrm{~s}, 1 \mathrm{H}), 7.91-7.96(\mathrm{~m}, 1 \mathrm{H}), 8.12-8.15(\mathrm{~m}, 2 \mathrm{H}), 8.18-8.21(\mathrm{~m}, 1 \mathrm{H}), 8.32-8.36$ $(\mathrm{m}, 1 \mathrm{H}) \mathrm{ppm} ;{ }^{13} \mathrm{C}\left\{{ }^{1} \mathrm{H}\right\} \mathrm{NMR}\left(75 \mathrm{MHz}, \mathrm{CDCl}_{3}\right) \delta: 16.3\left(\mathrm{~d},{ }^{3} J_{\mathrm{CP}}=6.5 \mathrm{~Hz}, 2 \mathrm{CH}_{3}\right), 62.3(\mathrm{~d}$, $\left.{ }^{2} J_{\mathrm{CP}}=5.5 \mathrm{~Hz}, 2 \mathrm{CH}_{2}\right), 115.9\left(\mathrm{~d},{ }^{2} J_{\mathrm{CF}}=21.7 \mathrm{~Hz}, 2 \mathrm{HC}\right), 116.1\left(\mathrm{~d},{ }^{2} J_{\mathrm{CF}}=21.5 \mathrm{~Hz}, \mathrm{HC}\right), 119.8$ (HC), $124.8\left(\mathrm{~d},{ }^{3} J_{\mathrm{CP}}=17.3 \mathrm{~Hz}, \mathrm{C}\right), 126.5\left(\mathrm{~d},{ }^{1} J_{\mathrm{CP}}=189.7 \mathrm{~Hz}, \mathrm{C}\right), 129.6\left(\mathrm{~d},{ }^{3} J_{\mathrm{CF}}=8.5 \mathrm{~Hz}, 2\right.$ HC), $130.5\left(\mathrm{~d},{ }^{2} J_{\mathrm{CP}}=2.5 \mathrm{~Hz}, \mathrm{HC}\right), 130.6\left(\mathrm{~d},{ }^{2} J_{\mathrm{CP}}=1.8 \mathrm{~Hz}, \mathrm{HC}\right), 131.2\left(\mathrm{~d},{ }^{3} J_{\mathrm{CF}}=8.3 \mathrm{~Hz}, 2 \mathrm{HC}\right)$, $131.4\left(\mathrm{~d},{ }^{3} J_{\mathrm{CP}}=11.9 \mathrm{~Hz}, \mathrm{HC}\right), 133.4(\mathrm{C}), 135.0(\mathrm{C}), 149.2(\mathrm{C}), 150.2(\mathrm{C}), 157.7$ (C), $163.2(\mathrm{~d}$, $\left.{ }^{1} J_{\mathrm{CF}}=249.1 \mathrm{~Hz}, \mathrm{C}-\mathrm{F}\right), 164.1\left(\mathrm{~d},{ }^{1} J_{\mathrm{CF}}=250.2 \mathrm{~Hz}, \mathrm{C}-\mathrm{F}\right) \mathrm{ppm} ;{ }^{31} \mathrm{P}\left\{{ }^{1} \mathrm{H}\right\} \mathrm{NMR}\left(120 \mathrm{MHz}, \mathrm{CDCl}_{3}\right)$ $\delta: 19.1 \mathrm{ppm} ;{ }^{19} \mathrm{~F}$ NMR $\left(282 \mathrm{MHz}, \mathrm{CDCl}_{3}\right) \delta:-114.5$ and $-116.4 \mathrm{ppm}$. HRMS (EI): calculated for $\mathrm{C}_{25} \mathrm{H}_{22} \mathrm{~F}_{2} \mathrm{NO}_{3} \mathrm{P}[\mathrm{M}]^{+}$453.1305; found 453.1317. Purity 95.51\% (EtOH/Heptane $=10 / 90$, $\mathrm{Rt}=5.479 \mathrm{~min})$.

Diethyl (2-(3,4-difluorophenyl)-4-(4-fluorophenyl)quinolin-6-yl)phosphonate (7u). The general procedure was followed using aminophenylphosphonate $1 \mathrm{c}(1 \mathrm{mmol}, 0.23 \mathrm{~g}), 3,4-$ difluorobenzaldehyde $(1 \mathrm{mmol}, 0.11 \mathrm{~mL})$, 4-fluorostyrene $(1.5 \mathrm{mmol}, 0.18 \mathrm{~mL})$ and $\mathrm{BF}_{3} . \mathrm{Et}_{2} \mathrm{O}$ affording $0.33 \mathrm{~g}(71 \%)$ of a white solid identified as $7 \mathbf{u}, \mathrm{mp} 130-132{ }^{\circ} \mathrm{C}$ (ethyl acetate/hexane). ${ }^{1} \mathrm{H}$ NMR $\left(300 \mathrm{MHz}, \mathrm{CDCl}_{3}\right) \delta: 1.22-1.25\left(\mathrm{~m}, 6 \mathrm{H}, 2 \mathrm{CH}_{3}\right), 3.97-4.14\left(\mathrm{~m}, 4 \mathrm{H}, 2 \mathrm{CH}_{2}\right), 7.17-7.27$ $(\mathrm{m}, 3 \mathrm{H}), 7.42-7.47(\mathrm{~m}, 2 \mathrm{H}), 7.71(\mathrm{~s}, 1 \mathrm{H}), 7.84-7.88(\mathrm{~m}, 1 \mathrm{H}), 7.92-7.98(\mathrm{~m}, 1 \mathrm{H}), 8.02-8.07(\mathrm{~m}, 1$ $\mathrm{H}), 8.17-8.21(\mathrm{~m}, 1 \mathrm{H}), 8.32-8.37(\mathrm{~m}, 1 \mathrm{H}) \mathrm{ppm} ;{ }^{13} \mathrm{C}\left\{{ }^{1} \mathrm{H}\right\} \mathrm{NMR}\left(75 \mathrm{MHz}, \mathrm{CDCl}_{3}\right) \delta: 16.3(\mathrm{~d}$, $\left.{ }^{3} J_{\mathrm{CP}}=6.4 \mathrm{~Hz}, 2 \mathrm{CH}_{3}\right), 62.3\left(\mathrm{~d},{ }^{2} J_{\mathrm{CP}}=5.1 \mathrm{~Hz}, 2 \mathrm{CH}_{2}\right), 116.1\left(\mathrm{~d},{ }^{2} J_{\mathrm{CF}}=21.7 \mathrm{~Hz}, 2 \mathrm{HC}\right), 116.8(\mathrm{~d}$, $\left.{ }^{2} J_{\mathrm{CF}}=19.3 \mathrm{~Hz}, \mathrm{HC}\right), 117.6\left(\mathrm{~d},{ }^{2} J_{\mathrm{CF}}=17.4 \mathrm{~Hz}, \mathrm{HC}\right), 119.5(\mathrm{HC}), 123.7\left(\mathrm{dd},{ }^{4} J_{\mathrm{CF}}=3.5 \mathrm{~Hz},{ }^{3} J_{\mathrm{CF}}=\right.$ $8.7 \mathrm{~Hz}, \mathrm{C}), 125.0\left(\mathrm{~d},{ }^{3} J_{\mathrm{CP}}=17.2 \mathrm{~Hz}, \mathrm{HC}\right), 126.9\left(\mathrm{~d},{ }^{1} J_{\mathrm{CP}}=189.8 \mathrm{~Hz}, \mathrm{C}\right), 130.5\left(\mathrm{~d},{ }^{3} J_{\mathrm{CF}}=24.0 \mathrm{~Hz}\right.$, $\mathrm{HC}), 130.7(\mathrm{HC}), 131.2\left(\mathrm{~d},{ }^{3} J_{\mathrm{CF}}=8.3 \mathrm{~Hz}, 2 \mathrm{HC}\right), 131.4\left(\mathrm{~d},{ }^{3} J_{\mathrm{CP}}=11.8 \mathrm{~Hz}, \mathrm{HC}\right), 133.2(\mathrm{C}), 136.0$ (C), $149.5(\mathrm{C}), 150.1\left(\mathrm{~d},{ }^{4} J_{\mathrm{CP}}=3.0 \mathrm{~Hz}, \mathrm{C}\right), 150.7\left(\mathrm{dd},{ }^{2} J_{\mathrm{CF}}=12.7 \mathrm{~Hz},{ }^{1} J_{\mathrm{CF}}=248.6 \mathrm{~Hz}, \mathrm{C}\right), 151.8$ $\left(\mathrm{dd},{ }^{2} J_{\mathrm{CF}}=12.4 \mathrm{~Hz},{ }^{1} J_{\mathrm{CF}}=252.0 \mathrm{~Hz}, \mathrm{C}\right), 156.3(\mathrm{C}), 163.2\left(\mathrm{~d},{ }^{1} J_{\mathrm{CF}}=249.3 \mathrm{~Hz}, \mathrm{C}-\mathrm{F}\right) \mathrm{ppm} ;{ }^{31} \mathrm{P}$ $\left\{{ }^{1} \mathrm{H}\right\}$ NMR $\left(120 \mathrm{MHz}, \mathrm{CDCl}_{3}\right) \delta: 19.0 \mathrm{ppm} ;{ }^{19} \mathrm{~F} \mathrm{NMR}\left(282 \mathrm{MHz}, \mathrm{CDCl}_{3}\right) \delta:-112.6,-136.1$ and -137.1 (m) ppm. HRMS (EI): calculated for $\mathrm{C}_{25} \mathrm{H}_{21} \mathrm{~F}_{3} \mathrm{NO}_{3} \mathrm{P}[\mathrm{M}]^{+} 471.1211$; found 471.1224 . Purity $99.96 \%(\mathrm{EtOH} /$ Heptane $=10 / 90, \mathrm{Rt}=7.363 \mathrm{~min})$.

Diethyl (2-(4-fluorophenyl)-4-(p-tolyl)quinolin-6-yl)phosphonate (7v). The general procedure was followed using aminophenylphosphonate $1 \mathrm{c}(1 \mathrm{mmol}, 0.23 \mathrm{~g})$, 4-fluorobenzaldehy de $(1 \mathrm{mmol}, 0.11 \mathrm{~mL})$, 4-methylstyrene $(1.5 \mathrm{mmol}, 0.20 \mathrm{~mL})$ and $\mathrm{BF}_{3} . \mathrm{Et}_{2} \mathrm{O}$ affording $0.44 \mathrm{~g}$ (98\%) of a white solid identified as $7 \mathbf{v}, \mathrm{mp} 153-155^{\circ} \mathrm{C}$ (ethyl acetate/hexane). ${ }^{1} \mathrm{H}$ NMR $\left(300 \mathrm{MHz}, \mathrm{CDCl}_{3}\right) \delta: 1.21-1.25\left(\mathrm{~m}, 6 \mathrm{H}, 2 \mathrm{CH}_{3}\right), 2.40\left(\mathrm{~s}, \mathrm{CH}_{3}\right), 3.96-4.12\left(\mathrm{~m}, 4 \mathrm{H}, 2 \mathrm{CH}_{2}\right)$, 7.11-7.16 (m, $2 \mathrm{H}), 7.28-7.30(\mathrm{~m}, 2 \mathrm{H}), 7.35-7.37(\mathrm{~m}, 2 \mathrm{H}), 7.75(\mathrm{~s}, 1 \mathrm{H}), 7.90-7.95(\mathrm{~m}, 1 \mathrm{H})$, 8.11-8.15 (m, $2 \mathrm{H}), 8.16-8.19(\mathrm{~m}, 1 \mathrm{H}), 8.40-8.44(\mathrm{~m}, 1 \mathrm{H}) \mathrm{ppm} ;{ }^{13} \mathrm{C}\left\{{ }^{1} \mathrm{H}\right\} \mathrm{NMR}(75 \mathrm{MHz}$, $\left.\mathrm{CDCl}_{3}\right) \delta: 16.3\left(\mathrm{~d},{ }^{3} J_{\mathrm{CP}}=6.5 \mathrm{~Hz}, 2 \mathrm{CH}_{3}\right), 21.3\left(\mathrm{CH}_{3}\right), 62.2\left(\mathrm{~d},{ }^{2} J_{\mathrm{CP}}=5.4 \mathrm{~Hz}, 2 \mathrm{CH}_{2}\right), 115.8$ $\left(\mathrm{d},{ }^{2} J_{\mathrm{CF}}=21.6 \mathrm{~Hz}, 2 \mathrm{HC}\right), 119.71(\mathrm{HC}), 125.0\left(\mathrm{~d},{ }^{3} J_{\mathrm{CP}}=17.3 \mathrm{~Hz}, \mathrm{C}\right), 126.1\left(\mathrm{~d},{ }^{1} J_{\mathrm{CP}}=189.3\right.$ $\mathrm{Hz}, \mathrm{C}), 129.3(2 \mathrm{HC}), 129.6(3 \mathrm{HC}), 129.7\left(\mathrm{~d},{ }^{3} J_{\mathrm{CF}}=8.5 \mathrm{~Hz}, 2 \mathrm{HC}\right), 130.4\left(\mathrm{~d},{ }^{2} J_{\mathrm{CP}}=12.8 \mathrm{~Hz}\right.$, $\mathrm{HC}), 131.9\left(\mathrm{~d},{ }^{2} J_{\mathrm{CP}}=12.0 \mathrm{~Hz}, \mathrm{HC}\right), 134.5(\mathrm{C}), 135.2(\mathrm{C}), 138.9(\mathrm{C}), 150.2(\mathrm{C}), 150.4(\mathrm{C}), 157.7$ (C), $164.0\left(\mathrm{~d},{ }^{1} J_{\mathrm{CF}}=249.9 \mathrm{~Hz}, \mathrm{C}-\mathrm{F}\right) \mathrm{ppm} ;{ }^{31} \mathrm{P}\left\{{ }^{1} \mathrm{H}\right\} \mathrm{NMR}\left(120 \mathrm{MHz}, \mathrm{CDCl}_{3}\right) \delta: 19.4 \mathrm{ppm} ;{ }^{19} \mathrm{~F}$ NMR (282 MHz, $\mathrm{CDCl}_{3}$ ) $\delta:-111.9 \mathrm{ppm}$. HRMS (EI): calculated for $\mathrm{C}_{26} \mathrm{H}_{25} \mathrm{FNO}_{3} \mathrm{P}[\mathrm{M}]^{+}$ 449.1556; found 449.1573. Purity 99.23\% (EtOH/Heptane $=10 / 90, \mathrm{Rt}=5.138 \mathrm{~min})$.

Diethyl (2-(3,4-difluorophenyl)-4-(p-tolyl)quinolin-6-yl)phosphonate (7x). The general procedure was followed using aminophenylphosphonate $1 \mathrm{c}(1 \mathrm{mmol}, 0.23 \mathrm{~g}), 3$,4-difluorobenzaldehyde $(1 \mathrm{mmol}, 0.11 \mathrm{~mL})$, 4-methylstyrene $(1.5 \mathrm{mmol}, 0.20 \mathrm{~mL})$ and $\mathrm{BF}_{3} . \mathrm{Et}_{2} \mathrm{O}$ affording $0.46 \mathrm{~g}$ (98\%) of a white solid identified as $7 \mathbf{x}, \mathrm{mp} 158-160{ }^{\circ} \mathrm{C}$ (ethyl acetate/hexane). ${ }^{1} \mathrm{H}$ NMR $\left(300 \mathrm{MHz}, \mathrm{CDCl}_{3}\right) \delta: 1.21-1.25\left(\mathrm{~m}, 6 \mathrm{H}, 2 \mathrm{CH}_{3}\right), 2.40\left(\mathrm{~s}, \mathrm{CH}_{3}\right), 3.96-4.13\left(\mathrm{~m}, 4 \mathrm{H}, 2 \mathrm{CH}_{2}\right)$, 7.19-7.25 (m, $1 \mathrm{H}), 7.28-7.30(\mathrm{~m}, 2 \mathrm{H}), 7.34-7.36(\mathrm{~m}, 2 \mathrm{H}), 7.72(\mathrm{~s}, 1 \mathrm{H}), 7.83-7.87(\mathrm{~m}, 1 \mathrm{H})$, 
7.91-7.96 (m, $1 \mathrm{H}), 8.01-8.07(\mathrm{~m}, 1 \mathrm{H}), 8.16-8.19(\mathrm{~m}, 1 \mathrm{H}), 8.40-8.44(\mathrm{~m}, 1 \mathrm{H}) \mathrm{ppm} ;{ }^{13} \mathrm{C}\left\{{ }^{1} \mathrm{H}\right\}$ $\operatorname{NMR}\left(75 \mathrm{MHz}, \mathrm{CDCl}_{3}\right) \delta: 16.3\left(\mathrm{~d},{ }^{3} J_{\mathrm{CP}}=6.5 \mathrm{~Hz}, 2 \mathrm{CH}_{3}\right), 21.3\left(\mathrm{CH}_{3}\right), 62.3\left(\mathrm{~d},{ }^{2} J_{\mathrm{CP}}=5.4 \mathrm{~Hz}\right.$, $\left.2 \mathrm{CH}_{2}\right), 116.8\left(\mathrm{~d},{ }^{2} J_{\mathrm{CF}}=19.3 \mathrm{~Hz}, \mathrm{HC}\right), 117.6\left(\mathrm{~d},{ }^{2} J_{\mathrm{CF}}=17.6 \mathrm{~Hz}, \mathrm{HC}\right), 119.4(\mathrm{HC}), 123.7(\mathrm{dd}$, $\left.{ }^{4} J_{\mathrm{CF}}=3.5 \mathrm{~Hz},{ }^{3} J_{\mathrm{CF}}=6.6 \mathrm{~Hz}, \mathrm{HC}\right), 125.2\left(\mathrm{~d},{ }^{3} J_{\mathrm{CP}}=17.4 \mathrm{~Hz}, \mathrm{C}\right), 126.5\left(\mathrm{~d},{ }^{1} J_{\mathrm{CP}}=189.4 \mathrm{~Hz}, \mathrm{C}\right)$, $129.3(2 \mathrm{HC}), 129.6$ (2 HC), $130.5\left(\mathrm{~d},{ }^{2} J_{\mathrm{CP}}=11.7 \mathrm{~Hz}, \mathrm{HC}\right), 130.6\left(\mathrm{~d},{ }^{3} J_{\mathrm{CP}}=7.4 \mathrm{~Hz}, \mathrm{HC}\right), 131.9$ $\left(\mathrm{d},{ }^{2} J_{\mathrm{CP}}=11.9 \mathrm{~Hz}, \mathrm{HC}\right), 134.3(\mathrm{C}), 136.2\left(\mathrm{dd},{ }^{4} J_{\mathrm{CF}}=3.6 \mathrm{~Hz},{ }^{3} J_{\mathrm{CF}}=6.7 \mathrm{~Hz}, \mathrm{C}\right), 139.1(\mathrm{C}), 150.1$ $\left(\mathrm{d},{ }^{4} J_{\mathrm{CP}}=3.0 \mathrm{~Hz}, \mathrm{C}\right), 150.7\left(\mathrm{dd},{ }^{2} J_{\mathrm{CF}}=13.8 \mathrm{~Hz},{ }^{1} J_{\mathrm{CF}}=248.1 \mathrm{~Hz}, \mathrm{C}\right), 150.7(\mathrm{C}), 151.6(\mathrm{dd}$, $\left.{ }^{2} J_{\mathrm{CF}}=12.7 \mathrm{~Hz},{ }^{1} J_{\mathrm{CF}}=250.4 \mathrm{~Hz}, \mathrm{C}\right), 156.3(\mathrm{C}) \mathrm{ppm} ;{ }^{31} \mathrm{P}\left\{{ }^{1} \mathrm{H}\right\} \mathrm{NMR}\left(120 \mathrm{MHz}, \mathrm{CDCl}_{3}\right) \delta: 19.2$ ppm; ${ }^{19} \mathrm{~F} \mathrm{NMR} \mathrm{(282} \mathrm{MHz,} \mathrm{CDCl}_{3}$ ) $\delta$ : -136.4 and $-137.2 \mathrm{ppm}$. HRMS (EI): calculated for $\mathrm{C}_{26} \mathrm{H}_{24} \mathrm{~F}_{2} \mathrm{NO}_{3} \mathrm{P}[\mathrm{M}]^{+}$467.1462; found 467.1472. Purity 99.47\% (EtOH $/$Heptane $=10 / 90$, $\mathrm{Rt}=6.241 \mathrm{~min})$.

\subsection{Biology}

\subsubsection{Materials}

Reagents and solvents were used as purchased without further purification. CPT was purchased from Sigma-Aldrich. All stock solutions of the investigated compounds were prepared by dissolving the powdered materials in an appropriate amount of DMSO. The final concentration of DMSO never exceeded $5 \%(v / v)$ in reactions. Under these conditions, DMSO was also used in the controls and was not seen to affect hTOP1B activity. The stock solution was stored at $5{ }^{\circ} \mathrm{C}$ until it was used.

\subsubsection{Expression and Purification of Human Topoisomerase 1B}

The yeast Saccharomyces cerevisiae TopI null strain RS190, which was used for expression of recombinant human Top 1 (hTOP1B) was a kind gift from R. Sternglanz (the State University of New York, Stony Brook, NY). Plasmid pHT143, for the expression of recombinant hTOP1B under the control of an inducible GAL promoter, was described [33]. The plasmids pHT143 were transformed into the yeast $S$. cerevisiae strain RS190. The proteins were expressed and purified by affinity chromatography essentially as described [34]. The protein concentrations were estimated from Coomassie blue-stained SDS/polyacrylamide gels by comparison to serial dilutions of bovine serum albumin (BSA).

\subsubsection{Cytotoxicity Assays}

Cells were cultured according to the supplier's instructions, A549 (ATCC ${ }^{\circledR}$ CCL-185), SKOV3 (ATCC ${ }^{\circledR}$ HTB-77), HEK293 (CLS GmbH), MRC-5 (ATCC ${ }^{\circledR}$ CCL-171 ${ }^{\mathrm{TM}}$ ). Cells were seeded in 96-well plates at a density of 2-2.5 $\times 10^{3}$ cells per well and incubated overnight in $0.1 \mathrm{~mL}$ of media supplied with $10 \%$ Fetal Bovine Serum (Lonza, Basel, Switzerland) in a $5 \% \mathrm{CO}_{2}$ incubator at $37^{\circ} \mathrm{C}$. On day 2, drugs (concentration between $0.5-50 \mu \mathrm{M}$ ) were added and samples were incubated for $48 \mathrm{~h}$. After treatment, $10 \mu \mathrm{L}$ of cell counting kit- 8 was added to each well for an additional $2 \mathrm{~h}$ incubation at $37^{\circ} \mathrm{C}$. The absorbance of each well was determined by an Automatic Elisa Reader System at $450 \mathrm{~nm}$ wavelength. CPT was purchased from Sigma-Aldrich and used as a positive control.

\subsection{4. hTOP1B DNA Relaxation Assays}

TOP1B activity was assayed using a DNA relaxation assay by incubating $110 \mathrm{ng} / \mu \mathrm{L}$ of hTOP1B with $0.5 \mu \mathrm{g}$ of negatively supercoiled pUC18 in $20 \mu \mathrm{L}$ of reaction buffer $(20 \mathrm{mM}$ Tris- $\mathrm{HCl}, 0.1 \mathrm{mM} \mathrm{Na} 2$ EDTA, $10 \mathrm{mM} \mathrm{MgCl} 2,50 \mu \mathrm{g} / \mathrm{mL}$ acetylated BSA and $150 \mathrm{mM} \mathrm{KCl}$, $\mathrm{pH}$ 7.5). The effect of the synthesized tetracyclic 7 derivatives on topoisomerase activity was measured by adding the compounds, at different time points as indicated in the text. The reactions were performed at $37^{\circ} \mathrm{C}$, stopped by the addition of $0.5 \%$ SDS after indicated time intervals. The samples were protease digested, electrophoresed in a horizontal $1 \%$ agarose gel in $1 \times$ TBE ( $50 \mathrm{mM}$ Tris, $45 \mathrm{mM}$ boric acid, $1 \mathrm{mM}$ EDTA) at $26 \mathrm{~V}$ for $20 \mathrm{~h}$. The gel was stained with gel red (Biotium, CA, USA, $5 \mu \mathrm{g} / \mathrm{mL}$ ), destained with water and photographed under UV illumination. 
Since all drugs were dissolved in dimethyl sulfoxide (DMSO), a positive control sample containing the same DMSO concentration as the samples incubated with the drugs was included in all experiments. As a control for drug inhibition, the well-known hTOP1B specific drug CPT was included.

\subsubsection{Docking Study}

First, we proceeded with the choice of the most suitable hTOP1B/DNA complex for the docking in the Protein Data Bank (PDB). The Xray structure code 1T8I [27] (3.00 A resolution) was chosen, a TOP1B of human origin covalently bounded to DNA and containing the anti-cancer agent CPT as a ligand. Maestro [35] graphic interface was used, and the Glide 6.9 application [36] in XP mode (extra precision) [37] was chosen for the docking. The grid was set up in a box of $20 \times 20 \times 20 \AA$, centered in the geometric center of CPT. The DNA-binding region in the active site was selected as the target for the screening. The hTOP1B/DNA complex was prepared by reconstructing the phosphoester bond to nucleobase C12 in the 1T8I structure, and the $5^{\prime}-\mathrm{SH}$ of nucleobase G11 of the cleaved strand was converted to a $5^{\prime}-\mathrm{OH}$ by changing the sulfur atom by oxygen. The hydrogen atoms were added. The binding orders and the protonation states of waste and DNA were corrected. The complex was optimized and minimized using the Protein Preparation Wizard panel of Schrödinger Suites 2015.1 [38]. Likewise, the structure of the ligand to interact with the protein and the ligand initially present in the complex, CPT, were prepared as previously indicated and used for the different docking processes.

\subsubsection{In Vitro L. infantum Promastigotes Assays}

A genetically modified strain of $L$ infantum $B C N$ 150, expressing iRFP protein from Rhodopseudomonas palustris bacteriophytochrome (iRFP-L. infantum), was used to obtain the $\mathrm{EC}_{50}$ values of the different compounds against promastigotes, through the detection of the near-infrared radiation emitted by living parasites exposed to tested molecules [39]. Thus, the viability of promastigotes was calculated after recording their fluorescence at $708 \mathrm{~nm}$ in an Odyssey (Li-Cor, NE, USA) infrared imaging.

iRFP-L. infantum promastigotes were cultured using M199 medium (Gibco, Thermo Fisher Scientific, MA, USA), supplemented with $25 \mathrm{mM}$ 4-(2-hydroxyethyl)-1-piperazineethanesulfonic acid (HEPES) pH 6.9, 7.6 mM hemin, $10 \mathrm{mM}$ glutamine, $0.1 \mathrm{mM}$ adenosine, $0.01 \mathrm{mM}$ folic acid, $1 \times$ RPMI 1640 vitamin mix (Sigma, Darmstadt, Germany), 10\% $(v / v)$ heat-inactivated foetal bovine serum (Gibco, Thermo Fisher Scientific, MA, USA), $50 \mathrm{U} / \mathrm{mL}$ penicillin and $50 \mu \mathrm{g} / \mathrm{mL}$ streptomycin. The assay was carried out, seeding $1 \times 10^{6}$ cells $/ \mathrm{mL}$ of iRFP- $L$. infantum promastigotes into 96-well optical bottom black plates (Thermo Scientific, MA, USA) along with different concentrations of compound to each well. The final concentration of DMSO, the solvent used to prepare the stock solutions of compounds, was never higher than $0.1 \%$. All of the compounds' concentrations and controls were assayed by triplicate.

Plots of the infrared fluorescence emitted by viable promastigotes against the different concentrations of tested compounds after $96 \mathrm{~h}$ of exposure (fitted by nonlinear analysis using the Sigma Plot 10.1 statistical package), were used to calculate the $\mathrm{EC}_{50}$ values.

\subsubsection{Ex Vivo Murine Splenic Explant Cultures}

All protocols described in this work comply with European Union Legislation (2010/63/UE) and Spanish Act (RD 53/2013).

The $\mathrm{EC}_{50}$ values of compounds against the amastigote forms were calculated using a cell suspension obtained from spleens extracted from BALB/c mice. Mice had been infected previously with $i R F P$ L. infantum metacyclic promastigotes and sacrificed five weeks after infection. To obtain the cell suspension containing amastigotes, spleens washed with cold phosphate-buffered saline (PBS), were cut into pieces, and incubated with $5 \mathrm{~mL}$ of $2 \mathrm{mg} / \mathrm{mL}$ collagenase D (Sigma, Darmstadt, Germany), which was prepared in buffer (10 mM HEPES, pH 7.4, $150 \mathrm{mM} \mathrm{NaCl}, 5 \mathrm{mM} \mathrm{KCl}, 1 \mathrm{mM} \mathrm{MgCl} 2$ and $1.8 \mathrm{mM} \mathrm{CaCl}_{2}$ ) for $20 \mathrm{~min}$. Subsequently, these cells were passed through a $100 \mu \mathrm{m}$ cell strainer, collected by 
centrifugation ( $500 \times g$ for 7 min at $\left.4{ }^{\circ} \mathrm{C}\right)$, washed twice with PBS, and suspended in RPMI medium (Gibco, Thermo Fisher Scientific, MA, USA) supplemented with $10 \mathrm{mM}$ HEPES, $1 \mathrm{mM}$ sodium pyruvate, 1xRPMI 1640 vitamin mix, $10 \%(v / v)$ FBS, $50 \mathrm{U} / \mathrm{mL}$ penicillin and $50 \mu \mathrm{g} / \mathrm{mL}$ streptomycin, at $37^{\circ} \mathrm{C}$ under a $5 \% \mathrm{CO}_{2}$ atmosphere.

To assay the effect of the different compounds against amastigotes, which infect splenic cells, these cells were seeded to confluence into 384-well black optical bottom plates (Thermo Scientific, Waltham, MA, USA) in addition to different concentrations of compound to each well. The viability of amastigotes was calculated by recording their fluorescence at $708 \mathrm{~nm}$ in an Odyssey (Li-Cor, NE, USA) infrared imaging system, after $96 \mathrm{~h}$ of exposure. Plots of the infrared fluorescence against the concentrations of tested compounds were fitted by nonlinear analysis using the Sigma Plot 10.1 statistical package and used to calculate $\mathrm{EC}_{50}$ values. As well as promastigotes viability, the assays were performed in triplicate.

\subsubsection{Selectivity Index (SI) Determination}

The viability of splenocytes cells against the different compounds was measured using the Alamar Blue staining method (Invitrogen, MA, USA). For this purpose, these cells were obtained following the protocol indicated in the previous section, from uninfected mice. Plots of absorbance of viable cells (obtained following manufacturer's recommendations of Alamar Blue) vs compounds concentration were used to calculate $\mathrm{CC}_{50}$ values. Plots were fitted by nonlinear analysis using the Sigma Plot 10.1 statistical package. The assays were performed by triplicate.

The selectivity index for each compound was calculated as the ratio between the $\mathrm{IC}_{50}$ value for splenic cells and the $\mathrm{EC}_{50}$ value for amastigotes.

\subsubsection{Purification of Leishmanial Topoisomerase 1B}

Purification of leishmanial DNA topoisomerase 1B (LTOP1B) was carried out as reported previously [5]. Shortly, LTOP1B was purified using the deficient in TOP1 activity yeast strain, EKY3 MAT $\alpha$ ura3-52 his3 $\triangle 20$ ting, from the union of the bicistronic expression vector $\mathrm{pESC}$-URA to both subunits of LTOP1B. The yeast cells were grown in a yeast synthetic drop-out medium without uracil (Sigma) supplemented with $2 \%$ raffinose (w/v) to $\mathrm{OD}_{600}: 0.8-1$ and induced for $10 \mathrm{~h}$ with $2 \%$ galactose $(w / v)$. After that, the cells were harvested, washed with cold TEEG buffer (50 mM Tris-HCl pH 7.4, 1 mM EDTA, $1 \mathrm{mM}$ EGTA, 10\% glycerol), resuspended in $15 \mathrm{~mL}$ of $1 \times$ TEEG buffer supplemented with $0.2 \mathrm{M}$ $\mathrm{KCl}$ and a protease inhibitors cocktail (Thermo Scientific, Waltham, MA, USA) and lysed. Protein extract obtained was loaded on a $5 \mathrm{~mL}$ Heparin Sepharose column (GE Healthcare, MA, USA). LTOP1B enzyme was eluted at $4{ }^{\circ} \mathrm{C}$ with a discontinuous gradient of $\mathrm{KCl}(0.2$, $0.4,0.6 \mathrm{M})$ in TEEG buffer.

\subsubsection{LTOP1B Relaxation Activity Assay}

Leishmanial TOP1B activity was tested by the relaxation of supercoiled plasmid DNA assay. Each reaction contained: one unit of purified LTOP1B enzyme, $100 \mu \mathrm{M}$ of each compound, $0.5 \mu \mathrm{g}$ of supercoiled pSK DNA, $10 \mathrm{mM}$ Tris- $\mathrm{HCl}$ buffer $\mathrm{pH} 7.5,5 \mathrm{mM} \mathrm{MgCl}$, $0.1 \mathrm{mM}$ EDTA, $15 \mu \mathrm{g} / \mathrm{mL}$ bovine serum albumin, and $150 \mathrm{mM} \mathrm{KCl}$. The final volume of each reaction was $20 \mu \mathrm{L}$. Reaction mixtures were incubated for $1 \mathrm{~min}$ at $37{ }^{\circ} \mathrm{C}$ and stopped by the addition of a $4 \mu \mathrm{L}$ loading buffer ( $5 \%$ sarkosyl, $0.12 \%$ bromophenol blue, $25 \%$ glycerol). The DNA topoisomers were resolved in $1 \%$ agarose gels by electrophoresis in $0.1 \mathrm{M}$ Tris borate EDTA buffer $(\mathrm{pH} 8.0)$ at $2 \mathrm{~V} / \mathrm{cm}$ for $16 \mathrm{~h}$ and visualized with UV illumination after ethidium bromide $(0.5 \mu \mathrm{g} / \mathrm{mL})$ staining. The percentage of inhibition was calculated by measuring the intensity of the band corresponding to the supercoiled DNA after separating and staining the different DNA topoisomers. This analysis was performed using the GeneTools from Syngene software (Version 4.3.8, MD, USA). 


\section{Conclusions}

In conclusion, in this work, the preparation of 23 quinoline derivatives 7 with aromatic and phosphonate substituents at different positions of the quinoline skeleton has been carried out. The synthesis was performed by a [4+2] cycloaddition reaction from the corresponding phosphorated anilines, aromatic aldehydes, and olefins, by a two-step or MCR protocol, and subsequent oxidation of the quinoline derivatives with DDQ or directly by a $[4+2]$ cycloaddition reaction with acetylenes used as dienophiles. The compounds showed an interesting biological activity, with cytotoxicity against cancer cells (A549, SKOV3, and HEK293) while they presented no cytotoxicity against the non-cancerous cell line (MRC5). When tested against the $\mathrm{A} 549$ cancer cell line, the $\mathrm{IC}_{50}$ values observed are generally lower than 3 micromolar, with compounds $7 \mathbf{j}$ and $7 \mathbf{v}$ being the most cytotoxic with $\mathrm{IC}_{50}$ values in the nanomolar range.

Regarding the behavior against the biological target, TOP1B, we may say that compounds $\mathbf{7 b}, \mathbf{7} \mathbf{j}$, and $\mathbf{7 k}$ showed an inhibitory effect against human TOP1B similar to that observed for the natural inhibitor, CPT. On the other hand, compounds $7 \mathrm{k}$ and $7 \mathbf{o}$ showed inhibitory effects on LTOP1B. These data could be useful for the design of new molecules with selective inhibitory activity against LTOP1B, although the overall low SI of the tested drugs suggests that additional targets could be involved in their mode of action.

Supplementary Materials: The following are available online at https://www.mdpi.com/article/ 10.3390/ph14080784/s1, 1H NMR, 13C NMR, 31P NMR and 19F NMR spectra of compounds and Table S1.

Author Contributions: Methodology, B.R.K., F.P., R.B.-F., R.M.R., Y.P.-P. and C.A.; investigation, M.F., A.S. and E.M.-F.; writing — original draft preparation, C.A.; writing - review and editing, B.R.K.; F.P., R.B.-F., R.M.R., Y.P.-P. and C.A. All authors reviewed and revised the publication. All authors have read and agreed to the published version of the manuscript.

Funding: This research was financially supported by Ministerio de Ciencia, Innovación y Universidades (MCIU), Agencia Estatal de Investigación (AEI) y Fondo Europeo de Desarrollo Regional (FEDER; RTI2018-101818-B-I00, UE) and by Gobierno Vasco, Universidad del País Vasco (GV, IT 992-16; UPV) is gratefully acknowledged. Technical and human support provided by IZO-SGI, SGIker (UPV/EHU, MICINN, GV/EJ, ERDF, and ESF) is gratefully acknowledged. AS thanks the Basque Government for a formation contract. This collaborative research was funded by MINECO; SAF2017-83575-R to RMR.

Institutional Review Board Statement: All the in vivo experiments described in this manuscript were conducted in compliance with the Spanish Act (RD 53/2013) and European Union Legislation (2010/63/UE). The protocols were approved by the Animal Care Committee of the Universidad de León (ULE, León, Spain), project license number 2019/07.

Informed Consent Statement: Not applicable.

Data Availability Statement: Data is contained within the article and Supplementary Materials.

Conflicts of Interest: The authors declare no conflict of interest.

$\begin{array}{ll}\text { Abbreviations } \\ \text { AMB } & \text { Amphotericin B } \\ \text { CCK8 } & \text { Cell counting kit } \\ \text { CPT } & \text { Camptothecin } \\ \text { DDQ } & \text { Dichloro-5,6-dicyanobenzoquinone } \\ \text { MCR } & \text { Multicomponent reaction } \\ \text { SDS } & \text { Sodium dodecyl sulfate; SI, selectivity index } \\ \text { TOP1B } & \text { DNA topoisomerase 1B } \\ \text { TLC } & \text { Thin layer chromatography }\end{array}$




\section{References}

1. International Agency for Research on Cancer, GLOBOCAN 2018. Available online: http:/ /gco.iarc.fr/today/home (accessed on 13 November 2020).

2. Burza, S.; Croft, S.L.; Boelaert, M. Leishmaniasis. Lancet 2018, 392, 951-970. [CrossRef]

3. Reguera, R.M.; Elmahallawy, E.K.; García-Estrada, C.; Carbajo-Andrés, R.; Balaña-Fouce, R. DNA Topoisomerases of Leishmania Parasites; Druggable Targets for Drug Discovery. Curr. Med. Chem. 2019, 26, 5900-5923. [CrossRef] [PubMed]

4. Hosoya, N.; Miyagawa, K. Targeting DNA damage response in cancer therapy. Cancer Sci. 2014, 105, 370-388. [CrossRef]

5. Villa, H.; Otero Marcos, A.R.; Reguera, R.M.; Balaña-Fouce, R.; García-Estrada, C.; Pérez-Pertejo, Y.; Tekwani, B.L.; Myler, P.J.; Stuart, K.D.; Bjornsti, M.A.; et al. A novel active DNA topoisomerase I in Leishmania donovani. J. Biol. Chem. 2003, 278, 3521-3526. [CrossRef]

6. Balaña-Fouce, R.; Alvarez-Velilla, R.; Fernández-Prada, C.; García-Estrada, C.; Reguera, R.M. Trypanosomatids topoisomerase re-visited. New structural findings and role in drug discovery. Int. J. Parasitol. Drugs Drug Resist. 2014, 24, 326-337. [CrossRef] [PubMed]

7. Champoux, J.J. DNA Topoisomerases: Structure, Function, and Mechanism. Annu. Rev. Biochem. 2001, 70, 369-413. [CrossRef] [PubMed]

8. Selas, A.; Martin-Encinas, E.; Fuertes, M.; Masdeu, C.; Rubiales, G.; Palacios, F.; Alonso, C. A patent review of topoisomerase I inhibitors (2016-present). Expert Opin. Ther. Pat. 2021, 31, 473-508. [CrossRef] [PubMed]

9. Alonso, C.; González, M.; Palacios, F.; Rubiales, G. Study of the hetero-[4+2]-cycloaddition reaction of aldimines and alkynes. Synthesis of 1,5-naphthyridine and isoindolone derivatives. J. Org. Chem. 2017, 82, 6379-6387. [CrossRef]

10. Alonso, C.; Fuertes, M.; González, M.; Rubiales, G.; Palacios, F. Synthesis and biological evaluation of indeno[1,5]naphthyridines as topoisomerase I (TopI) inhibitors with antiproliferative activity. Eur. J. Med. Chem. 2016, 115, 179-190. [CrossRef]

11. Alonso, C.; Fuertes, M.; González, M.; Rubiales, G.; Rodríguez-Gascón, A.; Rubiales, G.; Palacios, F. Synthesis and biological evaluation of 1,5-naphthyridines as topoisomerase I inhibitors. A new family of antiproliferative agents. Curr. Top. Med. Chem. 2014, 14, 2722-2728. [CrossRef]

12. Tejeria, A.; Perez-Pertejo, Y.; Reguera, R.M.; Balana-Fouce, R.; Alonso, C.; Gonzalez, M.; Rubiales, G.; Palacios, F. Substituted 1,5-naphthyridine derivatives as novel antileishmanial agents. Synthesis and biological evaluation. Eur. J. Med. Chem. 2018, 152, 137-147. [CrossRef] [PubMed]

13. Tejeria, A.; Perez-Pertejo, Y.; Reguera, R.M.; Balana-Fouce, R.; Alonso, C.; Fuertes, M.; Gonzalez, M.; Rubiales, G.; Palacios, F. Antileishmanial effect of new indeno-1,5-naphthyridines, selective inhibitors of Leishmania infantum type IB DNA topoisomerase. Eur. J. Med. Chem. 2016, 124, 740-749. [CrossRef] [PubMed]

14. Akkachairin, B.; Rodphon, W.; Reamtong, O.; Mungthin, M.; Tummatorn, J.; Thongsornkleeb, C.; Ruchirawat, S. Synthesis of neocryptolepines and Carbocycle-Fused Quinolines and Evaluation of Their Anticancer and Antiplasmodial Activities. Bioorg. Chem. 2020, 98, 103732. [CrossRef] [PubMed]

15. Ahadi, H.; Emami, S. Modification of 7-piperazinylquinolone antibacterials to promising anticancer lead compounds: Synthesis and in vitro studies. Eur. J. Med. Chem. 2020, 187, 111970. [CrossRef] [PubMed]

16. Musiol, R. An overview of quinoline as a privileged scaffold in cancer drug discovery. Expert Opin. Drug Discov. 2017, $12,583-597$. [CrossRef] [PubMed]

17. Afzal, O.; Kumar, S.; Haider, M.R.; Ali, M.R.; Kumar, R.; Jaggi, M.; Bawa, S. A review on anticancer potential of bioactive heterocycle quinolone. Eur. J. Med. Chem. 2015, 97, 871-910. [CrossRef]

18. Maslanka, M.; Mucha, A. Recent developments in peptidyl diaryl phoshonates as inhibitors and activity-based probes for serine proteases. Pharmaceuticals 2019, 12, 86. [CrossRef] [PubMed]

19. Patani, G.A.; LaVoie, E.J. Bioisosterism: A Rational Approach in Drug Design. Chem. Rev. 1996, 96, 3147-3176. [CrossRef]

20. Rye, C.S.; Baell, J.B. Phosphate isosteres in medicinal chemistry. Curr. Med. Chem. 2005, 12, 3127-3141. [CrossRef]

21. Berube, G. An overview of molecular hybrids in drug Discovery. Expert Opin. Drug Discov. 2016, 11, 281-305. [CrossRef] [PubMed]

22. Fortin, S.; Berube, G. Advances in the development of hybrid anticancer drugs. Expert Opin. Drug Discov. 2013, 8, 1029-1047. [CrossRef] [PubMed]

23. Alonso, C.; Fuertes, M.; Martin-Encinas, E.; Selas, A.; Rubiales, G.; Tesauro, C.; Knudssen, B.R.; Palacios, F. Novel topoisomerase I inhibitors. Syntheses and biological evaluation of phosphorus substituted quinoline derivates with antiproliferative activity. Eur. J. Med. Chem. 2018, 149, 225-237. [CrossRef]

24. Tejería, A.; Pérez-Pertejo, Y.; Reguera, R.M.; Carbajo-Andrés, R.; Balaña-Fouce, R.; Alonso, C.; Martin-Encinas, E.; Selas, A.; Rubiales, G.; Palacios, F. Antileishmanial activity of new hybrid tetrahydroquinoline and quinoline derivatives with phosphorus substituents. Eur. J. Med. Chem. 2019, 162, 18-31. [CrossRef] [PubMed]

25. Ghashghaei, O.; Masdeu, C.; Alonso, C.; Palacios, F.; Lavilla, R. Recent advances of the Povarov reaction in medicinal chemistry. Drug Discov. Today 2018, 29, 71-79. [CrossRef]

26. Cadogan, J.I.G.; Sears, D.J.; Smith, D.M. The reactivity of organophosphorus compounds. Part XXV. Displacement of activated aromatic nitro-groups by tervalent phosphorus reagents. J. Chem. Soc. 1969, 1314-1318. [CrossRef] 
27. Staker, B.L.; Feese, M.D.; Cushman, M.; Pommier, Y.; Zembower, D.; Stewart, L.; Burgin, A.B. Structures of three classes of anticancer agents bound to the human topoisomerase I-DNA covalent complex. J. Med. Chem. 2005, 48, 2336-2345. [CrossRef] [PubMed]

28. Pommier, Y.; Marchand, C. Interfacial inhibitors: Targeting macromolecular complexes. Nat. Rev. Drug Discov. 2012, 11, 25-36. [CrossRef] [PubMed]

29. Baker, N.M.; Rajan, R.; Mondragon, A. Structural studies of type I topoisomerases. Nucleic Acids Res. 2009, 37, 693-701. [CrossRef] [PubMed]

30. Marchand, C.; Antony, S.; Kohn, K.W.; Cushman, M.; Ioanoviciu, A.; Staker, B.L.; Burgin, A.B.; Stewart, L.; Pommier, Y. A novel norindeniosoquinoline structure reveals a common interfacial inhibitor paradigm for ternary trapping of the topoisomerase I-DNA covalent complex. Mol. Cancer Ther. 2006, 5, 287-295. [CrossRef] [PubMed]

31. Koster, D.A.; Paile, K.; Bot, E.S.M.; Bjornsti, M.A.; Dekker, N.H. Antitumour drugs impede DNA uncoiling by topoisomerase I. Nature 2007, 448, 213-217. [CrossRef]

32. Lauria, A.; Ippolito, M.; Almerico, A.M. Molecular docking approach on the Topoisomerase I inhibitors series included in the NCI anti-cancer agents mechanism database. J. Mol. Model. 2007, 13, 393-400. [CrossRef] [PubMed]

33. Lisby, M.; Krogh, B.O.; Boege, F.; Westergaard, O.; Knudsen, B.R. Camptothecins inhibit the utilization of hydrogen peroxide in the ligation step of topoisomerase I catalysis. Biochemistry 1998, 37, 10815-10827. [CrossRef] [PubMed]

34. Knudsen, B.R.; Straub, T.; Boege, F. Separation and functional analysis of eukaryotic DNA topoisomerases by chromatography and electrophoresis. J. Chromatogr. B Biomed. Appl. 1996, 684, 307-321. [CrossRef]

35. Schrödinger Release 2015-1: Maestro, version 10.1; Schrödinger, L.L.C.: New York, NY, USA, 2015.

36. Schrödinger Release 2015-1: Glide, version 6.9; Schrödinger, L.L.C.: New York, NY, USA, 2015.

37. Friesner, R.A.; Murphy, R.B.; Repasky, M.P.; Frye, L.L.; Greenwood, J.R.; Halgren, T.A.; Sanschagrin, P.C.; Mainz, D.T. Extra precision glide: Docking and scoring incorporating a model of hydrophobic enclosure for protein-ligand complexes. J. Med. Chem. 2006, 49, 6177-6196. [CrossRef]

38. Schrödinger Release 2015-1: Protein Preparation Wizard; epik 3.1; Schrödinger, L.L.C.: New York, NY, USA, 2015.

39. Calvo-Álvarez, E.; Stamatakis, K.; Punzón, C.; Álvarez-Velilla, R.; Tejería, A.; Escudero-Martínez, J.M.; Pérez-Pertejo, Y.; Fresno, M.; Balaña-Fouce, R.; Reguera, R.M. Infrared fluorescent imaging as a potent tool for in vitro, ex vivo and in vivo models of visceral leishmaniasis. PLoS Negl. Trop. Dis. 2015, 9, e0003666. [CrossRef] 